\title{
MAXIMIZING INFORMATION FOR EVALUATION OF INCIDENT MANAGEMENT SYSTEMS WITH AN EMPHASIS ON SECONDARY ACCIDENTS
}

\begin{tabular}{l} 
A Dissertation \\
presented to \\
the Faculty of the Graduate School \\
at the University of Missouri-Columbia \\
In Partial Fulfillment \\
of the Requirements for the Degree \\
Doctor of Philosophy \\
\hline Dr. Carlos Sun, Dissertation Supervisor \\
VENKATA CHILUKURI \\
by
\end{tabular}

JULY 2011 
The undersigned, appointed by the dean of the Graduate School, have examined the dissertation entitled

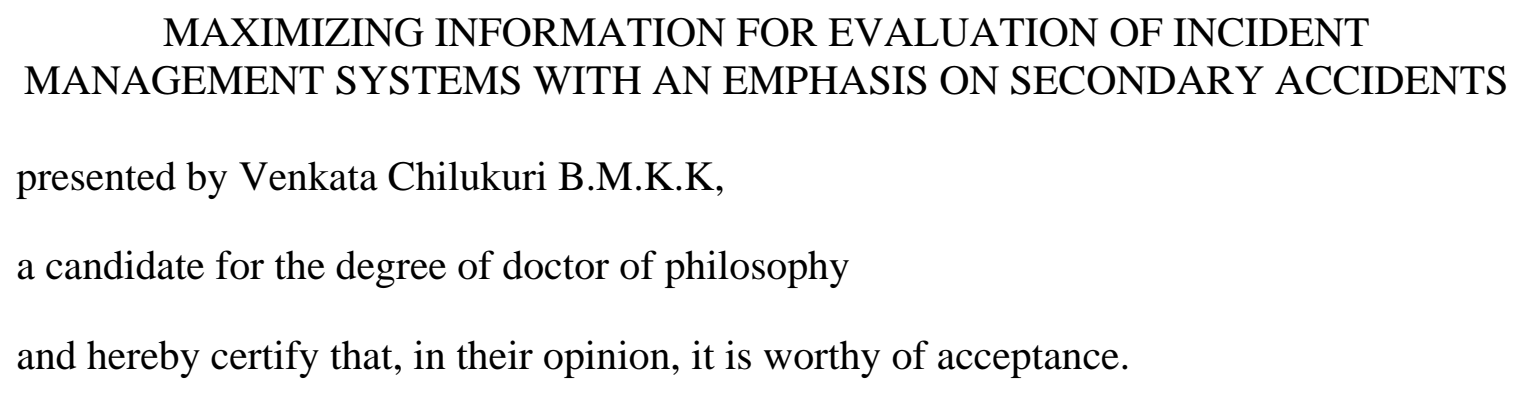

Dr. Carlos Sun

Dr. Cerry Klein

Dr. Mark Virkler

Dr. Wooseung Jang

Mr. Charles Nemmers

Dr. Edara Praveen 
.....Thank You Mom, Dad, Checks and Shiv 


\section{ACKNOWLEDGEMENTS}

I would like to thank my Dr. Carlos Sun for his support throughout my $\mathrm{PhD}$. He is one of the best mentors a student can wish for. Years down the lane, I will still be thankful as I incrementally realize his value. The amount of hard work he puts in to create a positive impact, with everyone he works with, is just truly amazing and inspiring. Thank you very much Dr. Sun. I also would also like to thank the rest of my committee members: Dr. Mark Virkler, Dr. Cerry Klein, Dr. Wooseung Jang, Mr. Charles Nemmers and Dr. Praveen Edara.

I really am grateful to have worked with many great fellow students: both graduate and undergraduate students. I want to thank all of them. Especially Ryan Pierce, Jason Sommerer and David Wood for designing POST system with Dr. Sun; Narasimha Medeme, Tirulokesh Krishnan and Sandeep Menneni for their problem solving skills; Christopher Beard for his help on MA Evaluation and knowledge of St. Louis Freeways; Bulbul Ganguly and Jason Lemp for processing Media Reports; Srinivasa Yanamanamanda and Rajan Vasudevan for their support. 


\section{TABLE OF CONTENTS}

\section{Chapter Chapter Title}

ACKNOWLEDGEMENTS

Page

Number

ii

LIST OF FIGURES ......................................... $\mathrm{v}$

LIST OF TABLES................................................ vii

LIST OF ABBREVATIONS................................... ix

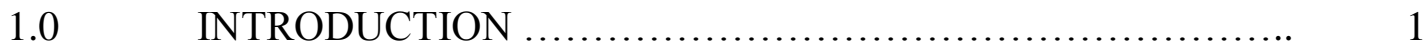

Layout of The Research....................................... 2

2.0 INNOVATIVE DATA SETS FOR PERFORMANCE EVALUATION OF IMS.

Data For Evaluating Performance

GPS Data

ReID Data...

POST.

ReID software.

Capturing Incident Information

Incident Chasing

Motorist Assist Paper Logs.

Media Traffic Reports.

Processing traffic reports

Planned Incidents.

Video and Radar.....

A CASE STUDY FOR EVALUATING IMS WITH AND WITHOUT MA.

Literature Review of FSP Programs. 29

Methodology For Evaluating Efficiency. 34

Estimating Efficiency Benefits.

i.
x

1


Results of Efficiency Benefits.

Number

Estimation of Safety Benefits................................... 60

Results of Safety Benefits.................................... 69

Limitation of Safety Evaluation............................... 75

IMPROVED METHODOLOGY FOR CLASSIFYING

SECONDARY ACCIDENTS....................................... 76

Motivation................................................ 76

Literature review for estimating secondary accidents............ 78

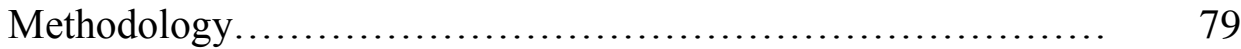

Filling in Incomplete Incident Data .................................... 80

Shape of Accident Backup ....................................................... 85

Master Incident Progression Curve ......................................... $\quad 89$

Extraction of Secondary Accidents......................................

Results..................................................... 91

Investigating Multiple IPCs.................................. 93

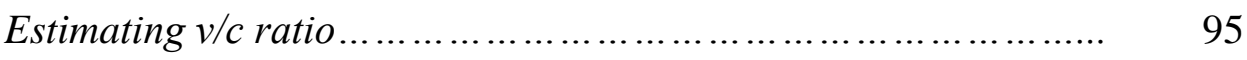

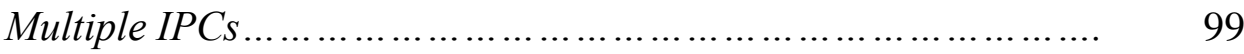

5.0 CONCLUSIONS .............................................. 105

Implications of This Research................................ 107

REFERENCES .......................................... 108

APPENDIX A ............................................. 106

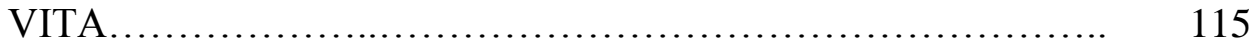




\section{LIST OF FIGURES}

Figure Figure Title

2.01 Typical set up of POST for data collection

2.02

2.03

2.04

2.05

2.06

2.07

3.01

3.02

3.03

3.04

3.05

3.06

3.07

3.08

3.09

3.10

3.11

3.12

3.13

4.01

4.02

4.03

4.04

4.05

4.06

Screen shot of ReID cataloger.
Page

Number

9

10

11

18

21

22

24

37

38

40

47

48

52

59

63

65

67

69

70

71

76

80

89

93

95

100 
Figure Number

Figure Title

4.07 IPC based on number of vehicles

4.08 IPC based on PDO accidents and v/c

4.09 IPC based on injury accidents and v/c
Page

Number

102

104

104 


\section{LIST OF TABLES}

Table Number

2.01

2.02

3.01

3.02

3.03

3.04

3.05

3.06

3.07

3.08

3.09

3.10

3.11

3.12

4.02

4.03

4.04

4.05

4.06

4.07

4.08

4.09

4.10

4.11
Table Title

Incident Chasing Data Sets

Sample Media Traffic Data Entry Form.

Average Percentage Distribution of Lane Blockage.

Percentage of Original Capacity Remaining Due to Incidents

Hourly AADT Averaged by Time and Patrol Zone.

GPS Runs Conducted on I-70 and I-270....

Average Space Mean Speed on I-70 and I-270.

MA Response Times Based on Sampled Customer Returned

Surveys

Assist Code Descriptions and Non MA Response Time.

Sample Traffic Incident Report Summaries

Cost of Crash by Severity.

Regression of Secondary Accidents on I-70....

Regression of Secondary Accidents on I-270.

Distribution of Secondary Accidents by Severity

Distribution of Incidents Based on Time of the Day.

Estimated Duration Based on Different Polynomial Models

SSE and R-Square

Comparison of Dynamic Versus Static Thresholds

Relationship Between FFS and Freeway Capacity.

Sample of The Data Used For Developing Multiple Master Curves.

IPC Polynomial and Static Thresholds Based on v/c Ratio

IPC Polynomial Coefficients Based on v/c Ratio

IPC Polynomial and Static Threshold Based on Number of

IPC Polynomial Coefficients Based on Number of Vehicles

IPC Polynomial and Static Threshold Based on Severity and v/c Ratio
Page

Number

15

19

34

34

44

48

49

51

58

65

69

72

73

75

81

85

88

93

97

98

100

100

101

101

103 
Table

Number Table Title

4.12
Page

Number

103 


\section{LIST OF ABBREVIATIONS}

$\begin{array}{ll}\text { FSP } & \text { Freeway Service Patrol } \\ \text { IPC } & \text { Incident Progression Curve } \\ \text { IMS } & \text { Incident Management Systems } \\ \text { ITS } & \text { Intelligent Transportation Systems } \\ \text { MA } & \text { Motorist Assist } \\ \text { TMC } & \text { Transportation Management Center }\end{array}$




\section{CHAPTER 1: INTRODUCTION}

Traffic incidents can be defined as planned or unplanned disruptions in the traffic flow. The planned disruptions include construction activity, traffic from special events like games, political rallies. And disruptions due to accidents, stalled vehicles or debris on the road fall under the unplanned incidents. In order to mitigate the negative impacts of such incidents many of the metropolitan areas rely on their incident management system. An Incident Management System (IMS) can be defined as "systematic, planned and coordinated use of human, institutional, mechanical and technical resources to reduce the duration and impact of incidents, and improve the safety of motorist, crash victims and incident responders” (Traffic Incident Management Handbook, 2000). The various partnering agencies that include IMS are local and state departments of transportation, local and state police agencies, fire agencies, private companies like towing, emergency medical services, radio and television stations.

From engineering perspective one can sense the benefits of an IMS program. The IMS, by responding, to incidents reduces the traffic delays and it could also increase traffic safety by keeping the public informed about the status of the incident. In spite of perceived benefits, each IMS program needs to be evaluated for understanding at what cost the benefits are obtained so that it would be useful in decision making, and also for critically analyzing which areas of the program need to be improved. While the evaluations are essential to understand the performance of a system, it is also essential to 
understand how the evaluation is done i.e. one need to evaluate not only the system but also the methodology of the evaluation.

Unplanned incidents like accidents or stalled vehicle are random in nature, meaning one cannot predict well in advance about the location and time of the incident. And this increases the time, money and skilled personnel needed for collecting and processing the incident data. Hence, most of the incident management systems that were evaluated as a whole or as a part of intelligent transportation systems (ITS) were based on surveys and simulation modeling. Detroit Freeway Corridor ITS Evaluation (Shah and Wunderlich, 2001), Smart Trek (Bunch, 1999) which is a Seattle Metropolitan Model Deployment Initiative (MMDI), San Antonio MMDI (FHWA, 2000) are some of the examples of such approaches.

In contrast to the existing research this work incorporates significant amount of real data that was collected using innovative data collection and processing methods. One of the primary reasons for this approach was the preference of the sponsoring agency's (MoDOT's) on the inclusion of real data for modeling. And based on a freeway service patrol evaluation this work also improves the classification of secondary accidents which is an important performance indicator for safety analysis.

\section{LAYOUT OF THE RESEARCH}

Chapter 2 presents the data required for doing an evaluation of IMS and the different approaches that were explored and pursued for obtaining the data. Chapter 3 shows how real incident data was sampled and then used in evaluation of IMS based on efficiency 
and safety aspects of the system. This chapter notes the drawbacks of the safety evaluation. And this is improved in the next chapter.

Chapter 4 explains the drawback of the safety evaluation used in chapter 3 . The drawback is related to the current methodology for extracting secondary accidents. This methodology is improved by taking advantage of a data set in a novel way. Finally the conclusions of this research are presented in the chapter 5 . 


\section{CHAPTER 2: INNOVATIVE DATA SETS FOR EVALUATION OF INCIDENT MANAGEMENT SYSTEMS (IMS)}

The information needed for evaluating an Incident Management System (IMS) are as follows

a) Time and location of incidents.

b) Lateral location of incident

c) Type of incident.

d) Number of vehicles involved.

e) Number of relief agencies involved and their response time.

f) Time of clearance of the accident and

g) Traffic volume.

In order to obtain the required data, all the public and private agencies that could potentially have a stake in (St. Louis, Missouri) IMS were contacted. The agencies that our team contacted were Missouri Department of Transportation (MoDOT) headquarters, Gateway Guide which is St. Louis transportation management center (TMC) and its freeway service patrol, various police and fire agencies in St. Louis region, American Automobile Association (AAA), and few towing companies.

Interaction with these agencies helped in building relationships and understanding the finer elements of incident management process i.e. how the coordination between agencies occur, what kind of data each agency might collect and what kind of data an agency is willing to share etc. Based on the interactions with these agencies, our research 
team was convinced that the two steps for maximizing the information are 1) developing innovative procedures for collecting traffic data sets such as segment travel times, space mean speeds 2) creatively tapping into data sets such as traffic reports, which have escaped the eyes of existing research.

Based on the above two steps, innovative data collection and data processing techniques were developed. These procedures are described in the following sections.

\section{DATA FOR EVALUATING PERFORMANCE}

\section{GPS Data}

The average travel times and space mean speeds can be collected using a Global Positioning System (GPS) instrumented vehicle. The setup is simple; it consists of connecting the GPS to a laptop and magnetically attaching the antenna to the roof of the car.

Then the driver of the instrumented vehicle is instructed to adopt the floating car methodology for collecting travel times. In floating car methodology, the driver needs to overtake same number of vehicles that have overtaken the driver. Say four vehicles have overtaken the driver then the driver should attempt to overtake four other vehicles. But on a freeway this becomes challenging especially when there is lot of traffic and hence the driver needs to estimate and travel at a speed that is representative of the existing traffic's average speed. 
Even though GPS has penetrated well into the civilian market there still some transportation agencies that use stop watch for gathering travel time information. Compared to data collection using stop watch, the GPS data collection is advantageous in two ways, for one it can be archived and combined with other GPS datasets more easily. Secondly, the data is useful for analyzing the trouble spots along the network.

The advantage of this dataset is that it gives an estimate of performance conditions in a short amount of time but the disadvantages is that one cannot get individual vehicle travel times for understanding the travel time or speed distribution. If an agency wants to study the impacts of incidents at a detailed level then capturing variation in vehicle speeds would be very helpful. The next technique shows how to track individual speeds for capturing the variation in speeds.

\section{REID DATA}

ReID is a computer package developed to aid in the extraction of travel times from simultaneous video (i.e. video of traffic shot at both ends of a corridor at the same time). This section describes the data collection using video and the use of ReID to extract travel times.

Data collected using GPS, as described in the above section yields in data set in which each point is already an average value of space mean speed or travel times. This methodology gives a rough estimate of base line conditions. To get more accurate base line conditions travel time of each vehicle should be tracked along the corridor. Another common method is to extrapolate section travel times from point speeds (e.g. inductive loop speed traps). This method assumes uniformity of flow, which is a restrictive 
assumption, especially under more congested conditions. More sophisticated methods use point measures and stochastic traffic-flow modeling. One example is the use of cross-correlation for measuring the propagation time of traffic (Dailey, 1993). Another example is the use of the assumption that upstream and downstream travel times have the same probability distribution (Petty, 1997a).

The proposed ReID tools fall under the category of vehicle reidentification methods for deriving travel time. Vehicle reidentification is the matching of vehicle signatures among data collected at two locations. In other words, detector signatures or images from an upstream station are compared with the signatures from a downstream station for a match. Signatures can come from a variety of detectors including video cameras, inductive loops, lasers, and so on. Some algorithms match individual inductive loop signatures or lengths from vehicles by correlating such signatures from two contiguous sites (Kuhne, 1991; Coifman, 1998; Sun et al., 1999). A more traditional method of vehicle reidentification is license-plate matching (Turner et al., 1998). Manual license-plate matching can involve the tape recording and transcription of license-plate numbers from multiple sites. Video images have been used for reidentification and include the use of color (Zeng and Crisman, 1998) and video signature vectors (MacCarley and Hemme, 2001). Other detector technologies that have been used for vehicle reidentification include laser profiles (Kreeger and McConnell, 1996), weigh-inmotion axle profiles (Chistiansen and Hauer, 1996), and ultrasonic detectors (Yokota et al., 1996).

There are some alternative technologies that could be employed in conjunction with fixed location detectors for deriving spatial traffic measures (Eisele and Rilett, 
2002). One is the use of so-called toll tags or AVI (Advanced Vehicle Identification). This type of system requires that vehicles have a toll tag or transceiver to communicate with the readers at points on the transportation network. A drawback to this system is that toll tags currently have a limited market share. Consequently, only a small subset of vehicles is detected. An advantage of this system is that the accuracy in identification is high, because each toll tag transmits a unique identification number. Another type of probe-based system involves the use of cellular telephones with integrated global positioning satellite (GPS) receivers. This type of system is also very accurate and allows an almost continuous tracking of vehicles. However, the sample size is also dependent upon market penetration, and privacy concerns can become an obstacle.

\section{$\underline{\text { POST }}$}

In St. Louis, Missouri many of the above ReID techniques were infeasible because they either required the installation of special hardware on the roadway or access to data that was not available (e.g. real-time cellular data). By developing the ReID system for reidentification, travel times could be extracted from simultaneous video footage, providing individual vehicle data and associated distributions, and the purchase and installation of additional roadside hardware could be averted. In order collect this video data for ReID purpose, a Portable overhead surveillance trailer (POST) was designed and built by researchers at University of Missouri-Columbia. FIGURE 2.1 shows a typical setup of the POST. As can be seen in the FIGURE 2.1 the POST has a mast that can be extended to more than 25 feet above ground, which is essential to minimize vehicular occlusion in the video data. 


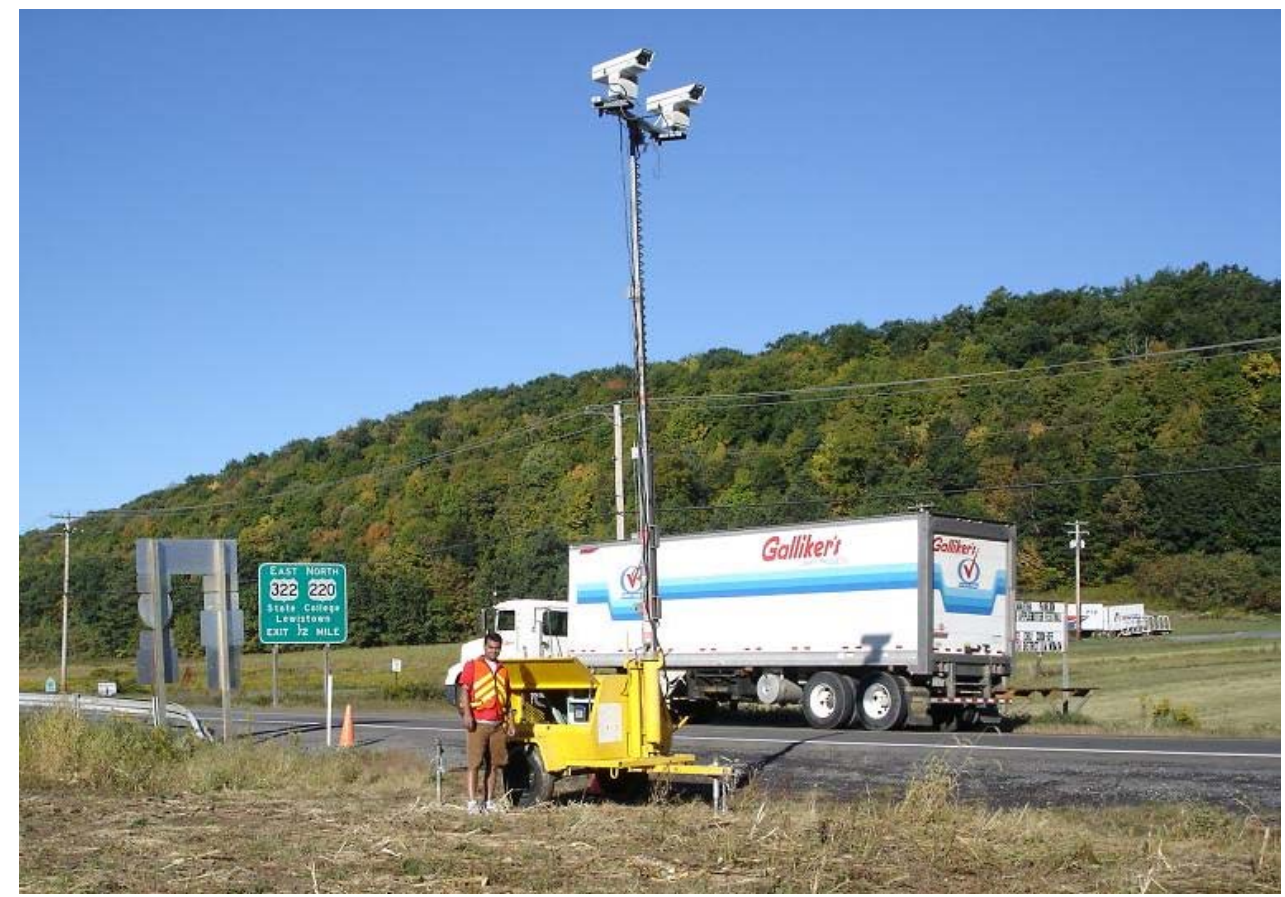

FIGURE 2.1 Typical set up of POST for data collection

\section{REID Software}

The fundamental approach involves videotaping traffic simultaneously at two locations on the same corridor. The video footage is catalogued, creating a database of vehicles (with images) observed in that video during a given time period. The catalogues from the two sites are then compared to identify matching records. The approach is similar to other reidentification methods in concept. However, the process is not automated because matching vehicles from video shot with different perspectives and lighting conditions cannot be effectively accomplished by current computer technology. To overcome this difficulty, ReID is designed to utilize human pattern-matching to verify each match and utilize the computer to extract and catalogue vehicle images, so that 
searching video footage for a particular vehicle is never required. ReID which is

developed by University of Kansas comprises of two modules, the ReID Cataloguer and the ReID Matcher.

ReID Cataloguer is used to build a catalogue of vehicles that occur in each of the videotapes during a given time period. The user steps through the video, selecting each vehicle and entering its basic characteristics. For each vehicle, the area designated by the user is saved as a bitmap, and the entire video frame is saved as a second bitmap. The characteristics that can be entered include the vehicle type (or class), color, a special characteristic such as racing stripes, and the lane the vehicle is in. In the screen shot of Cataloguer shown in FIGURE 2.2, these characteristics appear in the upper half of the left side of the window.

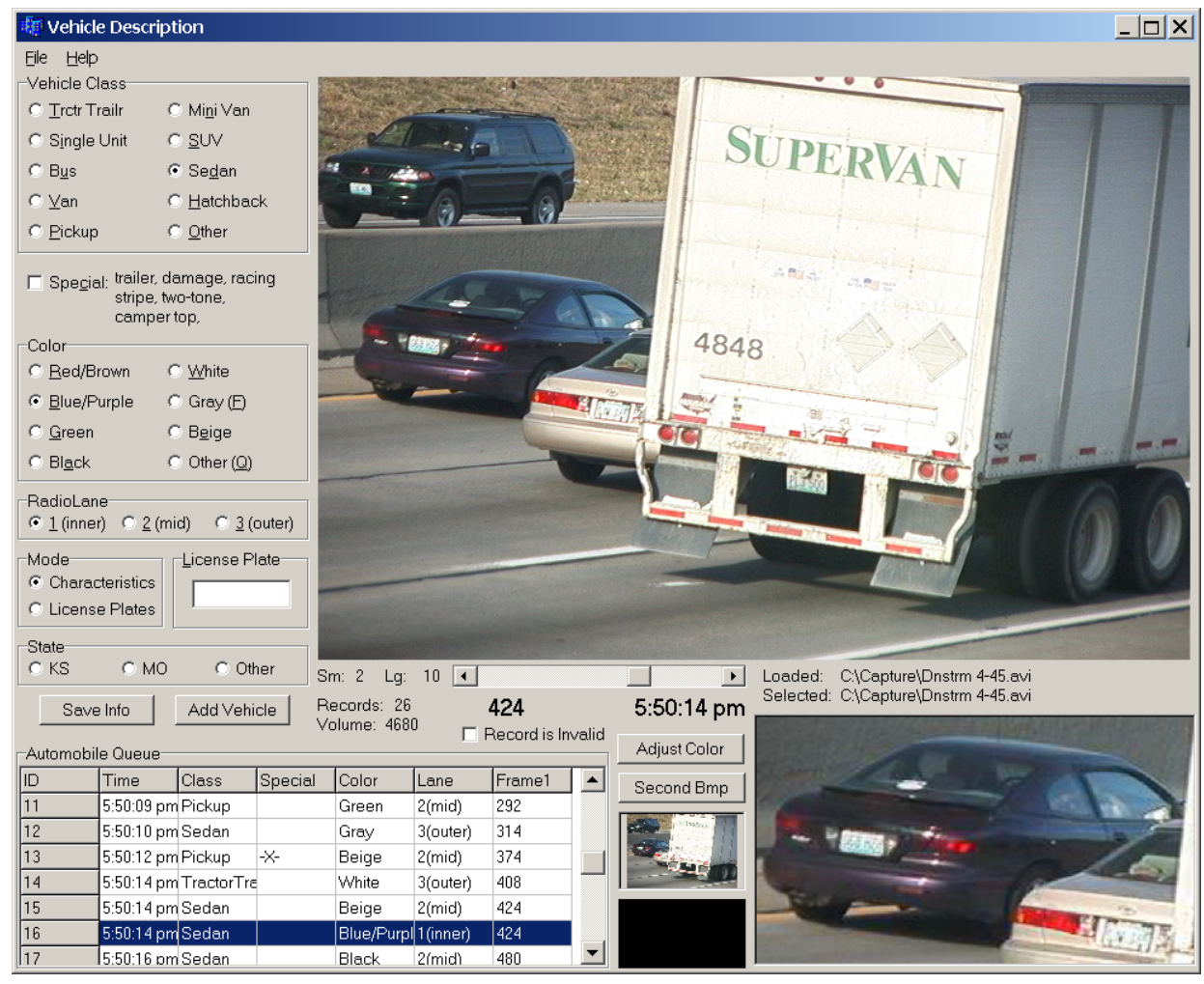

FIGURE 2.2 Screen shot of ReID Cataloguer. 
Once the video from both observation points has been catalogued for a given time period, Matcher can be used to help identify vehicles in the upstream data that match vehicles in the downstream data. A screen shot of Matcher is shown in FIGURE 2.3. The selected downstream vehicle is highlighted in the list in the bottom left, and the associated bitmap is shown in the top left. Matcher determines the most likely matches from the upstream catalogue and displays them as thumbnails. If the user can identify a match, that record is selected and confirmed by displaying the bitmap in the top right, side by side with the bitmap from the downstream data. If confirmed, the match is stored, and the speed statistics and distribution shown in the bottom right are updated.

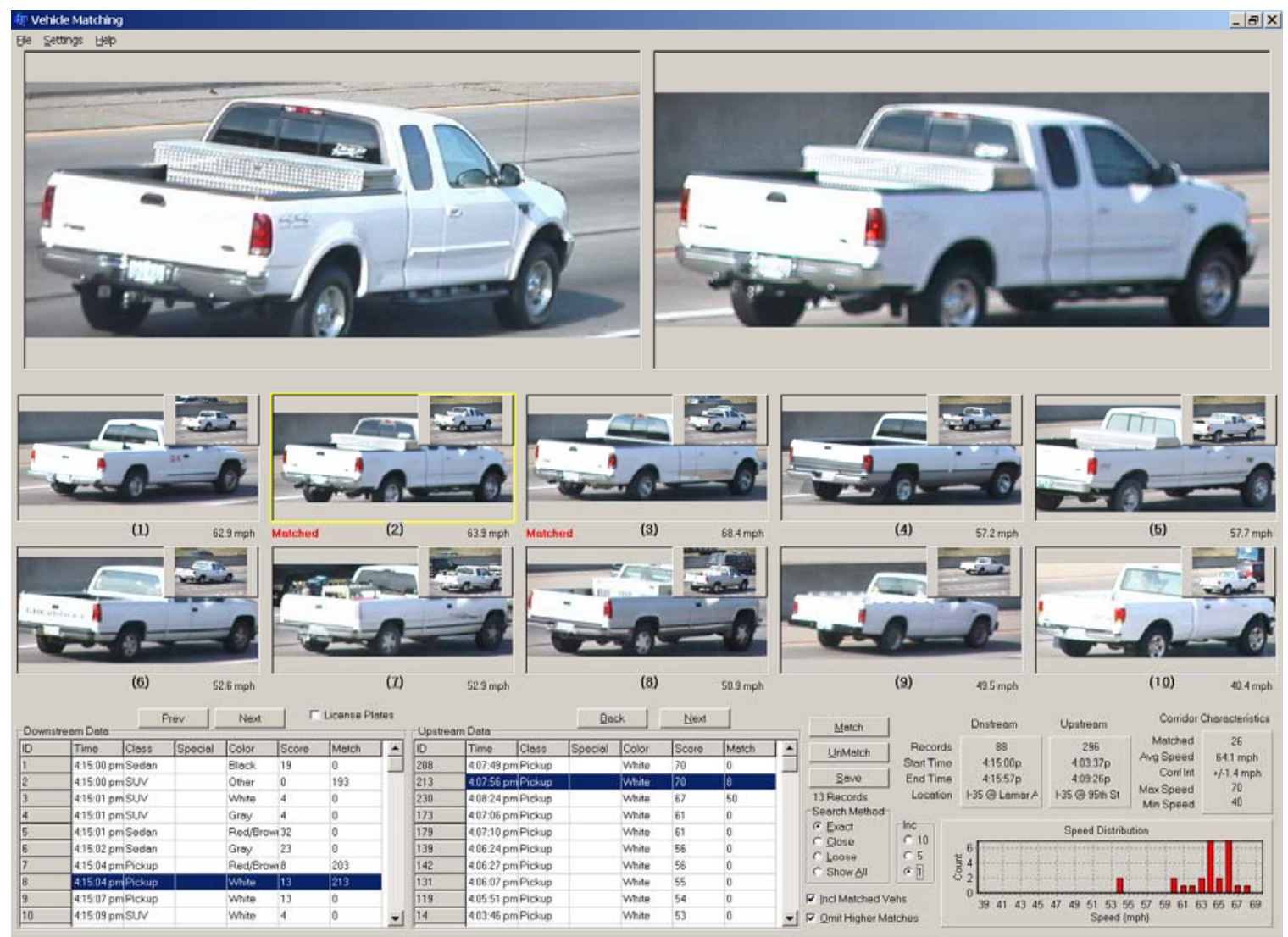

FIGURE 2.3 Screen shot of ReID Matcher. 
As mentioned earlier this gives a very accurate data of the traffic conditions by having the ability to track every vehicle that traverses the road segment. Also by having a video record of the data it can be used for various other studies like analyzing the difference in speeds between different classes of vehicles like passenger cars and trucks etc. But the disadvantage of this data collection is that it has high labor cost in processing the information.

\section{CAPTURING INCIDENT INFORMATION}

\section{Incident Chasing}

The POST system that is described in the previous section is only effective for planned data collection. The POSTs are ineffective in for capturing an unplanned event like accidents. As, for those unplanned incidents a research team needs to reach the location of incident and setup the data collection as soon as possible. The POSTs roughly needs 35 minutes to set up and by that time and the team will be incapable of capturing valuable data. Hence, for that reason, a more active approach of incident chasing methodology was developed.

The objective of incident chasing is to track incidents in the real time and capture as much data as possible by traveling light and using data collection equipment that can be set up with very little time. This process involved a team of two incident chasers equipped with a pickup truck, digital video cameras and tripods. In St. Louis the team was stationed strategically at the interchange of I-270 and I-64 or at the interchange of I270 and I-70. Then the team monitored radio and e-alert (real-time TMC incident 
message) reports for information regarding incidents. Scanners were not used as a monitoring device, because each agency had its own jargon to communicate information regarding incidents and other non-freeway incident related issues. Although the traffic reports were a little slow, they were preferable, because they dealt with freeway traffic conditions and were simple and direct. The traffic reports were given every 10 minutes during the peak periods. Nextel reports were also a good source of information, because they constantly updated the condition of the freeway. The only drawback to these reports was the reporting lag time.

When the teams monitored an incident through radio or e-alert, there were three warrants used to judge whether or not to pursue the incident:

1. How far was the incident?

2. What was the type of incident?

3. What was the status of the incident?

Based on the distance and the type of incident, it was estimated whether the team could reach the incident in time to obtain significant data. Also, the traffic reports sometimes mentioned the status of the incident, such as whether the involved vehicles were moved to the shoulder or whether they were cleared from the freeway. This information was useful in making the decision to take action on the incident or not. Once the team decided to pursue an incident, the data collection team would pick the best possible route to reach the incident location and the non driver records the incident details using a voice recorder. The information recorded included both when and how the incident was first monitored. Once the data collection team neared the incident location, one of the researchers was dropped off at the upstream location where he or she set up a 
camera in a good location (usually on an embankment beside the freeway) and started recording the traffic. Meanwhile, the other researcher, voice-recorded as much data as possible while driving past the incident location. The recorded data included the number of agencies and their units on the scene, number of lanes blocked, and the number and type of vehicles involved. Once past the incident location, the researcher would pull off the road and set up the downstream camera as close to the incident as possible without affecting the agencies involved or the incident recovery operations. Throughout the incident, the two researchers stayed in contact with cellular phones. When the researchers sensed that the traffic had normalized, they would continue to record the traffic for 10 minutes before turning off the cameras. This extra period of time was a precautionary measure, because even though the traffic appeared to have normalized at the camera locations, it may not have normalized between the cameras. After turning off the cameras, the downstream researcher would return to the truck and pick up the upstream researcher.

After incident data collection, the teams prepared a Preliminary Incident Report. The information recorded by the researchers during the incident was included in each report. Also included was the distance between the cameras, as well as any changes in the incident. Either GPS or the truck odometer was used to find the distance between the locations of the upstream camera, the incident, and the downstream camera. And this report was used when the tapes were processed using ReID software. TABLE 2.1 shows the list of incidents collected on St. Louis freeways. 
TABLE 2.1 Incident Chasing Data Sets

\begin{tabular}{|c|c|c|c|c|}
\hline Date & $\begin{array}{c}\text { Interstate } \\
\text { And } \\
\text { Direction }\end{array}$ & $\begin{array}{c}\text { Vehicles } \\
\text { Involved }\end{array}$ & $\begin{array}{c}\text { Number } \\
\text { of Lanes } \\
\text { Blocked }\end{array}$ & $\begin{array}{c}\text { Total Time } \\
\text { Congestion, } \\
\text { (min) }\end{array}$ \\
\hline $06 / 17 / 03$ & I-70 EB & $?$ & 2 of 3 & 29 \\
$06 / 25 / 03$ & I-270 WB & 1 & 1 of 3 & 59 \\
$07 / 01 / 03$ & I-64 WB & $?$ & 1 of 4 & 58.5 \\
$07 / 01 / 03$ & I-270 SB & 3 & ? of 4 & 48 \\
$07 / 02 / 03$ & I-70 EB & 2 & 3 of 3 & 37 \\
$07 / 02 / 03$ & I-70 WB & 4 & 1 of 3 & 46 \\
$07 / 08 / 03$ & I-270 SB & 2 & 2 of 5 & 59 \\
$07 / 17 / 03$ & I-64 EB & 2 & 1 of 4 & - \\
$07 / 22 / 03$ & I-270 NB & $?$ & 4 of 4 & 63.5 \\
$07 / 29 / 03$ & I-70 WB & 3 & $?$ & - \\
$07 / 30 / 03$ & I-64 WB & 2 & 2 of 3 & 47.5 \\
$08 / 06 / 03$ & I-170 SB & $?$ & 2 of 4 & 59.5 \\
$08 / 06 / 03$ & I-270 SB & 2 & 2 of 5 & 61.5 \\
$08 / 14 / 03$ & I-70 EB & 4 & 1 of 5 & 56 \\
$08 / 21 / 03$ & I-270 NB & $?$ & 1 of 5 & 89 \\
$10 / 22 / 03$ & I-270 NB & 5 & 1 of 4 & 40 \\
$10 / 23 / 03$ & I-70 EB & 2 & 1 of 5 & 53 \\
$10 / 30 / 03$ & I-70 EB & 2 & 1 of 5 & 63 \\
\hline
\end{tabular}

\section{MOTORIST ASSIST PAPER LOGS}

The Motorist Assist (MA) program in St. Louis is a freeway service patrol. The job of MA personnel is to patrol the freeways so that they can respond to an incident quickly and thus bringing the freeway to normal operating conditions. The MA personnel maintain a log of assists they performed in each shift. (A sample log sheet is shown in FIGURE 3.3 which is in the next chapter, where the MA is described in more detail). These logs are very informative on the type of incidents that occur on freeways but the drawback of these logs are that they are not in the electronic format and for each day there are at least 22 logs for the metro region i.e. at least two log per patrol zone. So this 
involves significant effort in converting the information in paper to electronic format. Chapter 3 shows how this data was used in modeling the performance benefits of the IMS.

\section{Media Traffic Reports}

Traffic management centers and traffic news agencies can provide wide spatial coverage of incidents as well as track the incidents over time. They can use information from aircrafts, elevated traffic cameras, Motorist Assist, emergency management (fire, police, ambulance, and HAZMAT), and motorist calls. They can also monitor and update this information throughout the course of an incident. Such intranet traffic information can be independent from police information, therefore such information can complement the accident database from the police. Combining these two data sets viz. accident database and traffic reports helps to incorporate more information about the incidents. By analyzing individual traffic reports in detail, the reporting times of the incident and the dynamic locations of the back of the queue can be found. The difference between the initial and final times gives an estimate of the total duration of the incident, and the distance from the location of the incident to the back of the queue gives an estimate of the length of the roadway that is affected by the incident.

However, the intranet reports need to be processed significantly in order for them to be in a usable format. The methodology for processing such reports is as follows. Pages of traffic reports are downloaded daily at regular intervals, say 3 minutes. A Unix script was written to perform this automatically. These reports then need to be consolidated and parsed so that pieces of information are extracted into specific fields 
such as incident reporting time, incident type, and incident description. A major task is to extract the traffic information for a particular highway along a particular direction in the sequence they are reported in the files on a particular day. A computer program saves the information pertaining to a single incident through multiple reports in a single day. Since there is no unique identifier associated with the information pertaining to a particular incident, the lines containing information related to a particular incident need to be extracted through the use of keywords present in those lines and absent in other lines. There can be difficulties in this process since traffic reports are human generated and can include syntax variability as well as errors. As an example, consider the primary route eastbound interstate 70. In the reports, eastbound can also be expressed as “EB”, “E/B”, or "east”, and interstate 70 as “70”, “I70”, or "I-70”. There can also be descriptions of the route expressed in phrases such as "eastbound lanes of 70" or "east and westbound lanes of 70”. Figure 2.4 shows the result of this processing. The information pertaining to a single incident is tracked throughout the incident giving the queue length as the incident progresses. Even though the processing of intranet traffic reports is laborious, a valuable incident dataset is produced. 


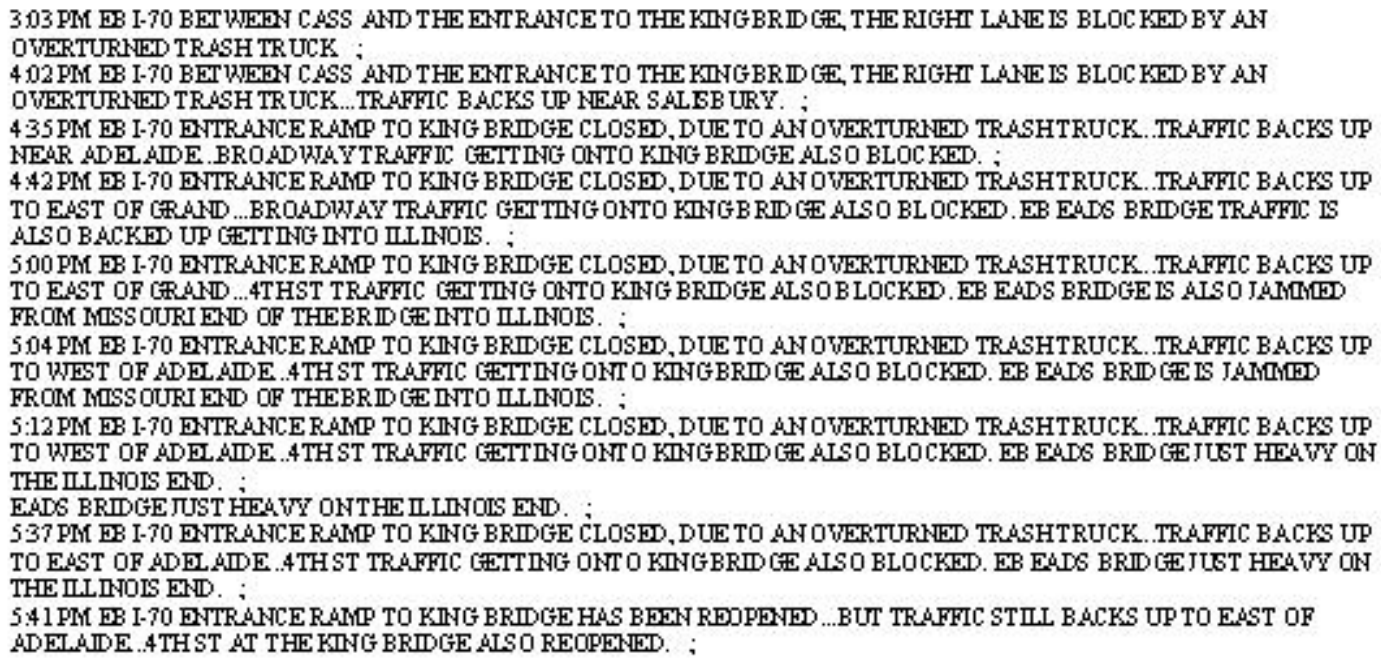

FIGURE 2.4 Example of intranet traffic report.

\section{Processing the Traffic Reports}

Each day’s traffic reports for the specified segment and direction were scanned for

incidents. And upon identifying an incident, the location and time are logged followed by recording the subsequent updates of the queue length, incident clearance and incident normalization information. Table 2.2 shows an example of how the data is entered. In this table each column represents an incident. The first six rows give information about the location of incident occurrence and the time it was reported. And in the subsequent rows each new traffic update is recorded. For the incidents the traffic updates varied in terms of number of updates and the time difference in between updates. 
TABLE 2.2 Sample Data Entry Form

\begin{tabular}{|c|c|c|c|}
\hline ID & 70EB_01 & 70EB_02 & 70EB_03 \\
\hline DATE & 9-May-03 & 9-Sep-03 & 6-Oct-03 \\
\hline $\begin{array}{l}\text { First Report } \\
\text { Time }\end{array}$ & $6: 35 \mathrm{AM}$ & 5:04 PM & 5:44 AM \\
\hline $\begin{array}{l}\text { Clearance } \\
\text { Time }\end{array}$ & 7:09 AM & 5:36 PM & 5:58 AM \\
\hline $\begin{array}{l}\text { Start Location } \\
\text { (Location 00) }\end{array}$ & $\begin{array}{l}\text { WEST } \\
\text { FLORISSANT } \\
\# 245.7\end{array}$ & $\begin{array}{l}\text { RIVERVIEW } \\
\text { DR \# } 243.48\end{array}$ & $\begin{array}{l}\text { CYPRESS \# } \\
235.69\end{array}$ \\
\hline Time 00 & $6: 20 \mathrm{AM}$ & 4:50 PM & 5:15 AM \\
\hline Location 01 & $\begin{array}{l}\text { Kingshighway } \\
\text { \# 244.71 }\end{array}$ & $\begin{array}{l}\text { Bermuda \# } \\
241.06\end{array}$ & $\begin{array}{l}\text { Rte.180 \# } \\
234.25\end{array}$ \\
\hline Time 01 & 6:39 AM & 5:21 PM & $6: 20 \mathrm{AM}$ \\
\hline Location 02 & $\begin{array}{l}\text { Goodfellow \# } \\
243.24\end{array}$ & $\begin{array}{l}\text { West Florissant } \\
\text { \# } 245.7\end{array}$ & $\begin{array}{l}\text { Rte.180 \# } \\
234.25\end{array}$ \\
\hline Time 02 & $6: 55 \mathrm{AM}$ & 5:25 PM & $6: 36$ AM \\
\hline Location 03 & $\begin{array}{l}\text { Jennings } \\
\text { Station \# } \\
242.92\end{array}$ & $\begin{array}{l}\text { West Florissant } \\
\text { \# } 245.7\end{array}$ & \\
\hline Time 03 & 7:11 AM & 5:36 PM & \\
\hline Location 04 & $\begin{array}{l}\text { Goodfellow \# } \\
243.24\end{array}$ & & \\
\hline Time 04 & $7: 22 \mathrm{AM}$ & & \\
\hline
\end{tabular}

The location of the incident report is usually referred to the closest exit or a cross road or a landmark (for example Blanchett Bridge). In case the location is reported as between two known reference points then the mile marker in between the reference points is recorded. For example

i. if an incident is reported as 'North/South of I-70' then the mile maker of the I-70 is noted down as the incident location. 
ii. if the incident is reported as 'Between I-70 and Dorsett' then the mile marker between I-70 and Dorsett is noted as the incident location. In addition, where the short backup is reported the length of queue is considered 0.5 mile or mid point between the exits, whichever is smaller.

In all the rows with location information there is also an additional numerical value after the '\#' symbol. The numerical value represents a continuous log point of the location. Continuous log points are part of reference system adopted by MoDOT. In this system the continuous log point reflects the actual distance of the road from its origin point. For example if we consider I-70 eastbound then the origin point of this freeway is at the state line in St. Louis where as for I-70 westbound the origin point is in western most part of Missouri i.e. in Kansas City. In this work continuous log points were used as it would be useful in combining this traffic information with MoDOT accident database. For both I-70 and I-270 based on their final and origin points a continuous log table is created for all the reference points (exits, crossroads and landmarks) for each freeway based on its direction. The distances between these reference points were measured using an online mapping tool of Cares website. This website has functionality to measure distance between any two points in the state of Missouri. Figure 2.5 shows a snapshot of the website. The functionality of this website can be accessed through the available menu buttons. The top row menu buttons like the 'zoom in', 'zoom out' help in navigating the map where as the bottom row of menu buttons like 'feature info', 'geographic coordinate', 'distance' help in accessing information about the selected point/points or an area. In this figure the distance button is selected and a I-270 segment between I-70 and Rte. D is traced with successive mouse clicks. The calculated distance of this path is 
shown on the right hand side of the map in both miles and feet format. Once these distances are transformed into a continuous log format then this information is populated into a list-box available in the Microsoft excel worksheet. And the list box is copied for all the rows that are supposed to contain location information. The list box helps in data entry by eliminating the tediousness involved in looking up for a distance marker for every incident's traffic report. Instead one could drop down the list box and select the required location with its continuous mile marker.

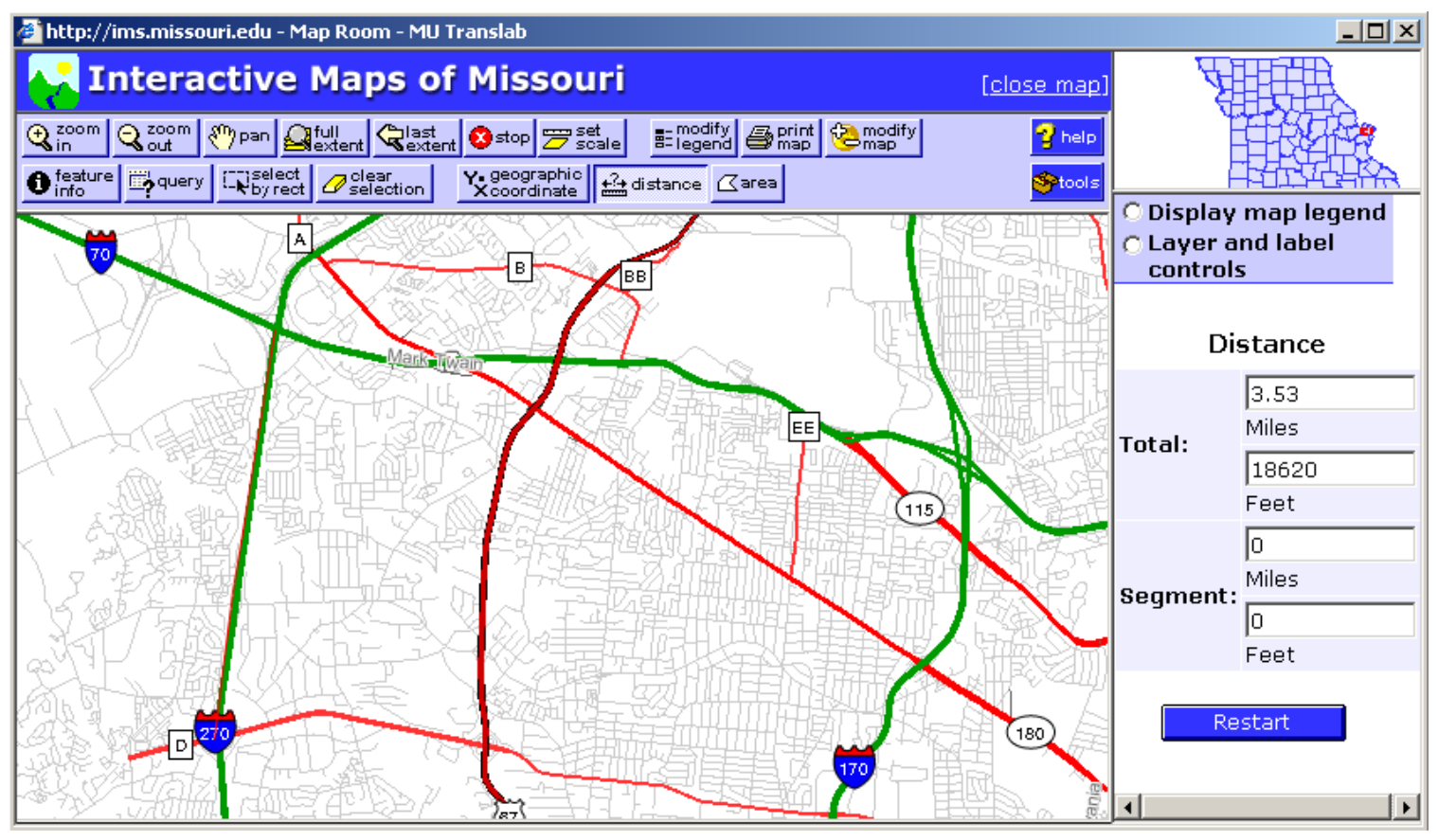

FIGURE 2.5 Online mapping tool from CARES website.

\section{PLANNED INCIDENTS}

In case of unplanned incidents like accidents, the emphasis is on how fast can the IMS detect, respond and clear the incident. But in case of planned incidents like work zones 
where the traffic disruption is pre determined, the transportation agency has more emphasis on facilitating smooth traffic flow without creating a safety concern for the public or highway workers..

But work zones have higher safety concerns than non-work zones (Ha and Nemeth, 1995; Pal and Sinha, 1996; Garber and Zhao, 2002). And to improve the safety and efficiency of the work zones several new techniques are being implemented. The underlying philosophy of these techniques is to communicate effectively with the traveling public to impart safer driving behavior. The communication is typically done via message boards like the one shown in the following figure. The message in the following figure says "Road Work Ahead". This message could vary depending on the traffic condition. Suppose a queue is building up at the starting point of a work zone then the traffic at the upstream point could be altered with a message like "Stopped Traffic Ahead".

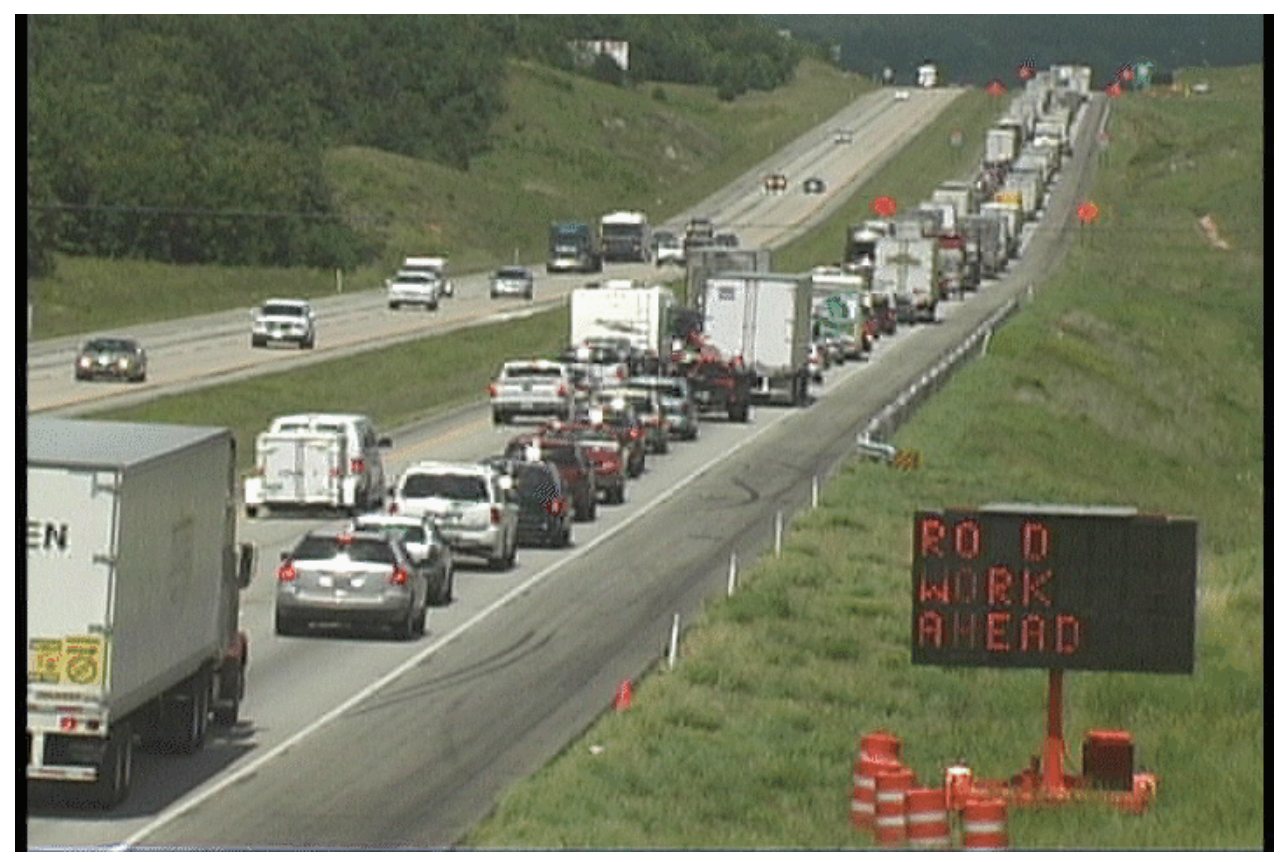

FIGURE 2.6: Set Up for Work Zone Data Collection 
In order to evaluate these systems one has to verify or quantify the changes in driver behavior. This can be done using the techniques discussed in the earlier section for unplanned incidents. Of all the techniques described before POST system is one of the best for evaluating the approach areas of the work zones. The advantage of POST is that not only can we get the individual vehicle travel times but we can also capture the driving behavior as the vehicles approach the work zone. Since POST is a non intrusive data collection system and it has to be at least fifteen feet from the edge of the pavement it creates an occlusion problem for the automation of extracting spot speed from the video. So another technique was developed for extracting spot speeds.

\section{Video and Radar}

In this technique radar is setup in the desired location for capturing vehicle speeds. And video camera is focused to capture both the vehicle and the radar. As it can be seen in the following figure, a tractor trailer is found to be traveling at $65 \mathrm{mph}$ by the radar. By using this approach one can verify if the vehicle speeds varied based on the messages. 


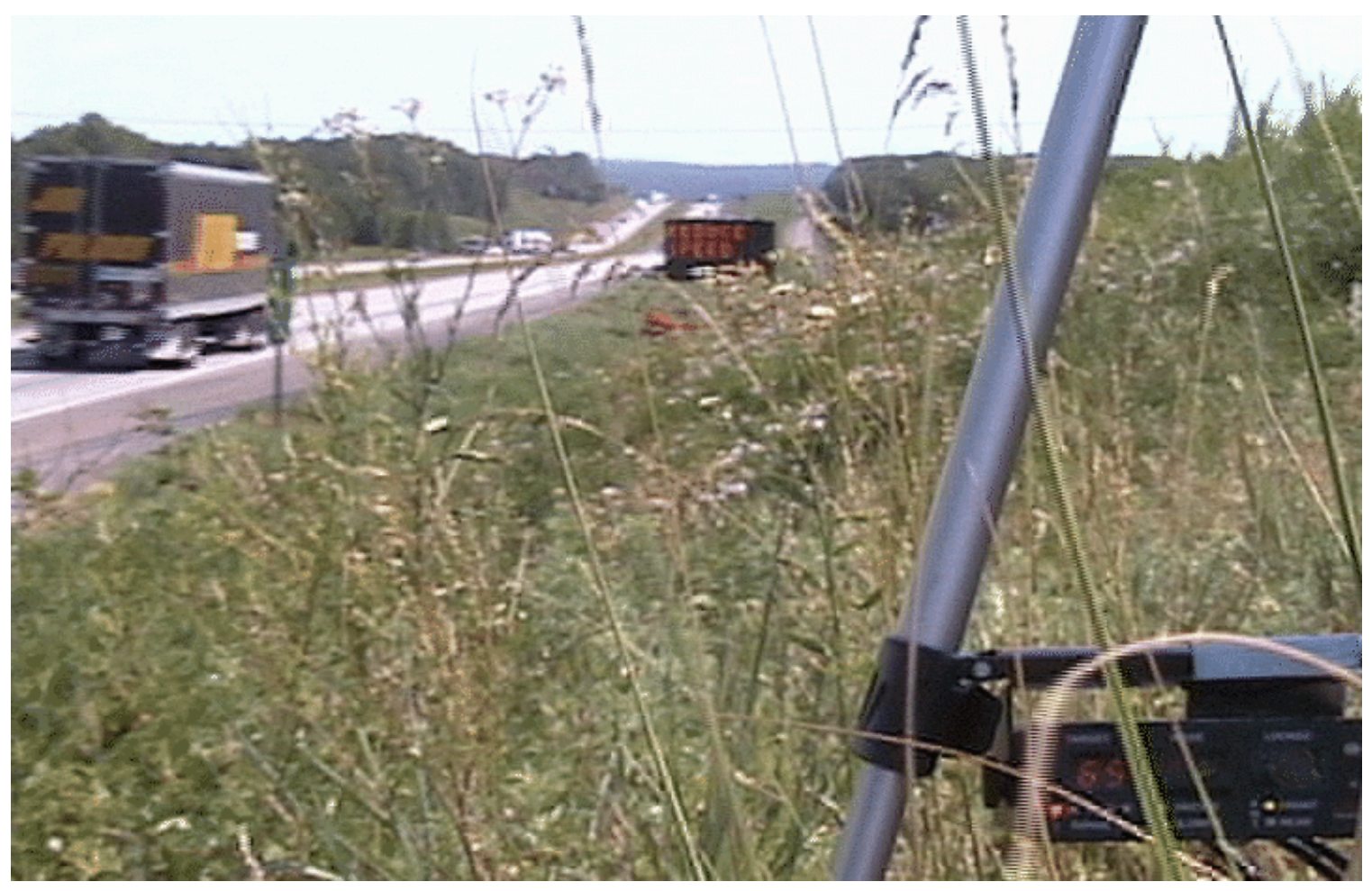

FIGURE 2.7: Combining Radar and Video for Spot Speeds 


\section{CHAPTER 3: A CASE STUDY FOR EVALUATION OF IMS WITH}

AND WITHOUT MA

The previous chapter provides a description of innovative data sets that can be used for evaluating an Incident Management System. In this chapter a case study is described to show how the data sets were used for a specific evaluation.

In this particular case study the benefits of including Motorist Assist (MA) as a part of IMS is evaluated. This study was done on the request of MoDOT. Although the objective was to understand the value of MA, in this context this study provides a frame work for evaluating an IMS using real data.

Since the inception of Motorist Assist in St. Louis in 1993, the feedback regarding Motorist Assist has been mostly informal in the appearance of public comment forms returned from motorists serviced by the program. While the response has been positive and the support overwhelming, the need for a formal quantification of the benefits of the program is apparent. A variety of data sources were used including Motorist Assist operator logs, traffic volume data, accident records, emergency service user surveys, AAA logs, Metro Networks incident information, and interviews with police and MA operators. The evaluation explores and attempts to quantify potential benefits. According to the results of a survey of similar services across the nation (Fenno, 1998), agencies operating freeway service patrols cite both primary and secondary benefits attributed to their service. Primary benefits include reduced incident duration, traffic control, debris 
removal, assistance for stranded motorists and accident victims, reduced impact of major events, and surveillance and timely reporting of freeway traffic conditions. Secondary benefits include a reduction in vehicular delay and improved traffic flow, a reduction in secondary accidents, reduced emissions and fuel consumption, fewer abandoned vehicles on the roadway, improved public relations, reporting of state damage, and a diversion of police manpower away from minor incidents. The goal of this evaluation is to identify these types of benefits as they apply to the St. Louis Motorist Assist program and attempt to quantify as many benefits as possible.

The Motorist Assist Program debuted on February $1^{\text {st }}, 1993$ in the St. Louis region. Initially, only four vehicles patrolled just three routes with a total centerline mileage of 31.5 miles. The hours of operation were limited to the morning and evening peak periods only. In 1996, the program was expanded by nine operators and four trucks. The additional manpower and equipment allowed for an increase in both the number of centerline miles patrolled and expanded the hours of operation to the current 2003 level of 5:00AM to 12:00PM and 1:00PM to 7:30PM. Another expansion in 2001 added I-44 and I-64/US 40 from west of Mason Rd into St. Charles County as patrol areas. In August 2002, Motorist Assist began patrolling on Saturday and Sunday for the first time.

The purpose of the Motorist Assist Program as defined in the Operator's Handbook is to "promote freeway safety and expedite the flow of high volume traffic by assisting disabled motorist in the patrol areas, clearing roadways of stalled vehicles and debris, and assisting emergency personnel at accident locations”. An estimated 60\% of vehicle-hours lost due to congestion is attributed to incidents as reported by a study sponsored by the Federal Highway Administration (Cambridge Systematics, 1990). 
Similarly, the 2003 Urban Mobility Study estimates that 54\% of all vehicular delay in the St. Louis region is a result of non-recurring incidents (TTI, 2003). Incidents include vehicle breakdowns and accidents, debris, hazardous material spills, etc. Motorist Assist improves the flow of traffic and increases safety by detecting and responding to incidents quickly, removing incidents in a timely manner, and providing high-visibility traffic control devices at incident scenes. Specific services provided include:

- Push a disabled vehicle out of a traffic lane

- Provide traffic control at an incident scene

- Remove debris from the roadway

- Establish initial containment of a hazardous materials spill

- Give directions to a lost motorist

- Mark an abandoned vehicle with the date and time to expedite removal by police

- Contact police to tow an abandoned vehicle impeding traffic flow

- Make basic repairs to a disabled or stalled vehicle

- Provide a stranded motorist a ride to a safe location

- Allow a motorist the use of a cellular phone

- Change a flat tire

- Dispense fluids such as gasoline or engine coolant

In addition to the many primary functions, throughout its existence the Motorist Assist program has accepted several secondary purposes. For instance, major accidents 
require a prolonged presence of emergency personnel to provide a "buffer zone" between moving traffic and the incident scene and to close necessary traffic lanes or even an entire freeway. Motorist Assist helps to fill this role by ensuring safety at an accident scene and by maintaining a presence at the point of a lane or freeway closure. An additional secondary function is checking for state property damage. Each roundtrip of Motorist Assist on a beat serves as a basic inspection for malfunctions and damage to the freeway system. Lighting facilities not working and damaged guard rail are just a couple examples of the types of problems possibly noted by Motorist Assist. Also since the inception of Gateway Guide, the Intelligent Transportation System (ITS) for the St. Louis region, Motorist Assist has become an integrated component of the system. Operators in the field provide information on traffic problems resulting from both recurrent congestion and incidents. Details of incident location and approximate clearance time are provided to dispatchers at Gateway Guide’s Transportation Management Center which in turn transmit the information to the public via ITS outlets such as the media, dynamic message boards, and the Gateway Guide website.

Motorist Assist operations consists of twenty-four patrol operators who are all employees of MoDOT. Operators receive training in minor first aide, CPR, auto mechanics, and traffic control. Patrolling takes place in the far right lane at speeds of approximately $55 \mathrm{mph}$, unless an incident warrants temporary travel in a different lane. Reversing directions on a beat is permitted if visual detection of an incident in the opposite direction is made or if the dispatcher notifies the operator of an incident requiring immediate attention. 
The patrol fleet is comprised entirely of pickup trucks most of which are powered by alternative fuels, either propane or compressed natural gas. The trucks are painted white with red and are marked very noticeably "Motorist Assist". Adding to the visibility on top of the truck are flashing yellow lights and a flashing arrow panel which increases the safety of the operators, motorists, and incident management partners. The trucks carry equipment necessary to perform basic auto repairs and are equipped with a front pushbumper for quickly clearing disabled vehicles from traffic lanes.

\section{LITERATURE REVIEW OF FSP PROGRAMS}

Across the US, the concept of freeway service patrols (FSP) is not a new one. One of the oldest known comprehensive freeway service patrols is the Chicago Emergency Traffic Patrol, better known as the Minutemen. The program began in April 1960 and continues today with a fleet of at least 51 vehicles (Morris, 1994). However, only a select few freeway service patrols have a long and distinguished history comparable to that of the Minutemen. Most patrols were initiated during 1990s; in fact, 33 FSPs made their debuts in the first eight years of the decade (Fenno, 1998). Many metropolitan areas turned to freeway service patrols as a cost-effective means to deal with the ever increasing problem of urban congestion. The trend caught on, and today there are well over 50 freeway service patrols in existence. With so many FSPs in operation, the type and quality of service provided does vary. Sponsorship and funding for freeway service patrols comes from a variety of sources including public agencies, public-private partnerships, and entirely private entities. These sponsoring organizations receive funding from 
combinations of federal, state, and local taxes and also private funds. The operation aspects of freeway service patrols can differ as well. For example, some services patrol only the morning and evening peak periods. While a select few patrol twenty-four hours a day. The type of vehicle utilized for patrolling can vary also. A majority use pickup trucks, but 28 percent utilize tow trucks (Fenno, 1998).

With the introduction of many freeway service patrols in the last decade, a number of reports have surveyed and evaluated the operations and cost-effectiveness of these patrols. Many reports generate measures of effectiveness. There appear to be three primary methods for generating these benefits. The three methods include simulation, real-time modeling, and personal preference surveys/economic models.

One such simulation-based report is the Evaluation of the Massachusetts Motorist Assistance Program (Stamatiadis, 1998). The study macroscopically simulates incidents in traffic conditions based on actual volumes, and the simulation software outputs total delay, fuel consumption, and emissions as measures of effectiveness. Simulations are run for two scenarios representing the before and after cases using estimated response times for each case. The advantage of this methodology is in the detail of the incident effects on traffic flow. The disadvantage is in the generation of incidents. Incidents were simulated at half-hour increments at only three locations (representing high, median, and low volume) on each of four routes. Adjustments of the measures of effectiveness were necessary to account for more or less incidents occurring at points of different volumes and for the routes that were not actually simulated. Many incidents from the FSP logs cannot be individually simulated so "category" incidents must be simulated and their measures of effectiveness adjusted to account for additional incidents. In contrast, this 
evaluation will utilize Motorist Assist logs and input all of the sampled incidents into a simple queuing model to compute the traffic effects. The queuing model does not model incident effects in as much detail as simulation, but the advantage is that the incidents are actual incidents occurring at actual locations. Only one adjustment is necessary to extrapolate the sample measures of effectiveness to represent an entire year of incidents.

Other reports have collected extremely large quantities of field data for FSP evaluation. Both the I-880 Field Experiment (Skabardonis, 1996) and The Los Angeles Freeway Service Patrol Evaluation (Petty, 1997) undertook large data collection efforts on a single segment of interest. Both studies utilized multiple probe vehicles simultaneously and a complex system of loop detectors to log a database of incident characteristics and the resulting traffic conditions. The probe vehicles traveled at headways of approximately 7 minutes and were responsible for logging all incident data including time of occurrence, response times, and clearance times. The induction loop detectors collected data on speeds, flows, and occupancies at intervals of one second. Such a system can instantly and accurately detect changes in traffic flow. The disadvantage of a methodology of this size and detail is that it is difficult to generalize the results of a single segment to an entire freeway service patrol system. In addition, the availability of advanced equipment to measure traffic conditions at very small time and space intervals along a corridor is limited and entirely unavailable in the St. Louis Area. For this report, a sample of Motorist Assist operator logs will provide incident data, and hourly AADT volumes averaged over several locations along each patrol beat will characterize traffic conditions. 
An Economic Evaluation of Freeway Service Patrols (Levinson, 2001) is a report based primarily on personal preference surveys and economic models. The evaluation links freeway service patrol benefits with the value that motorists place on those benefits versus the benefits of private assistance services. A pilot survey of 19 individuals obtained the stated preference of each regarding choosing to rely on the freeway service patrol or private assistance services. The factors found to influence the probability of an individual choosing to rely on the freeway service patrol are the time of waiting, time-ofday, cost of assistance, and the related socio-demographic variables. Using a logit model, the difference in the utilities of the two services was calculated and converted to a benefit. Computing an individual's willingness to pay for the freeway service patrol as compared to private assistance services is an interesting methodology but is not consistent with the approach of this evaluation. The Motorist Assist program is not in competition with private assistance services. Additionally, a survey of this nature is only able to quantify the benefits that individuals are aware of firsthand. For example, a user is able to provide a monetary value for roadside assistance provided his or her vehicle breaks down. But the user is most likely unable to provide a monetary value for the benefit of the FSP removing debris from a traffic lane. In contrast, the approach of this evaluation is to quantify benefits applied to all motorists from a regional perspective as opposed to an individual perspective.

Two reports examined freeway service patrols with a much broader approach. Fenno and Odgen (1998) performed a comprehensive telephone survey of managers responsible for 53 freeway service patrols across the nation. The report discusses the trends in operations, financing, services, equipment, and many other aspects of FSPs. 
Included are the results of fifteen benefit/cost studies in which the $\mathrm{B} / \mathrm{C}$ ratio ranged from 36.2:1 to just 2:1. Furthermore, Morris and Lee (1994) investigated the method of analysis of at least 8 freeway service patrol evaluations.

Also there are several reports available that evaluate and model freeway incident conditions and their influence on vehicular delay. Sullivan (1997) constructs four organized and structured sub models for computing incident rate of occurrence, incident severity, duration, and delay. This model is highly empirical based on data from freeway service patrols in four cities and other data from two other cities. For this report, the large sample of incidents from the Motorist Assist logs replaces the need to generate a number of incidents or their duration. However, this report will utilize two tables for assigning incident characteristics that are not addressed by the Motorist Assist Logs. Table 3.1 below presents the distributions of lane blockage for various incident types. Table 3.2 also below provides the percentage of capacity remaining for lane blockage scenarios based on the total number of lanes. Lastly, the delay sub model calculates an incident delay based on queuing using the cumulative arrival-departure curve method. The method for computing vehicular delay for this evaluation will follow a similar approach. 
Table 3.1 Average Percent Distributions of Lane Blockage

\begin{tabular}{|c|c|c|c|c|c|}
\hline $\begin{array}{c}\text { Incident } \\
\text { Type }\end{array}$ & $\begin{array}{c}\text { Number of } \\
\text { Incidents }\end{array}$ & 1-Lane & 2-Lane & 3-Lane & 4+-Lane \\
\hline Abandoned & 38 & 100 & 0 & 0 & 0 \\
Accidents & 350 & 80.8 & 15.8 & 2.7 & 0.7 \\
Drop Load & 82 & 96.7 & 3.3 & 0 & 0 \\
Mechanical & 348 & 97.8 & 2 & 0 & 0 \\
Stalled & 131 & 97.9 & 2.1 & 0 & 0 \\
Flat Tire & 63 & 96.9 & 3.3 & 0 & 0 \\
Other & 53 & 94.3 & 5.7 & 0 & 0 \\
\hline
\end{tabular}

Table 3.2 Percentage of Original Capacity Remaining Due to Incidents

\begin{tabular}{|c|c|c|c|c|c|c|}
\cline { 2 - 7 } \multicolumn{1}{c|}{} & \multirow{2}{*}{$\begin{array}{c}\text { Lateral Location of } \\
\text { Incident }\end{array}$} & \multicolumn{4}{c|}{ Original Width of Roadway (lanes) } \\
\cline { 3 - 7 } & & $\mathbf{4 +}$ & $\mathbf{3 . 5}$ & $\mathbf{3}$ & $\mathbf{2 . 5}$ & $\mathbf{2}$ \\
\hline \multirow{3}{*}{$\begin{array}{c}\text { Accidents } \\
\text { and Debris }\end{array}$} & Right Shoulder & 85 & 84 & 83 & 82 & 81 \\
& 1 Lane Blocked & 62 & 57.5 & 53 & 46 & 39 \\
& 2 Lanes Blocked & 26.7 & 22.55 & 18.4 & 9.2 & 0 \\
\hline \multirow{2}{*}{$\begin{array}{c}\text { All Other } \\
\text { Incidents }\end{array}$} & Right Shoulder & 96 & 93 & 90 & 87 & 84 \\
& 1 Lane Blocked & 66.7 & 61.85 & 57 & 49.5 & 42 \\
& 2 Lanes Blocked & 28.7 & 24.25 & 19.8 & 9.9 & 0 \\
\hline
\end{tabular}

\section{METHODOLOGY FOR EVALUATING EFFICIENCY}

The data that were used to understand the before and after MA conditions or more appropriately the "with MA" and "without MA" conditions are described in this section. The first three data sets viz. accident data, police data and towing data address what the 
conditions were before and after the MA program. The next data set named St. Louis freeway volume illustrates the 2002 volumes which will be used to estimate impacts of with and “without MA” program. The final five data sets relate to cost and quantifying the performance of MA program.

\section{Accident Data}

The details of all accident reports are logged by the police and transferred into the MoDOT database. This data illustrates how the accidents are occurring on the St. Louis Freeways and this data can also be used in estimating the number of secondary accidents before and after implementing MA program.

\section{Police Data}

The knowledge of police operations on the St. Louis freeways before and after the MA program helps in estimating detection, verification and response time to an incident. To obtain this data interviews were conducted with St. Louis City and St. Louis County police offices and their computer aided dispatch (CAD) data were requested.

\section{Towing Data}

The towing response time to an incident helps in painting a picture of before MA scenario as it provides a better estimate of incident duration time. The difficulty in obtaining the required data from towing companies, since such data are not usually kept, made it necessary to rely on estimates based on police interviews, surveys of actual users, and other studies. 


\section{St. Louis Freeway Hourly Volume Data}

MoDOT has permanent count stations on St. Louis freeways. Based on these data the hourly volumes at various segments on the freeways are estimated. These volumes can be retrieved from MoDOT's Transportation Management System (TMS). An example of the hourly volume is shown in FIGURE 3.1. This data helps in determining peak, and off peak periods and thus in quantifying the possible impact of an incident.

\section{MA Operations for the Time Frame}

As mentioned earlier MA operates from 5:30 Am to 7:30pm covering all the freeways in metro St. Louis. This data is used in estimating MA average response times.

\section{MA Paper Logs}

All motor assist personal log details related to the assists they performed in their log sheets. These logs provide information about the incident such as location, type, service time. An example of the log sheet is provided in the FIGURE 3.2. 


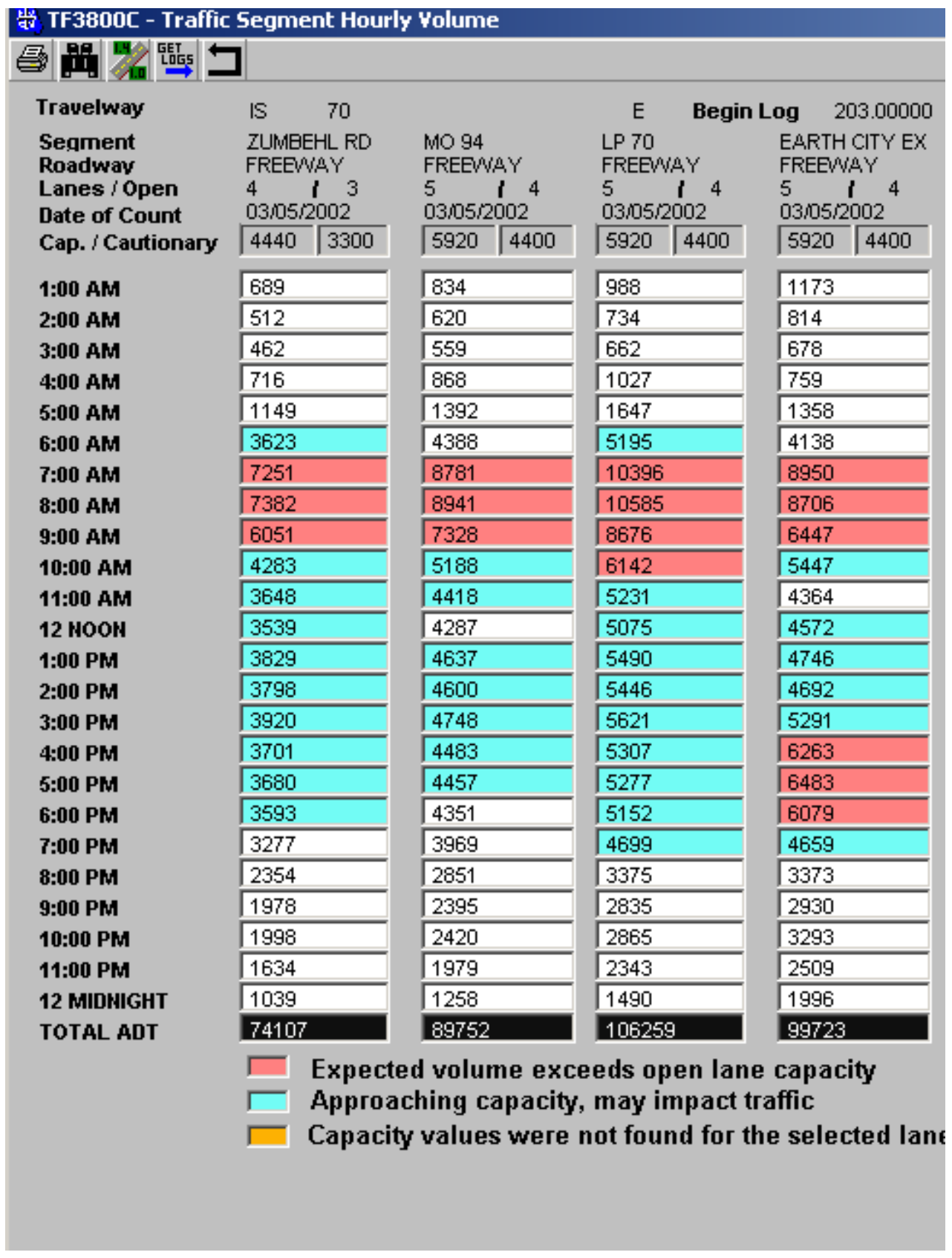

FIGURE 3.1 Sample hourly volume counts for I-70 east bound. 
25

MOTORIST ASSIST DAILY REPORT

Date: $08 / 22 / 02$ Truck \# B5301

Mileage: 8899

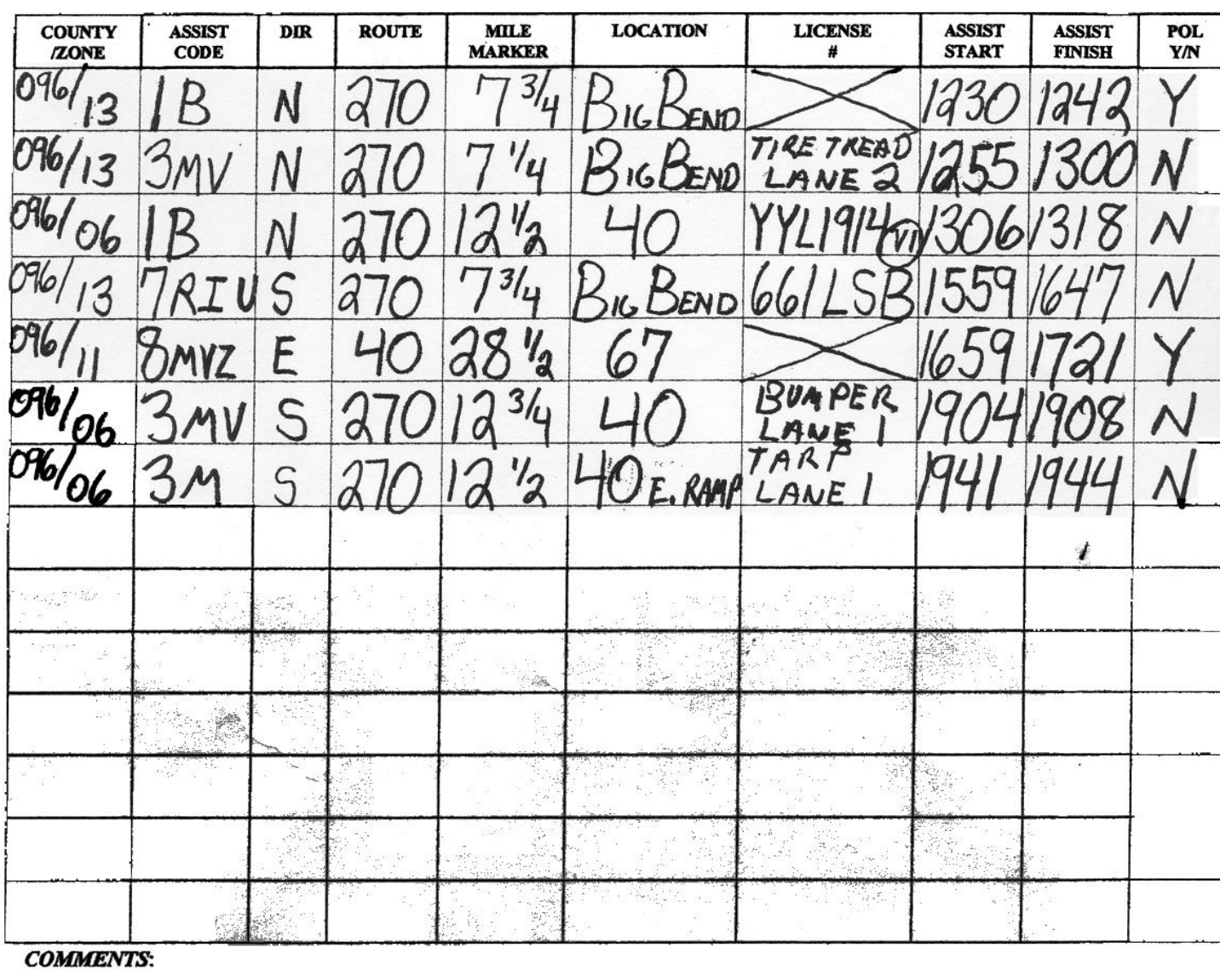

EATS:

Badge ti: 618

Driers signature: Da nd A. Jaunt

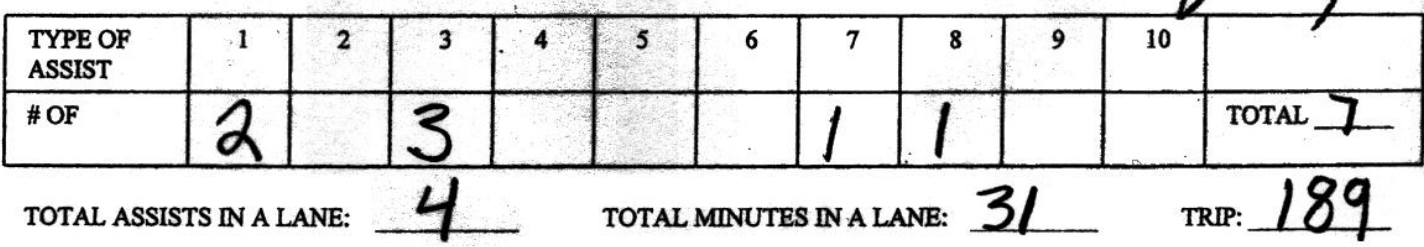

FIGURE 3.2 Sample sheet of motorist assist daily report.

38 


\section{MA Monthly and Annual Data}

MA does not compile electronically details such as location and duration of each assist but they provide summary of the number of assists performed based on region, month etc. This is useful in understanding the macroscopic patterns of the incidents over time and space. Paper logs were used to retrieve details of individual assists.

\section{MA Cost}

The cost of MA in St. Louis as obtained from MoDOT District 6 is 1.5 million dollars per year in the year 2003.

\section{MA Service Survey Letters}

After each assist the MA personal are required to hand out a survey letter. The returned survey letters indicate the MA personnel's courtesy and effectiveness of the assist. The survey letter also indicates the response time of the assist and the view point of consumer whether the service should be continued or not. A sample survey letter is provided in FIGURE 3.3. 


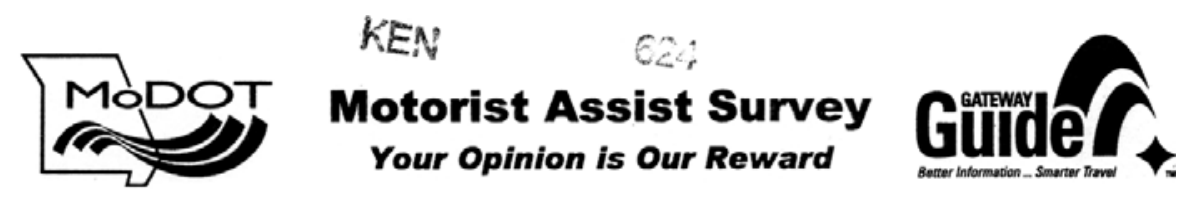

How would you rate our following services?

\begin{tabular}{|l|c|l|l|l|}
\multicolumn{2}{c}{ Excellent } & Good & Fair & Poor \\
\hline Driver Courtesy & - & & & \\
\hline Effectiveness of Assist & - & & & \\
\hline
\end{tabular}

How long did you wait before Motorist Assist Arrived? 10 (Minutes)

Date of Assistance: $3-18-03$

Do you think this service should continue? $y e s$

\section{Added Comments:}

Very Help fall and I want to
see this servuce continued. My
wite had trouble abuat a morth age
and she to had a good experrance wits
this servicealso. This is a good use
of our tax dollaws

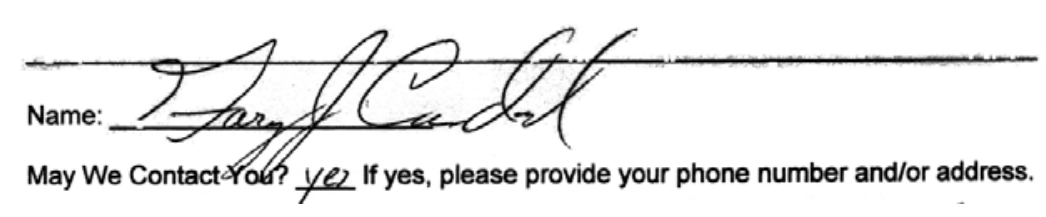

FIGURE 3.3. Sample letter of returned motor assist survey

\section{ESTIMATING EFFICIENCY BENEFITS}

Any type of incident can cause traffic delay, even the most minor such as an abandoned vehicle on the shoulder. Studies show that a parked vehicle on the shoulder of the freeway can reduce the overall capacity as much as $19 \%$ for a two lane freeway (Sullivan, 
1997). As stated in the Motorist Assist statement of purpose, one of the primary goals is to maintain traffic flow and improve the overall efficiency of the system. Three measures of effectiveness were computed to quantify the benefits contributed by Motorist Assist to improved system efficiency. Reduced vehicular delay, reduced fuel consumption, and reduced vehicular emissions were each quantified based on the Motorist Assist sample data to validate the Motorist Assist contribution. To calculate reduced vehicular delay, a with-and-without study was conducted to understand how Motorist Assist altered the dynamics of incident response. Total vehicular delay was computed based on the Motorist Assist sample data to represent the scenario with Motorist Assist present. The without Motorist Assist scenario was constructed based on aspects of the Motorist Assist sample data considered to be consistent in both scenarios. Based on this combination, total vehicular delay was computed for the without Motorist Assist scenario. Finally, the difference of these two delays is the delays savings attributed to Motorist Assist. Reduced fuel consumption and reduced emissions were each computed using direct correlations with the reduction in delay.

\section{Data Analysis}

The sample of approximately 5500 incidents from Motorist Assist incident logs were used for the purpose of modeling. One of the initial steps consisted of classifying the data to account for the spatial and temporal variation of incidents. The values for location and time of day as provided by the Motorist Assist logs are continuous variables extending across all possible service hours and all possible patrol routes and mile markers. 
For temporal classification, three time periods of AM Peak, PM Peak, and OffPeak were selected for analysis. An AM Peak period incident is an incident in which at least a portion of its clearance time falls within the hours of 6:00AM and 9:00AM. A PM Peak period incident is identical in that a portion of the clearance time must fall within the hours of 3:30 PM and 6:30 PM. The remaining incidents are Off-Peak incidents. The hours of each peak period were selected based on judgment and knowledge of peak periods in the St. Louis region. Three hour long peak periods were selected to account for variances in the peak periods by route. For a hypothetical example, the PM Peak may not end until after 6:30PM on I-270. On the other hand, the PM Peak may begin just after 3:00PM in the early afternoon on I-64 (US 40). But by 5:30 PM restoration of traffic to Off-Peak conditions could be complete.

For spatial classification, Motorist Assist patrol beats or zones were selected for analysis. Other considerations for further defining segments include a wide range of characteristics such as lane and shoulder geometrics, variations in volume, major conflict and driver decision areas, Motorist Assist patrol zones, and even political boundaries such as police jurisdictions. Categorizing incidents by patrol zones provide more than adequate spatial variation. Only one of eleven zones encompasses more than one freeway route. Roundtrip mileage in the zones ranges from 36 miles to just 18 miles. By averaging volumes by direction across several locations in each zone while taking into account the three time-of-day categories, an aggregate depiction of travel conditions is realized.

With the sample incidents classified into detailed time and space categories, the next step was to apply the characteristics of the categories to the data. Characteristics 
such as total and average number of lanes, volume, capacity, capacity reduction factors, and estimated Motorist Assist response times are all functions of time and space variables.

The total and average number of lanes was computed for each Motorist Assist patrol zone. The values were determined based on general knowledge of the St. Louis transportation system combined with numbers from the Missouri Department of Transportation traffic volume data. Care was taken to ensure that a high level of accuracy was involved in defining the number of lanes. For example, auxiliary and weaving lanes were not counted. Auxiliary lane speeds are generally lower than the free-flow speed in through lanes due to the large amount of weaving and lane changing taking place, not to mention the usually short distance of the lane. Thus consideration of an auxiliary lane as a through lane would have inaccurate effects on capacity calculations.

Volumes were applied to the Motorist Assist sample data as a function of both patrol zone and time of day. Hourly AADT volumes for twenty-four hours for locations corresponding to nearly every interchange on a freeway were obtained from MoDOT. Depending on the size of the zone and volume variability, volumes were taken at a minimum of three and a maximum of five locations along a zone for each hour between 6:00AM and 8:00PM excluding 1:00PM (volume is for the 60 minute time period before the hour noted). Typically each zone endpoint was selected followed by evenly spaced interior points. The volumes for the peak periods (6:00AM-9:00PM and 3:30PM6:30PM) were averaged followed by the volumes were all other operating hours (5:00AM-12:00PM and 1:00PM-7:30PM). The final result was three different volumes 
based on the time of day, for each patrol zone. The volume data for each zone based on the time period is presented in TABLE 3.3 below.

Table 3.3 Hourly AADT Averaged by Time and Patrol Zone

\begin{tabular}{|c|cc|c|c|c|}
\hline \multirow{2}{*}{ Zone } & & & \multicolumn{3}{|c|}{ Traffic Volume (vehicles per hour) } \\
\cline { 3 - 6 } & \multicolumn{2}{|c|}{ Segment } & AM Peak & Off Peak & PM Peak \\
\hline \multirow{2}{*}{5} & I-70 & EB & 6232 & 3748 & 4585 \\
& I-70 & WB & 4305 & 4365 & 6568 \\
\hline \multirow{2}{*}{6} & I-270 & NB/WB & 5648 & 4139 & 5602 \\
& I-270 & SB/EB & 5197 & 3946 & 5615 \\
\hline \multirow{2}{*}{7} & I-270 & EB & 2231 & 2470 & 3985 \\
& I-270 & WB & 3775 & 2685 & 3174 \\
\hline \multirow{2}{*}{8} & I-70 & EB & 4140 & 2831 & 3985 \\
& I-70 & WB & 5184 & 4295 & 5905 \\
\hline \multirow{2}{*}{9} & I-170 & NB & 4284 & 2581 & 3473 \\
& I-170 & SB & 2539 & 2274 & 3891 \\
\hline \multirow{4}{*}{10} & I-70 & EB & 3629 & 2599 & 3561 \\
& I-70 & WB & 3791 & 2828 & 4006 \\
& I-55 & NB & 5972 & 2209 & 2229 \\
& I-55 & SB & 1876 & 2389 & 5775 \\
& I-44 & EB & 4451 & 2040 & 2864 \\
& I-44 & WB & 2774 & 1840 & 5007 \\
\hline \multirow{2}{*}{11} & I-64 & EB & 4653 & 3389 & 4460 \\
& I-64 & WB & 4634 & 3446 & 4418 \\
\hline \multirow{2}{*}{12} & I-64 & EB & 4661 & 2734 & 3345 \\
& I-64 & WB & 3039 & 2741 & 4502 \\
\hline \multirow{2}{*}{13} & I- 270 & NB/WB & 5098 & 3295 & 4059 \\
& I- 270 & SB/EB & 2856 & 3104 & 5599 \\
\hline \multirow{2}{*}{14} & I-55 & NB & 5144 & 2401 & 2557 \\
& I-55 & SB & 1866 & 2468 & 5025 \\
\hline \multirow{2}{*}{15} & I-44 & EB & 4200 & 1927 & 2601 \\
& I-44 & WB & 2391 & 1759 & 4878 \\
\hline
\end{tabular}

The capacity was applied to the Motorist Assist sample data based on equation 3.1 provided by the Highway Capacity Manual (2000) for multilane uninterrupted flow facilities. 


$$
C=c_{I} * P H F^{*} N^{*} f_{H V} * f_{P}
$$

The capacity is computed as the product of the ideal capacity, the peak hour factor, the number of lanes by direction, the heavy vehicle adjustment factor, and the driver population adjustment factor. An ideal capacity value, $c_{\text {I }}$, was taken to be 2200 passenger vehicles per hour per lane corresponding to a free flow speed of $60 \mathrm{mph}$. The adjustment factor for heavy vehicles was 0.909 corresponding to an assumed truck traffic value of 10 percent. A truck traffic percentage of 10 percent is comparable to values for St. Louis freeways as found on a MoDOT commercial vehicle count map of Missouri. Default values of 0.9 and 1.0 were utilized for the peak hour factor, $P H F$, and the driver population adjustment factor, $f_{P}$, respectively. If specific data to the contrary is lacking, both values are deemed acceptable for urban and suburban freeways by the Highway Capacity Manual 2000.

\section{Estimating Response Time}

Motorist Assist response times are a function of primarily the length of patrol zones and the traffic conditions in the zone. For applying a response time to the Motorist Assist sample data, only the length of the patrol zone was considered for simplicity. In addition, detection of patterns of recurrent congestion based on AADT values averaged over a large area is extremely difficult. Very few of the average volumes approached the regular zonal capacity values. The roundtrip mileage was computed for each zone based on the mile markers of the endpoint interchanges. Utilizing one patrol vehicle per zone traveling at a program mandated speed of $55 \mathrm{mph}$ or less depending on the time of the day, the 
time headway was calculated as the zonal roundtrip mileage divided by the speed (equation 3.2). The average response time was estimated as half the time headway (equation 3.3).

Time Headway $(\min )=60 *$ Roundtrip Zone Mileage/Speed

Average Response Time $=0.5 *$ Time Headway

\section{Estimating Speed of St. Louis FSP}

Space mean speed data collected on I-70 and I-270 freeway segments in St. Louis, Missouri is presented in the TABLE 3.4. On I-270 the data collection was performed between I-64 and I-55, which was close to 12 miles in length, is shown in FIGURE 3.4. But in 2003 the length of the segment was reduced to 9.2 miles due to construction zones near I-55. FIGURE 3.5 shows the I-70 segment on which the GPS runs were conducted. 


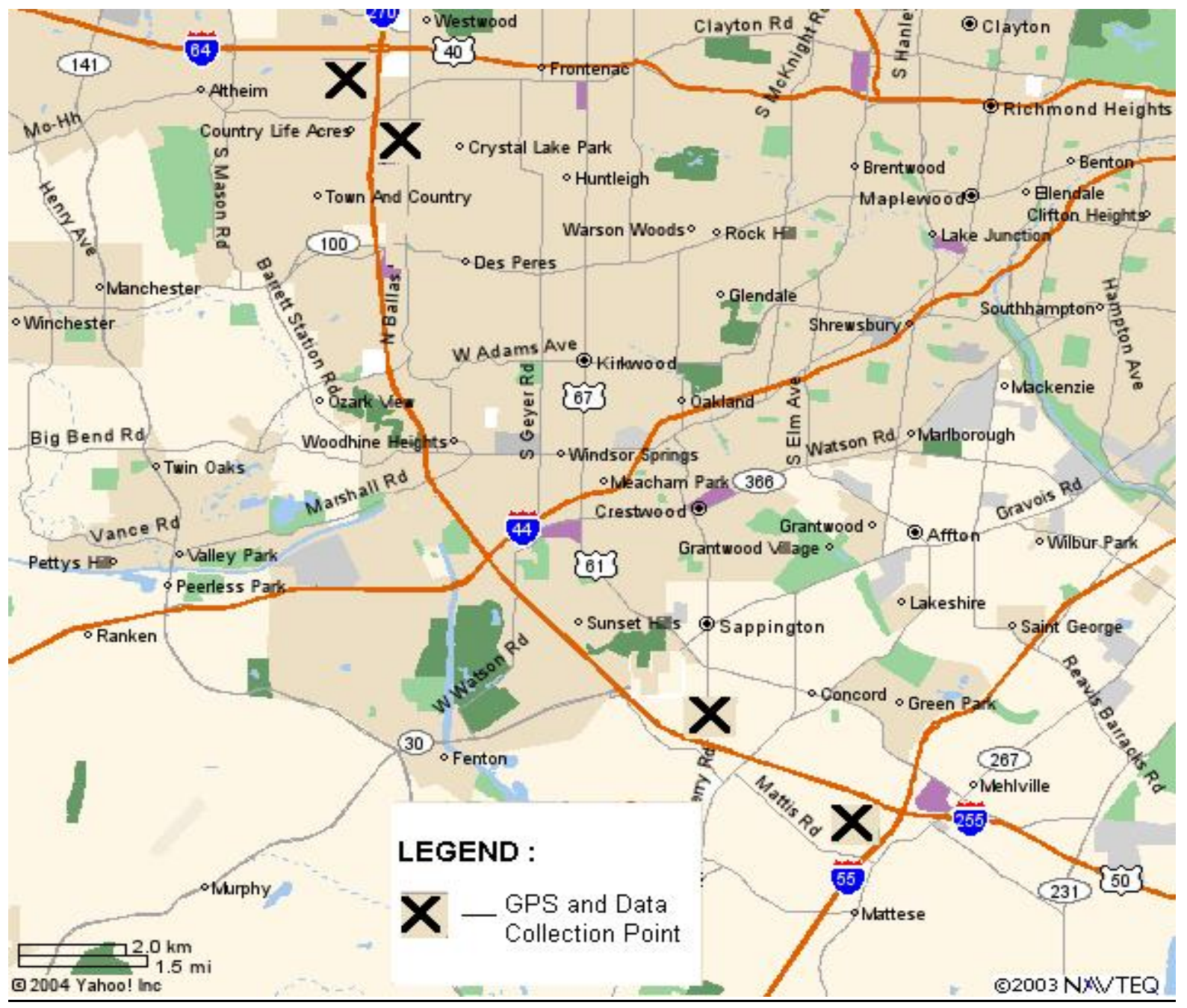

FIGURE 3.4 GPS data collection segment for I-270. 
TABLE 3.4 GPS Runs Conducted on I-70 and I-270

\begin{tabular}{|c|c|c|c|c|c|c|c|}
\hline Route & Direction & $\begin{array}{l}\text { Time } \\
\text { Period }\end{array}$ & Between & $\begin{array}{c}\text { Distance } \\
\text { (miles) }\end{array}$ & $\begin{array}{c}\text { AM } \\
\text { Peak }\end{array}$ & $\begin{array}{c}\text { PM } \\
\text { Peak }\end{array}$ & $\begin{array}{l}\text { Total } \\
\text { Runs }\end{array}$ \\
\hline \multirow{2}{*}{$\mathrm{I}-70$} & & $\begin{array}{c}\text { Summer } \\
2003\end{array}$ & $\begin{array}{l}\text { Earth City } \\
\text { and US-370 }\end{array}$ & 6.1 & 14 & 39 & 53 \\
\hline & $\begin{array}{l}\text { West } \\
\text { Bound }\end{array}$ & $\begin{array}{l}\text { Summer } \\
2003\end{array}$ & $\begin{array}{c}\text { Earth City } \\
\text { and US-370 }\end{array}$ & 7.7 & 24 & 41 & 65 \\
\hline \multirow{2}{*}{$\mathrm{I}-270$} & $\begin{array}{l}\text { North } \\
\text { Bound }\end{array}$ & $\begin{array}{l}\text { Summer } \\
2003\end{array}$ & $\begin{array}{c}\mathrm{I}-64 \\
\text { and } \mathrm{I}-55\end{array}$ & 9.2 & 28 & 43 & 71 \\
\hline & $\begin{array}{l}\text { South } \\
\text { Bound }\end{array}$ & $\begin{array}{l}\text { Fall } \\
2002\end{array}$ & $\begin{array}{c}\mathrm{I}-64 \\
\text { and } \mathrm{I}-55\end{array}$ & 12 & 23 & 36 & 59 \\
\hline
\end{tabular}

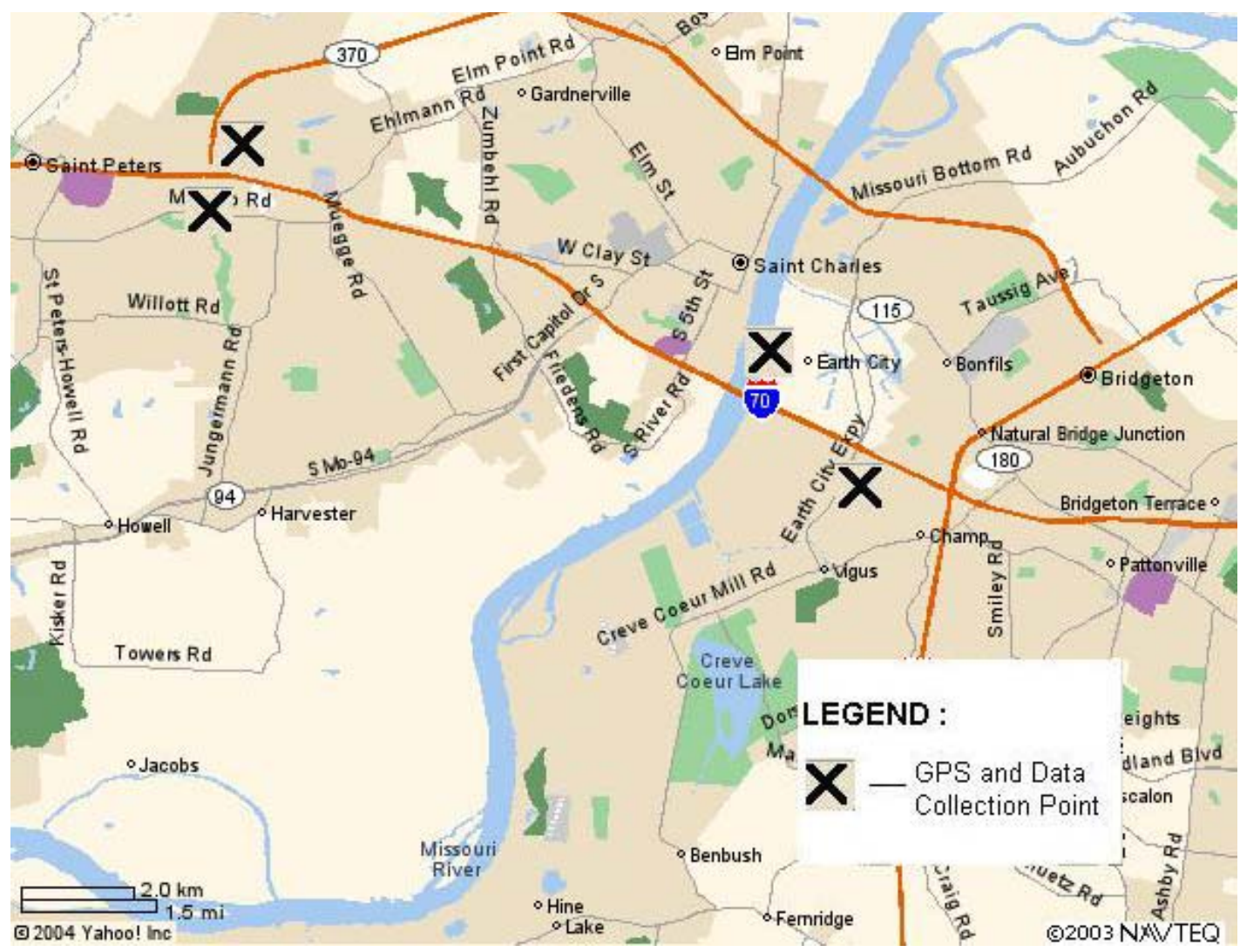

FIGURE 3.5 GPS data collection segment for I-70. 
During the morning period, the peak directional flow on I-270 occurs in the northbound direction. 28 runs were collected on I-270 northbound, between Sappington Rd. in the south to Clayton Rd in the north. These runs were collected from 6:10 AM to 8:50 AM. 19 out of these 28 runs were collected during peak traffic conditions that existed between 6:10 AM and 8:00 AM. The average speed was observed to be $51.6 \mathrm{mph}$ with a 95\% Confidence Interval (C.I) of $4.2 \mathrm{mph}$. The overall speeds ranged from 28 to $63 \mathrm{mph}$. The southbound, which is non-directional traffic, had very high traffic speeds ranging from 64 to $70 \mathrm{mph}$, with an average of $67.7 \mathrm{mph}$. The evening data collection illustrates that the peak occurs in the southbound direction. 36 runs were collected between 4:13 PM and 7:00 PM on I -270 southbound. 29 out of these 36 runs were collected during peak traffic conditions that existed between 4:13 PM and 6:00 PM. The average speed for peak traffic conditions was observed to be $48.14 \mathrm{mph}$ with a $95 \%$ C.I of $4.26 \mathrm{mph}$. While the overall speeds for this peak period ranged from $29.3 \mathrm{mph}$ to $65.3 \mathrm{mph}$. The northbound direction had fast-moving traffic with most speeds ranging between 60 and $70 \mathrm{mph}$.

TABLE 3.5 Average Space Mean Speed on I-70 and I-270

\begin{tabular}{|c|c|c|c|c|}
\hline Freeway & Direction & Period & $\begin{array}{c}\text { Average } \\
\text { (mph) }\end{array}$ & $\begin{array}{c}\text { 95\% Confidence } \\
\text { Interval (mph) }\end{array}$ \\
\hline \multirow{2}{*}{ I-270 } & NB & AM & 51.6 & 4.2 \\
& SB & PM & 48.14 & 4.26 \\
\hline \multirow{2}{*}{ I-70 } & EB & AM & 47 & 8.4 \\
& WB & PM & 56.7 & 1.8 \\
\hline
\end{tabular}

For I-70 the data collection was conducted from 6:30 to 9:30 AM, it was observed that directional traffic existed in the eastbound lanes between 6:45 and 8:45 AM. The speeds ranged from 19.7 to $63.7 \mathrm{mph}$. The average speed was observed to be $47 \mathrm{mph}$, with a 95\% confidence interval of $8.3 \mathrm{mph}$ (i.e. 95\% of the time the speeds would range from 
38.7 to $55.3 \mathrm{mph})$. During the evening data collection, it was observed that the westbound directional traffic existed from 3:15 to as late as 6:15 PM. The speeds ranged from 39.5 to $65 \mathrm{mph}$, with an average speed of $56.7 \mathrm{mph}$. The section between Earth City and the Blanchett Bridge was observed to be the most congested part of the segment during peakhour traffic. Congestion is more prevalent between I-270 (east of Earth City) and the Blanchett Bridge. The traffic on the eastbound was fairly off-peak, with speeds ranging from 63 to $73 \mathrm{mph}$. The average speed was observed to be $68 \mathrm{mph}$

\section{$\underline{\text { Response Time }}$}

The estimated response times are conservative as compared to a random sampling of survey responses from spring (March, April, and May) of 2002 displayed in TABLE 3.6 below. The average estimated response time for all zones using the method of above is 15 minutes. Over 83 percent of the survey responses indicate a response time of 15 minutes or less. The median response time from the survey responses is between 6 and 10 minutes. The sources of the disparity are most likely Motorist Assist patrol policies mentioned in the introduction that were not accounted for in the method above. One, Motorist Assist will respond directly to emergency calls for debris or accidents. Two, operators are allowed to reverse directions while patrolling if visual detection of an incident in the opposing lanes is made. The procedure for estimating response time above cannot numerically account for either of these policies. 
Table 3.6 MA Response Times Based On Sampled Customer Returned Surveys

\begin{tabular}{|c|c|c|}
\hline $\begin{array}{c}\text { Response } \\
\text { Time } \\
\text { (min) }\end{array}$ & $\begin{array}{c}\text { Total } \\
\text { Number of } \\
\text { Assists }\end{array}$ & $\begin{array}{c}\text { Cumulative } \\
\text { Percentage }\end{array}$ \\
\hline $0-5$ & 88 & 40.0 \\
$6-10$ & 62 & 68.2 \\
$11-15$ & 34 & 83.6 \\
$16-20$ & 19 & 92.3 \\
$21-30$ & 10 & 96.8 \\
$30-60$ & 6 & 99.5 \\
$>60$ & 1 & 100.0 \\
Total & 220 & \\
\hline
\end{tabular}

\section{Method of Analysis}

Several analysis tools are available for computing incident-induced delay. Queuing theory is the most common tool used and is based on the theory of demand and supply. Other methods include shock-wave analysis and the difference in travel time method. Shock-wave analysis requires a substantial amount of traffic density data. Due to the lack of permanent count stations in the area, this data could not be obtained. The difference in travel time method requires average travel time data that was not available. The available data, as previously mentioned, was annual average hourly volumes. Thus, queuing theory was selected as the best analysis tool based on the available data.

There are several different types of queuing theory analysis. The two main divisions are deterministic queuing and stochastic queuing. Stochastic queuing inputs values such as probability density functions, distributions, or other statistical values. In terms of this evaluation, stochastic queuing would construct probability distributions for incident clearance time, incident type, minutes in a lane, location, time of day, etc. based on the incidents sampled from the Motorist Assist operator logs. These distributions 
would then be multiplied by the 2002 Motorist Assist year-end incident total. The final product is a yearly total of incidents with the detailed characteristic trends of only a few incidents. Deterministic queuing is more advantageous. Directly analyzing a manageable amount of incidents and expanding the resulting measures of effectiveness to include all incidents during a given year produces more accurate results. Thus the sample of incidents from the Motorist Assist operator logs were analyzed directly using deterministic queuing.

Deterministic queuing is visually represented by a plot of vehicles versus time. FIGURE 3.6 shows four vehicle versus time curves: one for the arrival rate, two for reduced capacities, and one for the normal capacity. The arrival rate is the traffic volume approaching the incident. The reduced capacity is the maximum volume that can move past an incident impeding traffic. Two reduced capacity curves are shown to account for an incident which affects capacity differently over time. For example, an incident may block a lane initially but over time is cleared to the shoulder. Two different affects on capacity occur in this scenario. The normal capacity is simply the capacity of the roadway under normal conditions.

The analysis was simplified by two assumptions which are standard elements of queuing analysis. One, route diversion was not considered. For incidents not including crashes, the number of vehicles diverting is minimal and difficult to accurately estimate. As a result, the arrival rate was considered a constant. Two, the queuing resulting from an incident was assumed to discharge at the normal capacity.

The total delay is computed as the value of the area between the arrival rate curve, the reduced capacity curves, and the normal capacity curve. To compute this area, four 
data items are required. Required data associated with the roadway facility include the arrival rate and the normal capacity, and data associated with the incident include the reduced capacities and the associated time duration of each. The arrival rates and normal capacities have been calculated as previously mentioned. The reduced capacities were computed based on incident characteristics and the corresponding reduction factors from an incident delay model created by Sullivan. The incident duration is a combination of detection, response, and clearance times. Detection and response times were estimated for Motorist Assist and non-Motorist Assist responses such as towing services and police departments. Clearance times were based on the service duration of the sampled incidents from the 2002 Motorist Assist operator logs.

The specific equations used in the computation of total delay are as follows. If both lane and lane shoulder blockages are present, then the total delay (TD) is

$$
\begin{aligned}
T D= & \frac{1}{2} \lambda\left(\left(r+t_{1}\right)+t_{2}\right)^{2}+\frac{\left(\left(\left(t_{1}+r\right)+t_{2}\right) \lambda-\left(t_{1}+r\right) \mu_{1}-t_{2} \mu_{2}\right)^{2}}{2(C-\lambda)} \\
& -\frac{1}{2}\left(\left(t_{1}+r\right) \mu_{1}\right)^{2}-\frac{1}{2}\left(t_{2} \mu_{2}\right)^{2}-\left(t_{1}+r\right) t_{2} \mu_{1}
\end{aligned}
$$

where,

$$
\begin{aligned}
& r=\text { response time } \\
& t_{1}=\text { time duration of incident lane blockage } \\
& t_{2}=\text { time duration of shoulder blockage } \\
& \mu_{1}=\text { reduced capacity due to lane blockage } \\
& \mu_{2}=\text { reduced capacity due to shoulder blockage } \\
& \lambda=\text { vehicle arrival rate } \\
& C=\text { capacity under normal conditions }
\end{aligned}
$$


If there is only shoulder blockage, then total delay is

$T D=\frac{1}{2} \lambda\left(r+t_{2}\right)^{2}+\frac{\left(\left(r+t_{2}\right) \lambda-\left(r+t_{2}\right) \mu_{2}\right)^{2}}{2(C-\lambda)}-\frac{1}{2}\left(\left(t_{2}+r\right) \mu_{2}\right)^{2}-\left(r+t_{2}\right) \mu_{1}$

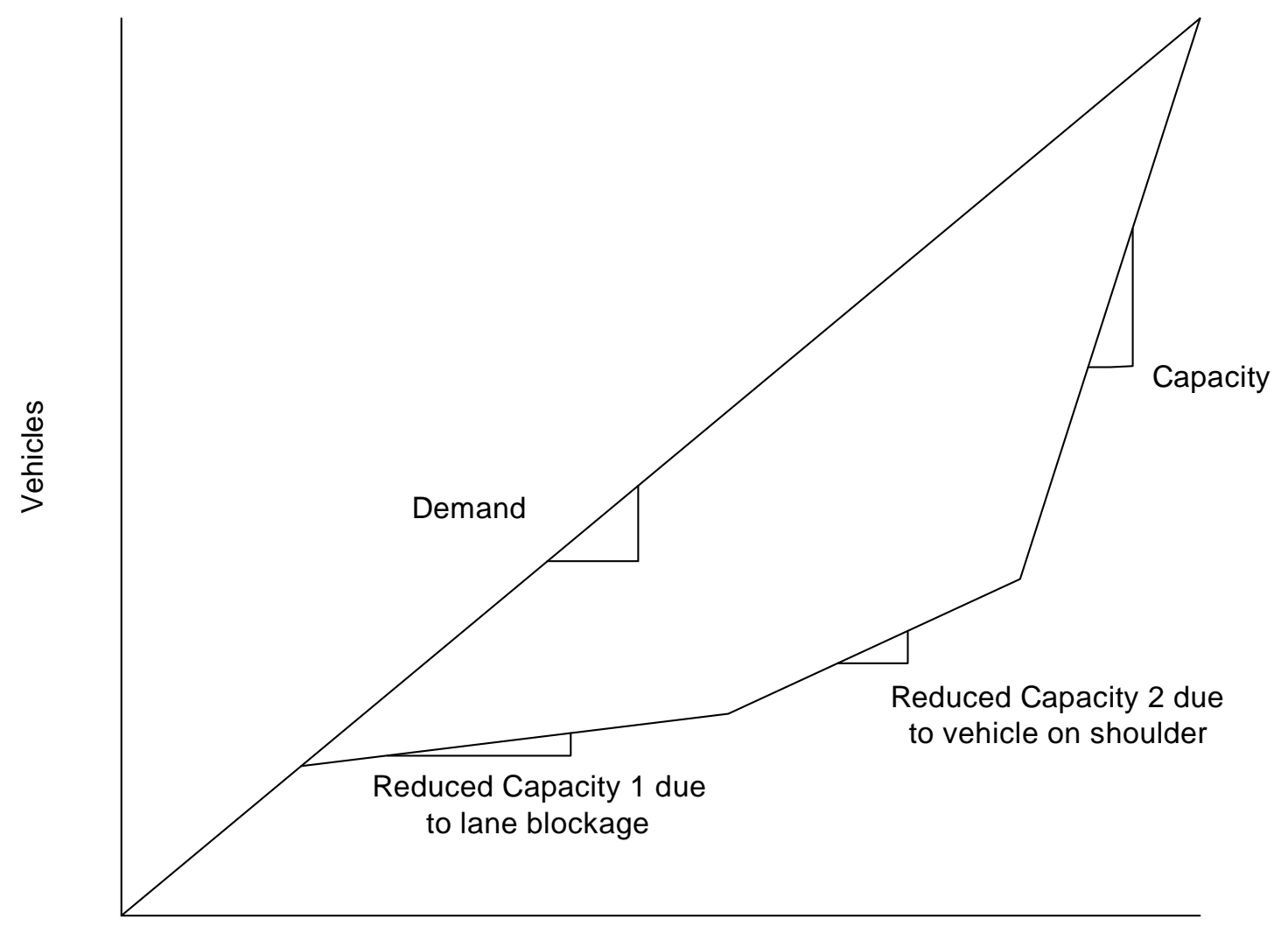

Time (hours)

\section{FIGURE 3.6 Illustration of Incident Delay}

\section{Modeling}

Motorist Assist developed an incident classification system to aid operators in logging detailed incident information. 10 numeric codes represent general incident categories 
such as a flat tire or a hazardous materials spill. 26 alpha codes are utilized in addition to the numeric codes to provide more specific details of each incident. For example, useful numeric codes for this evaluation were "in lane” and "shoulder". TABLE 3.7 includes the ten numeric incident codes used during efficiency modeling.

Due to the large number of variables involved and the complex nature of freeway incidents, the sampled incidents from the Motorist Assist operator logs were independently evaluated in two scenarios. The "without Motorist Assist” scenario represents incident conditions as if Motorist Assist did not exist. The "with Motorist Assist” scenario includes and illustrates as accurately as possible Motorist Assist operations and the incidents their MA operators serviced.

As previously mentioned vehicle arrival rate, normal capacity, reduced capacity due to the incident, and incident duration are required inputs in the total delay equation for queuing analysis. Three of the four input variables are assumed constant in both the “without Motorist Assist” and “with Motorist Assist” scenarios. For the 2002 analysis year, vehicle arrival rates and normal capacity would be identical regardless of Motorist Assist. These values are functions of freeway geometrics and travel demand, both of which are mostly independent of incident response. The reduced capacity due to the incident could conceivably be different in each of the two scenarios. The Motorist Assist patrol truck is a different response vehicle compared with a tow truck or a police car and thus could conceivably have a different affect on passing traffic. However for this evaluation, the reduced capacity due to an incident is assumed constant in both scenarios. The input value that entirely depends on the scenario is incident duration. 
Incident duration is typically comprised of four separate phases which must be understood in order to accurately compare incident duration in both scenarios.

\section{$\underline{\text { Incident detection }}$}

An incident occurs and information regarding that incident is forwarded to the appropriate authorities. This information is most often forwarded via emergency 911 calls. But detection through regular patrols by Motorist Assist or Police Departments is not uncommon. Verification of the incident is an optional phase that only a handful of agencies utilize before a full response is dispatched. Verification can take on several forms including initially dispatching a single unit to the scene and waiting for additional agencies or emergency 911 calls to confirm the incident. According to several local police agencies, approximately 20-25 emergency 911 calls are received per freeway incident. The decision to wait and verify an incident may also depend on the quality of the information received and the type of incident.

\section{Response time}

This is the time from when assistance is dispatched to the time of arrival at the scene. Response time is affected by the proximity of emergency services to the scene and by the traffic conditions approaching the scene.

\section{Clearance time}

This is the time that begins as soon as help arrives at the scene and ends when the incident is completely cleared away to the freeway shoulder. This includes all vehicles involved and any related debris. Within the clearance time phase, there can be several intermediate stages where some clearance is incrementally achieved. For example, an 
accident may initially block two lanes. But after 15 minutes, only 1 lane may be blocked. After 30 minutes, only the shoulder is blocked, and after 60 minutes the scene is cleared of all vehicles. The incident is not completely cleared until the shoulder is cleared. Thus the clearance time is 60 minutes. For some incidents computing the clearance time is difficult due to the many agencies involved at a scene. The decisions of each agency can drastically affect the clearance time. For example, arrival of the tow truck most often affects the clearance time of accidents. However, a complicated extrication of injured persons from a crashed vehicle may extend the duration of the incident such that towing services must wait for the rescuers to remove the injured. After the involved vehicles are removed from the scene, the incident is completely cleared but the affects are typically not cleared. The incident effects on traffic conditions are still contributing to the delay of motorists.

\section{Incident Normalization}

The fourth phase of an incident is normalization of traffic conditions to pre-incident levels through queue dissipation. An incident that has caused a two-mile queue requires a significant amount of time after incident clearance to dissipate the queue and restore traffic.

In the scenario of "with Motorist Assist", freeways are regularly patrolled by Motorist Assist. Patrol operators have the presence to detect incidents almost simultaneously as they occur. Response times to both dispatched and detected incidents are very good as previously estimated. 
The response times for the above types of incidents was estimated based on the interviews with St. Louis county police and St. Louis city police. Also towing and emergency response data from JD power associates (Lawlor, 2003) was used to understand the non MA scenario. The response time including detection and verification was considered 35 minutes for all the assist codes excepting for the incident where debris is in the lanes. It was assumed 20 minutes. As the sample data had only one data point for Hazmat (assist code 4) the hazmat data was not considered. Accidents (assist code 8) are treated exclusively under the safety section since it was difficult to quantify the efficiency benefits in this category. Based on the difference in response times and total incident duration of each sample incident the delays were estimated using standard queuing theory and the results are reported in the next section.

TABLE 3.7 Assist Code Descriptions and Non MA Response Times

\begin{tabular}{|c|c|c|c|c|}
\hline \multirow[b]{2}{*}{ Code } & \multirow[b]{2}{*}{$\begin{array}{l}\text { Description } \\
\text { of Code }\end{array}$} & \multicolumn{2}{|c|}{ Non MA Response } & \multirow[b]{2}{*}{ Comments } \\
\hline & & $\begin{array}{l}\text { Shoulder } \\
\text { (Minutes) }\end{array}$ & $\begin{array}{c}\text { In lane } \\
\text { (Minutes) }\end{array}$ & \\
\hline 1 & Changing Tire & 35 & 35 & \\
\hline 2 & Dispense Fluid & 35 & 35 & \\
\hline 3 & Debris & 35 & 20 & \\
\hline 4 & Hazmat & NA & NA & Not enough Data \\
\hline 5 & Lost Motor Assist & 35 & NA & $\begin{array}{l}\text { Assuming Lost motorist do not } \\
\text { stop in lane }\end{array}$ \\
\hline 6 & Abandon Vehicle & 35 & 35 & \\
\hline 7 & Disabled Vehicle & 35 & 35 & $\begin{array}{l}\text { Clearance was assumed } 10 \\
\text { minutes }\end{array}$ \\
\hline 8 & Accident & - & - & \\
\hline 9 & Stalled Vehicle & 35 & 35 & $\begin{array}{l}\text { Clearance was assumed } 10 \\
\text { minutes }\end{array}$ \\
\hline 10 & Other & 35 & 35 & \\
\hline
\end{tabular}




\section{RESULTS OF EFFICIENCY BENEFITS}

Based on the sample of 42 days of detailed 2002 motorist assist data, the estimated delay

reduction is 31,696 vehicle hours. And the annual reductions (250 weekdays) is estimated as follows

Annual reduction $=\frac{250}{42} * 31696=188667$ Vehicle-Hours

For computing the benefits of reduced delay the value of travel time for commercial and passenger cars was taken as $\$ 16.5$ and $\$ 10.0$ respectively. It was assumed an average occupancy of 1.25 for passenger cars i.e. out of every five cars on car will have two people including the driver. The benefits for commercial vehicles (truck) and passenger cars is estimated as follows

Benefits of Annual reduction in truck delays

$=$ Percent of truck volume*Annual Delay*Travel time cost per hour $=0.1 * 188667 * 16.5$

$=\$ 311,301$

Benefits of Annual reduction of passenger car delays

$=$ Percent of cars*Total Delay* Occupancy*Travel time cost per hour $=0.9 * 188667 * 1.25 * 10.0$

$=\$ 2,112,504$

The total performance benefit resulting from reduced passenger car and truck delays is 2.43 million dollars. Apart from this benefit, the reduction in non recurring delays reduces unnecessary fuel consumptions and thus reduced emissions of air 
pollutants such as carbon monoxide (CO), volatile carbons (VOC) and nitrogen oxides (NOx). The emission of these pollutants is usually high due to sudden deceleration and acceleration of vehicles. It was estimated that there would be an annual reduction of 3,000 pounds of VOC, 50,000 pounds of CO and about 900 pounds of NOx. These values are not monetized and thus not included in the overall benefit numbers.

\section{ESTIMATION OF SAFETY BENEFITS}

The primary reason for considering safety benefits of MA is the potential for MA and Gateway Guide to reduce the number of secondary accidents. Secondary accidents are accidents that result from an existing primary incident. Many times, these accidents occur at the end of queues that developed from the primary incident. The effects of MA and Gateway Guide on primary accidents would be much less than secondary accidents, because many of these accidents are caused by driver error such as fatigue, intoxication, or aggressive driving.

\section{Data}

The primary source of data used in this analysis is the accident database obtained from MoDOT. The accident database for freeways is compiled by police agencies and is consolidated by the State Highway Patrol. FIGURE 3.7 shows an example of an accident record snippet from I-70 in 2002. The electronic accident records that were used contain much more information than what is shown in FIGURE 3.7. In addition, images of the four-page accident reports are also kept in the MoDOT TMS database. The primary fields used in this analysis include name, direction, continuous log, date, severity, time, 
image number, and traffic condition. The same volume data that were described in the evaluation of efficiency were also used in the evaluation of safety.

The accident data from 1991 and 1992 were not usable, because a significant number of accidents were missing from those years. The problem occurred because those highway patrol accident reports were not transmitted electronically to the MoDOT TMS. There is a possibility that the data from 1991 and 1992 could be corrected in the future if the missing records were to be digitized.

The analysis of secondary accidents was performed on I-70 and I-270, because other segments did not contain a significant number of secondary accidents. For the years 1987 to 1996 (excluding 1991 and 1992), the average number of secondary accidents for I-70 and I-270 were 118 and 97, respectively, whereas the number for I-44 and I-55 were 25 and 19, respectively. 


\begin{tabular}{|c|c|c|c|c|c|c|c|c|c|c|c|}
\hline$\sum_{\Sigma}^{W}$ & $\stackrel{\underline{\underline{O}}}{\bar{\Delta}}$ & $\begin{array}{l}0 \\
0 \\
1 \\
\text { L } \\
0\end{array}$ & 崖 & 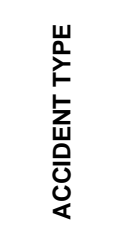 & 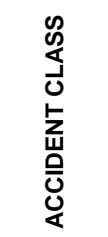 & 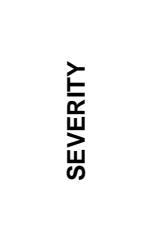 & $\sum_{F}^{W}$ & 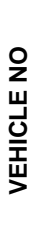 & 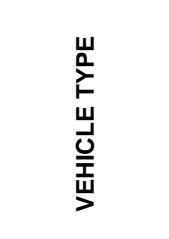 & 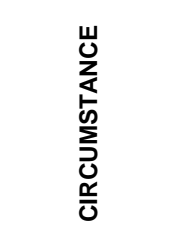 & 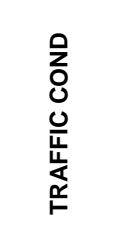 \\
\hline 70 & $\mathrm{E}$ & 223.409 & $1 / 1 / 02$ & $\begin{array}{c}\text { MOTOR } \\
\text { VEHICLE } \\
\text { IN } \\
\text { TRAFFIC }\end{array}$ & $\begin{array}{l}\text { REAR } \\
\text { END }\end{array}$ & $\begin{array}{c}\text { PROPERTY } \\
\text { DAMAGE } \\
\text { ONLY }\end{array}$ & 350 & 1 & $\begin{array}{c}\text { PASSENGER } \\
\text { CAR }\end{array}$ & DRINKING & NORMAL \\
\hline 70 & $\mathrm{E}$ & 223.409 & $1 / 1 / 02$ & $\begin{array}{c}\text { MOTOR } \\
\text { VEHICLE } \\
\text { IN } \\
\text { TRAFFIC }\end{array}$ & $\begin{array}{l}\text { REAR } \\
\text { END }\end{array}$ & $\begin{array}{l}\text { PROPERTY } \\
\text { DAMAGE } \\
\text { ONLY }\end{array}$ & 350 & 1 & $\begin{array}{c}\text { PASSENGER } \\
\text { CAR }\end{array}$ & INATTENTION & NORMAL \\
\hline 70 & $\mathrm{E}$ & 223.409 & $1 / 1 / 02$ & $\begin{array}{c}\text { MOTOR } \\
\text { VEHICLE } \\
\text { IN } \\
\text { TRAFFIC }\end{array}$ & $\begin{array}{l}\text { REAR } \\
\text { END }\end{array}$ & $\begin{array}{c}\text { PROPERTY } \\
\text { DAMAGE } \\
\text { ONLY }\end{array}$ & 350 & 2 & VAN & $\begin{array}{c}\text { NOT STATED } \\
\text { OR } \\
\text { UNKNOWN }\end{array}$ & NORMAL \\
\hline 70 & $\mathrm{E}$ & 250.312 & $1 / 1 / 02$ & $\begin{array}{c}\text { MOTOR } \\
\text { VEHICLE } \\
\text { IN } \\
\text { TRAFFIC }\end{array}$ & $\begin{array}{l}\text { REAR } \\
\text { END }\end{array}$ & $\begin{array}{c}\text { PROPERTY } \\
\text { DAMAGE } \\
\text { ONLY }\end{array}$ & 1110 & 1 & $\begin{array}{c}\text { PASSENGER } \\
\text { CAR }\end{array}$ & $\begin{array}{l}\text { IMPROPER } \\
\text { PASSING }\end{array}$ & NORMAL \\
\hline 70 & $\mathrm{E}$ & 250.312 & $1 / 1 / 02$ & $\begin{array}{c}\text { MOTOR } \\
\text { VEHICLE } \\
\text { IN } \\
\text { TRAFFIC }\end{array}$ & $\begin{array}{l}\text { REAR } \\
\text { END }\end{array}$ & $\begin{array}{c}\text { PROPERTY } \\
\text { DAMAGE } \\
\text { ONLY }\end{array}$ & 1110 & 2 & $\begin{array}{c}\text { PASSENGER } \\
\text { CAR }\end{array}$ & $\begin{array}{c}\text { NOT STATED } \\
\text { OR } \\
\text { UNKNOWN }\end{array}$ & NORMAL \\
\hline 70 & W & 15.57 & $1 / 2 / 02$ & $\begin{array}{c}\text { MOTOR } \\
\text { VEHICLE } \\
\text { IN } \\
\text { TRAFFIC }\end{array}$ & $\begin{array}{l}\text { REAR } \\
\text { END }\end{array}$ & INJURY & 815 & 1 & PICKUP & $\begin{array}{c}\text { FOLLOWING } \\
\text { TOO } \\
\text { CLOSELY }\end{array}$ & NORMAL \\
\hline 70 & W & 15.57 & $1 / 2 / 02$ & $\begin{array}{c}\text { MOTOR } \\
\text { VEHICLE } \\
\text { IN } \\
\text { TRAFFIC }\end{array}$ & $\begin{array}{l}\text { REAR } \\
\text { END }\end{array}$ & INJURY & 815 & 2 & $\begin{array}{c}\text { PASSENGER } \\
\text { CAR }\end{array}$ & $\begin{array}{c}\text { NOT STATED } \\
\text { OR } \\
\text { UNKNOWN }\end{array}$ & $\begin{array}{l}\text { CON- } \\
\text { GESTION } \\
\text { AHEAD }\end{array}$ \\
\hline 70 & $\mathrm{E}$ & 234.229 & $1 / 2 / 02$ & $\begin{array}{l}\text { RAN OFF } \\
\text { ROAD- } \\
\text { FIXED } \\
\text { OBJECT }\end{array}$ & $\begin{array}{l}\text { OUT } \\
\text { OF } \\
\text { CONTR } \\
\text { OL }\end{array}$ & $\begin{array}{c}\text { PROPERTY } \\
\text { DAMAGE } \\
\text { ONLY }\end{array}$ & 847 & 1 & $\begin{array}{c}\text { PASSENGER } \\
\text { CAR }\end{array}$ & $\begin{array}{c}\text { NOT STATED } \\
\text { OR } \\
\text { UNKNOWN }\end{array}$ & NORMAL \\
\hline
\end{tabular}

FIGURE 3.7 Sample accident record snippet from I-70, 2002.

In order to use secondary accidents as a performance measure for evaluating MA, it is necessary to separate such accidents from the rest. Starting in 1996, the category “accident ahead” has been recorded as part of the accident report. The number of accidents with this category marked is expected to be less than the number of secondary accidents, because the effects of secondary accidents might not be obvious at the scene. Also, the effects of an accident can persist long after the accident has been cleared completely from the road. Such persistent congestion still can result in secondary 
accidents. Also, starting in 1996, the category "congestion ahead” also has been recorded. However, it is not possible to discern from the reports if the congestion is incident-related or recurrent congestion. The use of the category "accident ahead" for finding secondary accidents would undercount the number of accidents, whereas adding the category "congestion ahead" would severely over count the number of accidents. Because of such problems, it is necessary to determine a distance and a time threshold to separate the secondary accidents from the rest of the accidents. In other words, an accident would be considered to be secondary only if it occurred within a certain time threshold and a certain distance threshold from a primary accident. For example, an accident would be considered to be secondary if it occurred within 1 hour and 2 miles of a previous accident. The category "accident ahead" was used to confirm the validity of these thresholds.

There are several methods for determining an appropriate value for both time and distance thresholds. Shock-wave analysis and simulation are both possible methods. However, a third method of using actual traffic reports and TMC logs was selected, because it involved the use of actual incident data. This third method was implemented in two ways. The first was to analyze some individual traffic reports in detail by finding the initial and the final reporting times of the incident, and by finding the location of the back of the longest queue. The difference between the initial and final times gives an estimate of the total duration of the incident, and the distance from the location of the incident to the back of the queue gives an estimate of the length of the roadway that is affected by the incident. TABLE 3.8 presents some examples of incident summaries that were used in this analysis. There are some challenges involved with the analysis of such 
traffic incident reports. Usually, an incident report is updated multiple times, and every incident report is analyzed until the last report of a particular incident. This last report, however, is not uniform in the information that is reported. TABLE 3.8 shows that this last report can involve the clearance of the incident, normalization of traffic conditions, or the persistence of incident conditions. The "duration time" in minutes that is shown in TABLE 3.8 does not necessarily represent the actual duration of the effects of the incident, and in fact, underestimates this duration most of the time. The average value of the duration is approximately 45 minutes, with a standard deviation of 23 minutes. Thus, the use of 30 minutes as the time threshold is quite conservative considering incident normalization time. Another challenge associated with finding the length of an incident arises because many times the location of the back of the queue is reported as the nearest cross street or landmark. As the back of the queue changes during an incident, the cross street or landmark also changes. No mileage is given in the reports and the mileage has to be derived from a map showing the landmark (e.g. Mid-Rivers Mall) or the milepost of the cross street. This makes the automated analysis of such traffic reports difficult. A sample of several incidents resulted in an average length of 4.63 miles and a standard deviation of 2.87 miles. A very conservative length of 2 miles is chosen as the distance threshold. 
TABLE 3.8 Sample Traffic Incident Report Summaries

\begin{tabular}{|c|c|c|c|c|c|c|c|c|c|}
\hline Date & Dir & Location & $\begin{array}{c}\text { End of } \\
\text { Queue }\end{array}$ & $\begin{array}{c}\text { Dist. } \\
\text { (miles) }\end{array}$ & $\begin{array}{c}\text { 1st } \\
\text { Rep. }\end{array}$ & $\begin{array}{c}\text { Last } \\
\text { Rep. }\end{array}$ & $\begin{array}{c}\text { Dur. } \\
\text { (min) }\end{array}$ & Lanes & Inc Type \\
\hline $10 / 11 / 02$ & NB & $270 @ 70$ & 40 & 7.5 & $16: 53$ & - & - & unknown & accident \\
$10 / 11 / 02$ & NB & $\begin{array}{c}270 @ 70 \\
\text { right } \\
\text { shoulder }\end{array}$ & Page & 3.5 & $16: 20$ & $16: 56$ & 36 & accident \\
$10 / 14 / 02$ & SB & $\begin{array}{c}270 @ \\
\text { rte21 }\end{array}$ & Ladue & 13 & $15: 41$ & $16: 31$ & 50 & $\begin{array}{c}\text { left lane } \\
\text { right } \\
\text { shoulder }\end{array}$ & injury \\
$10 / 14 / 02$ & WB & $70 @ 270$ & Lambert & 3 & $16: 52$ & $17: 28$ & 36 \\
\hline
\end{tabular}

The second way to derive time and distance thresholds is to analyze curves that show the relationship between the number of secondary accidents and the thresholds. An abrupt decrease in the number of secondary accidents as the threshold is increased might be indicative of the separation between true secondary accidents and accidents that happen in proximity to one another. FIGURE 3.8 uses data from I-70 from 2002. This year is used since the category "accident ahead" is available as a further check. Starting in 2002, the categories "normal," "congestion ahead," and "accident ahead” have been recorded in the traffic condition field, whereas they were included in the contributing circumstances field from 1996 to 2001. FIGURE 3.8 presents a fairly linear curve that shows increasing number of accidents with increasing threshold. Unfortunately, this figure does not show an abrupt change in the number of secondary accidents as the time threshold increases. However, there appears to be a kink in the curves around 2 miles and 60 minutes. This might mean that the 30 minutes is probably conservative, but it is close to 60 minutes. This result supports the thresholds that were derived using incident traffic reports. Another check can be performed using MA incident logs. According the 2002 MA incident logs, in-lane assists are approximately 15 minutes in duration. This 
again confirms that a 30 minute threshold is reasonable, albeit conservative. Finally, others have reported that an average accident lasts 45 to 60 minutes (Cambridge Systematics, 1990).

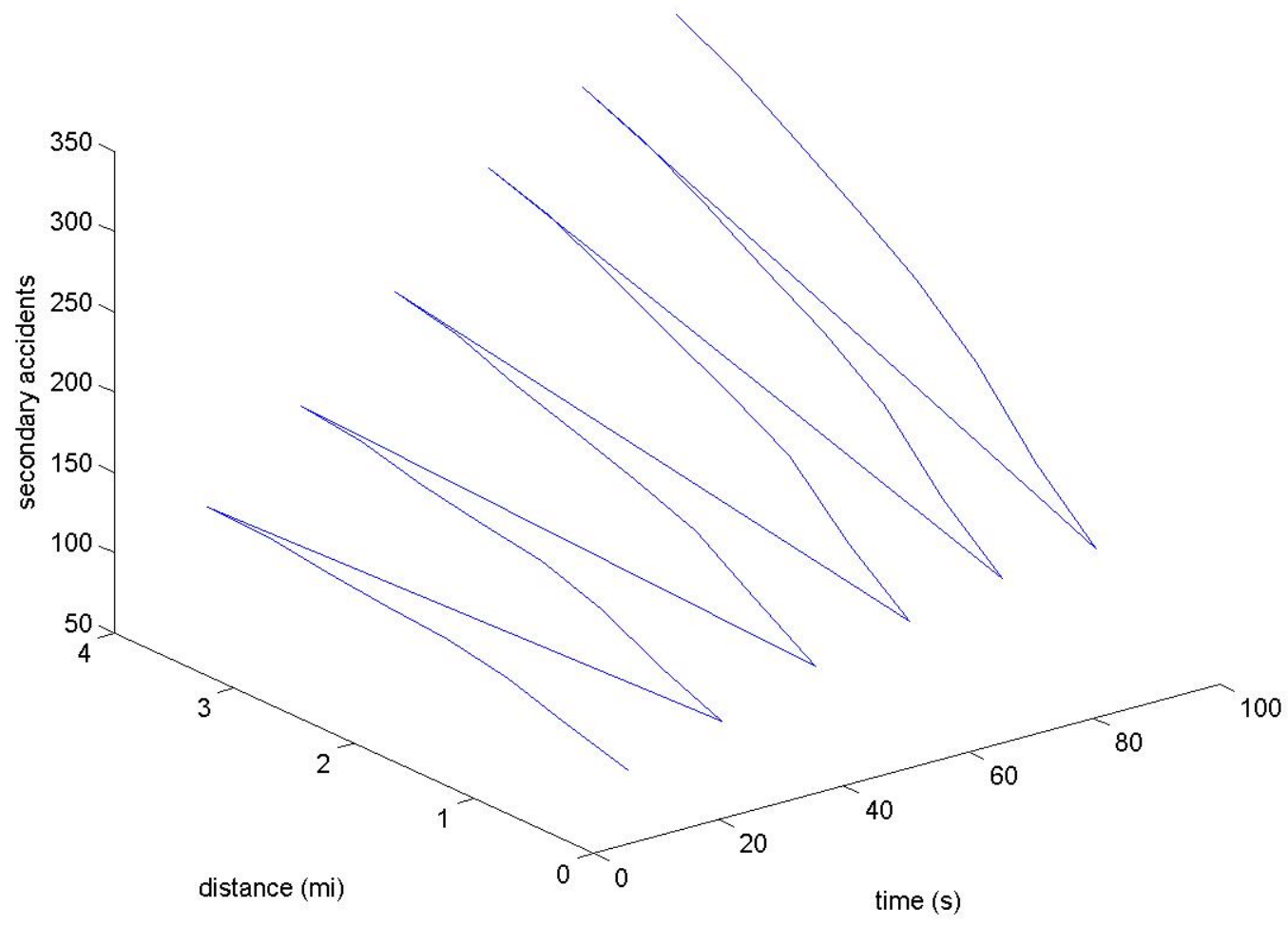

FIGURE 3.8 Secondary accidents and time and distance threshold (I-70, 2002).

Primary accidents in the opposite direction can also cause secondary accidents. There are many possible distractions to the oncoming traffic, including lights from emergency vehicles, the presence of a set of emergency vehicles, people at the scene, smoke or fire, and other commotion stemming from the accident. However, the number of opposite-direction secondary accidents is expected to be fewer than the number of same-direction. A difficulty in finding opposite-direction secondary accidents is the need 
to align the referencing system, or continuous log points, along both directions.

Therefore, due to the aforementioned reasons, opposite-direction secondary accidents are not utilized in this analysis.

There are several issues involved with the use of a constant time and distance threshold. First, because MA is expected to reduce the response and clearance times of secondary accidents, a shorter threshold is reasonable for use with the "after" MA data. Therefore, the use of the same thresholds for both the "before" and "after" MA scenarios results in a more conservative estimate of MA benefits, because there might be over counting of secondary accidents in the "after" scenario. Second, a dynamic threshold approach can be used in the future to improve the analysis. This can involve changing thresholds based on the severity of the accidents. For example, the number of lanes affected and the type of accident (e.g. fatality, injury, property damage only) can be used. The setting of dynamic thresholds will require further analysis of traffic incident reports, which is very labor intensive.

The process to extract secondary accidents from the accident database is as follows. First, the accident database is separated by route and by year (e.g. I-70, 2002). Each of the 28 fields that describe each accident record is parsed and stored. The time and date fields are translated for computation so that they can be added and subtracted. The entire accident file is then converted into a doubly-linked list so that the file can be collapsed into one record per accident. In other words, a file with one record per vehicle involved in an accident is consolidated into one record per accident. The secondary accidents and the accidents caused by parked vehicles are extracted then. Next, the total number of secondary accidents are tallied and recorded for each route and for each year. 
A routine in the MATLAB programming language (a C-like programming language for engineering) was coded for this purpose. FIGURE 3.9 gives an overview of the secondary accident extraction process.

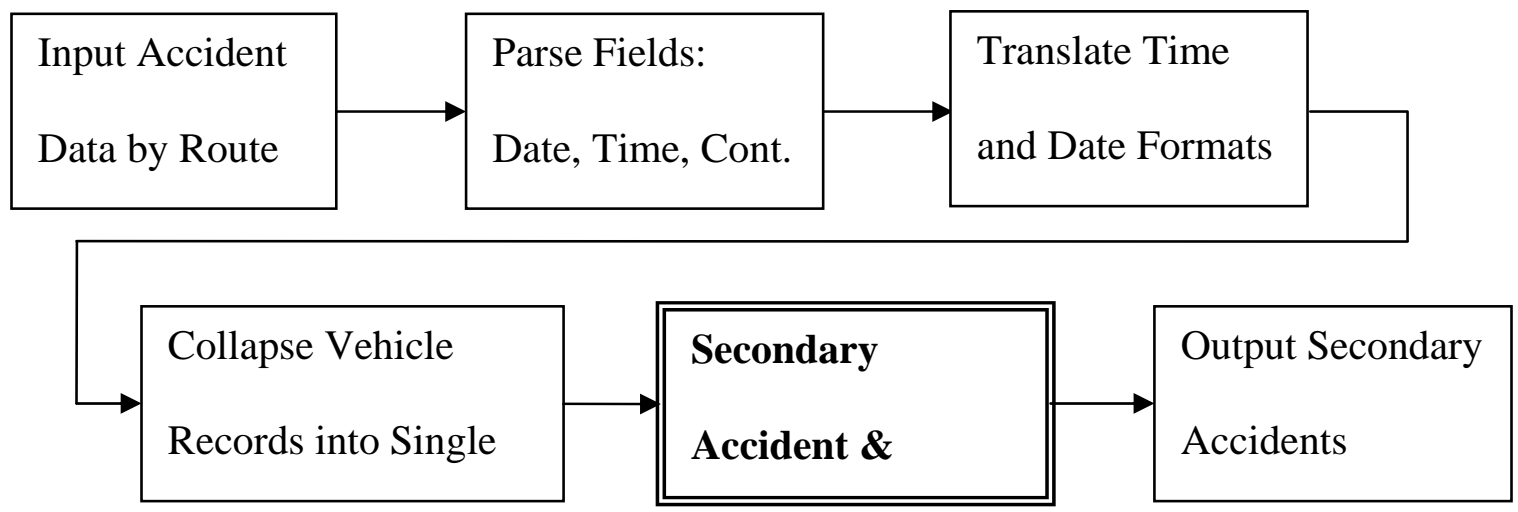

FIGURE 3.9 Pseudo-flowchart of the process of extracting secondary accidents.

There were significantly fewer parked vehicle accidents in the "with MA" scenario. For example, on I-70, there was an average of 10.75 such accidents for the years 1987 through 1990, whereas there was only an average of 0.25 such accidents for the years 1993 through1996. This result is not surprising, because MA is able to accelerate the towing of such abandoned vehicles. This is because MA tags abandoned vehicles with the time and date, which can be used by police as evidence. This quicker detection and documentation of abandoned vehicles allows quicker towing. In the end however, the secondary accidents caused by the incident type "parked vehicles" were not included in the analysis. There are only a small number of such accidents, thus it is difficult to make statistical inference with such data. 
Standard regression techniques were used in estimating the number of secondary accidents for the "without MA" and "with MA" scenarios. Regression was necessary to produce figures for the same year. In other words, pre-MA data were used for estimating the "without MA" data for post-MA years.

There are some complex issues related to the valuing of safety. The most obvious difficulty is with valuing the saving of lives. Instead of addressing such difficulties in this report, the recommendations of the Manual on Identification, Analysis, and Correction of High-Crash Locations, or HAL Manual (University of Columbia [UMC], 1999), were used. This manual contains sections on economic analysis and includes Missouri numbers for costs of fatal, injury, and property-damage-only crashes. TABLE 3.9 shows the crash costs of different types of accidents as presented in the HAL Manual. As per the recommendations of the manual, these figures have been used for years other than 1999 by using a reasonable rate of increase per year for all costs. A rate of $4 \%$ was chosen for this analysis.

TABLE 3.9 Cost of Crash by Severity

\begin{tabular}{|c|c|}
\hline Type of Crash & $\begin{array}{c}\text { Cost of Crash (in } \\
\text { 1999 dollars) }\end{array}$ \\
\hline Fatal & $\$ 3,390,000$ \\
Injury & $\$ 44,100$ \\
Property-Damage-Only (PDO) & $\$ 3220$ \\
\hline
\end{tabular}

\section{RESULTS OF SAFETY BENEFITS}

For I-70, the average number of secondary accidents per year was 124.25 for 1987 through 1990 and 111.75 for 1993 through 1996. There was an average reduction of 12.5 accidents per year, but this is a significant underestimate, because volumes have jumped 
by $20 \%$ from one period to the next. The change in volume on I-70 for the years 1987 to 2002 is shown in FIGURE 3.10. Other segments in the St. Louis region also exhibited similar increases in volume from 1987 to 2002. For I-270, the average number of secondary accidents per year was 108.75 for 1987 through 1990 and 85.5 for 1993 through 1996. The average reduction was 23.25 per year, but this again is an underestimate. Therefore, in order to compare the "without MA" and "with MA" scenarios adequately, the number of secondary accidents for each scenario need to be compared for the same year.

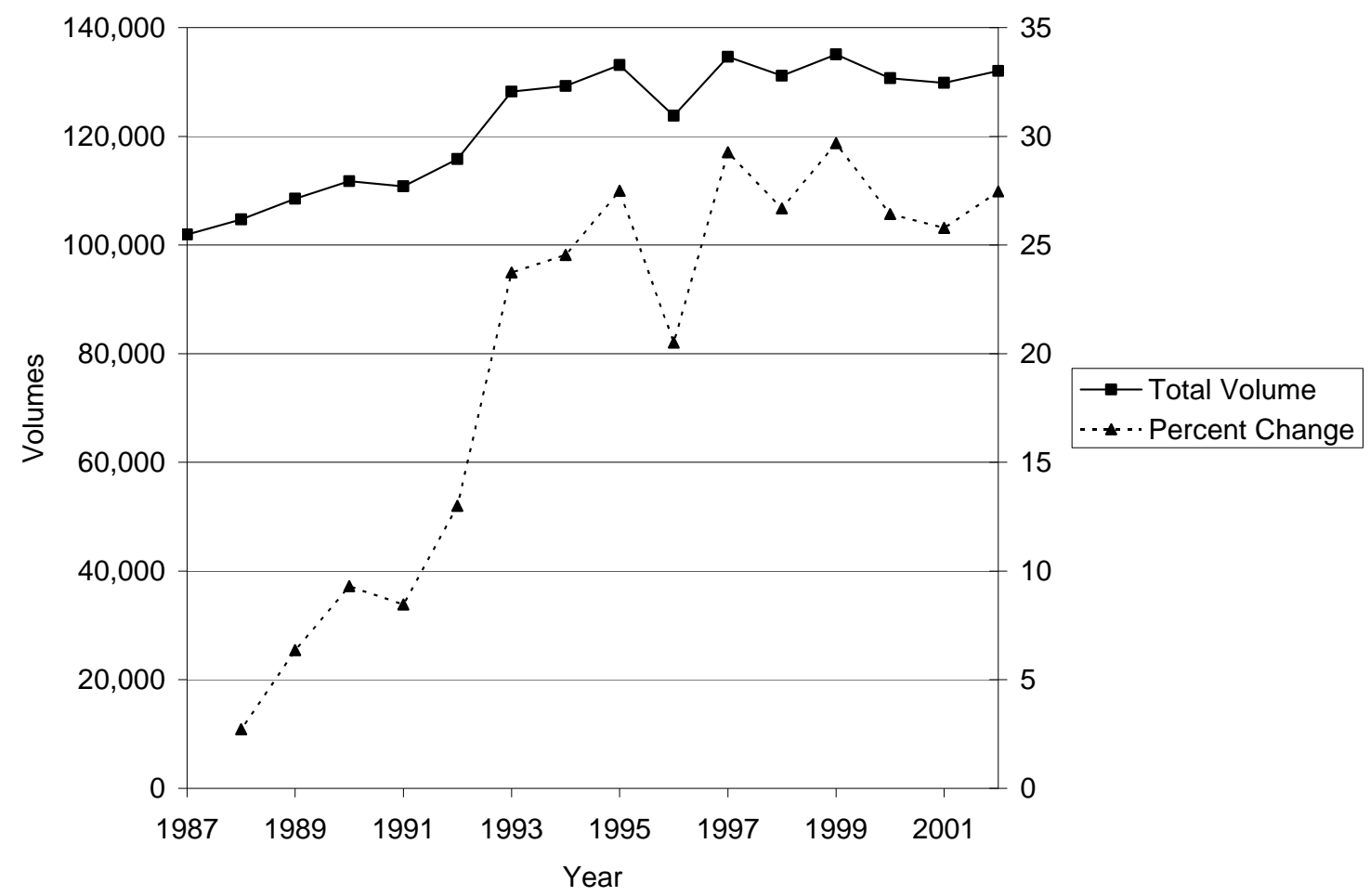

FIGURE 3.10 Volume and percentage volume change on I-70.

Two comparison years, 1992 and 2002, were chosen. The year 1992 was chosen because it is in the proximity of the pre-MA years of 1987 through 1990, as well as the 
post-MA years of 1993 through 1996. In performing regression or other types of estimation, the further-removed the estimate is from actual data, the greater the chance for errors to occur. Therefore, an analysis year that is close to both the "before" and "after" data is preferred. The year 2002 also was chosen, because the number of accidents and the traffic conditions had changed significantly over the 10 years since 1992.

The secondary accidents were extracted from the overall accident record for different routes and were aggregated for each year. Yearly aggregation is preferred over quarterly or monthly aggregation in order to take into account seasonal and monthly variations. These variations include summer vacation travel months, winter weather, and periods of intense travel during special holidays. However, the variability from year to year is still a source of error.

FIGURE 3.11 shows the actual number of secondary accidents on I-70 for the years 1987 through 1990 (without MA) and 1993 through 1996 (with MA). Linear regression is performed on the actual data to estimate the number of secondary accidents near the neighborhood of the actual data. The equations for the two regression lines and the corresponding R-square values are shown in Table 3.10. This table shows that the slope of the regression line in the "without MA" condition is steeper (21.3 versus 9.9). In other words, the number of secondary accidents grows at a much faster rate in the "without MA" scenario. Figure 3.11 also shows a shift in the intercept for the curves. Both slope and intercept are significantly smaller in the "with MA" case. Using linear regression, the number of secondary accidents in 1992 without and with MA was estimated to be 199 and 87, respectively. In other words, MA possibly prevented 112 
secondary accidents. For 2002, the estimated number of secondary accidents for the “without MA” scenario was 412, whereas the actual number “with MA” was 93.

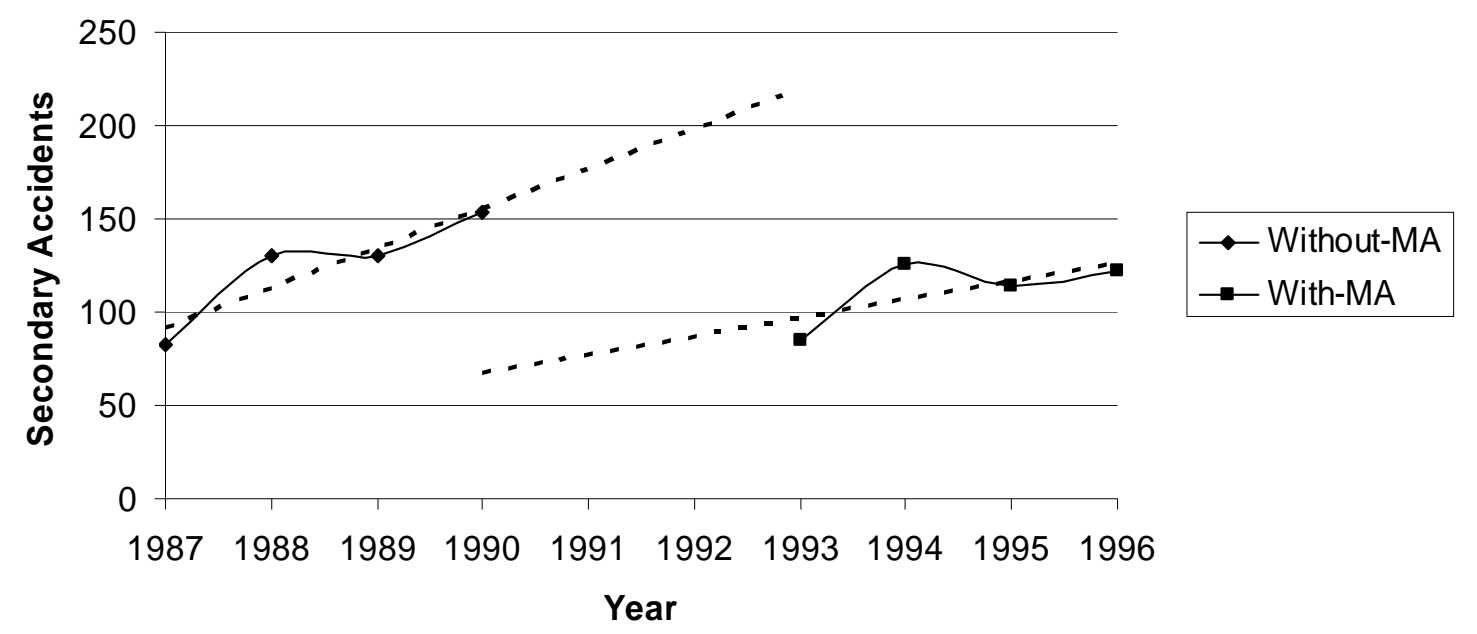

FIGURE 3.11 Secondary accidents before and after MA on I-70.

TABLE 3.10 Regression of secondary accident for I-70.

\begin{tabular}{|c|c|c|}
\hline Without MA & $\mathrm{y}=21.3 \mathrm{x}-42,231$ & R-square $=0.8551$ \\
\hline With MA & $\mathrm{y}=9.9 \mathrm{x}-19,634$ & R-square $=0.4764$ \\
\hline
\end{tabular}

Similar to I-70, FIGURE 3.12 shows the actual number of secondary accidents on I-270 for the years 1987 through 1990 (without MA) and 1993 through 1996 (with MA). The equations for the two regression lines and the corresponding R-square values for I-270 are shown in Table 3.11. This table shows that the slope of regression line in the “without MA" condition is steeper (14.1 versus 12.8). FIGURE 3.12 also shows a shift in the intercept for the curves, similar to the shift shown for I-70. Using linear regression, the number of secondary accidents in 1992 without and with MA was 
estimated to be 158 and 54, respectively. In other words, there were 104 fewer secondary accidents in the "with MA" scenario. For 2002, the estimated number of secondary accidents for the "without MA" scenario was 299, whereas the actual number "with MA" was 162 , or a reduction of 137 secondary accidents.

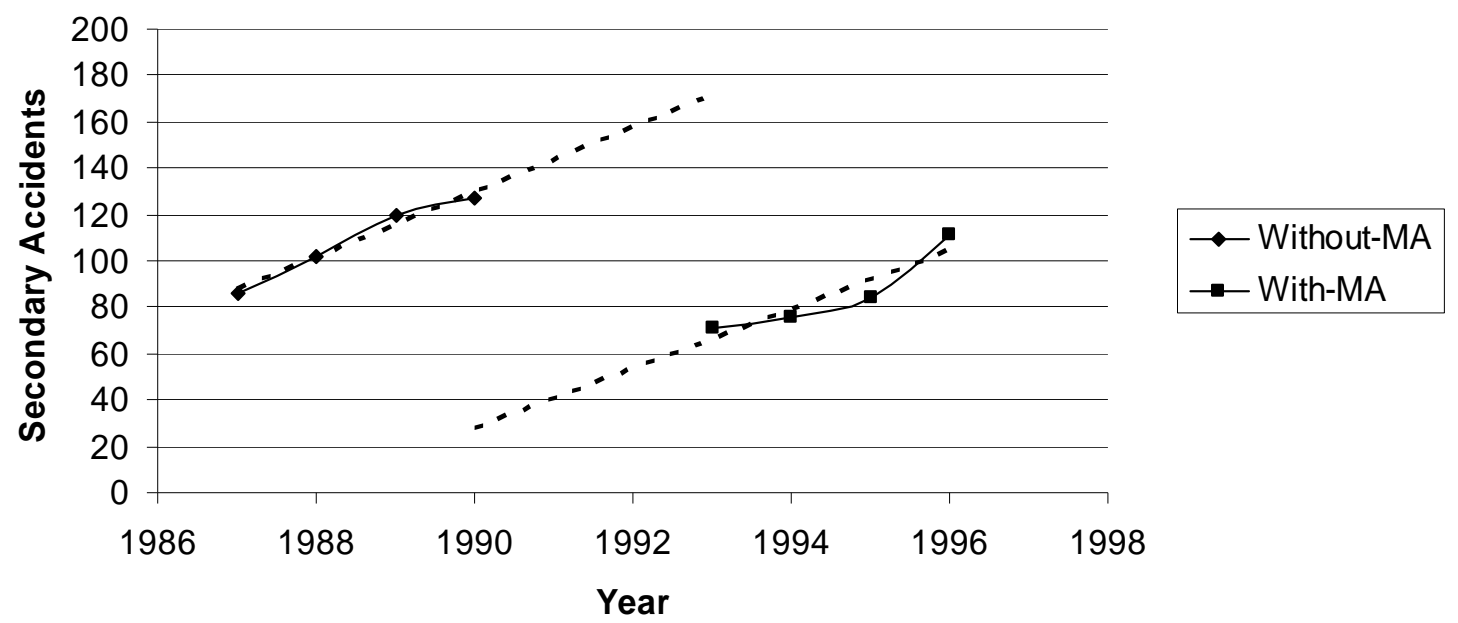

FIGURE 3.12 Secondary accidents before and after MA on I-270.

TABLE 3.11 Regression of Secondary Accident for I-270

\begin{tabular}{|c|c|c|}
\hline Without MA & $\mathrm{y}=14.1 \mathrm{x}-27,929$ & R-square $=0.9719$ \\
\hline With MA & $\mathrm{y}=12.8 \mathrm{x}-25,444$ & R-square $=0.8596$ \\
\hline
\end{tabular}

FIGURE 3.13 shows the total number of accidents for I-270 from 1987 to 1996, excluding 1991 and 1992. The total number of accidents increased, on the average, and the corresponding annual difference was 133.5 more accidents per year during the "with MA" years than during the "without MA" years. This figure shows that the total number of accidents did not behave in a similar manner to the number of secondary accidents. 
The comparison of the number of secondary accidents and total number of accidents is important, because this shows that MA did have an impact on the number of accidents and that this decrease was not due to a systematic decrease in the total number of accidents.

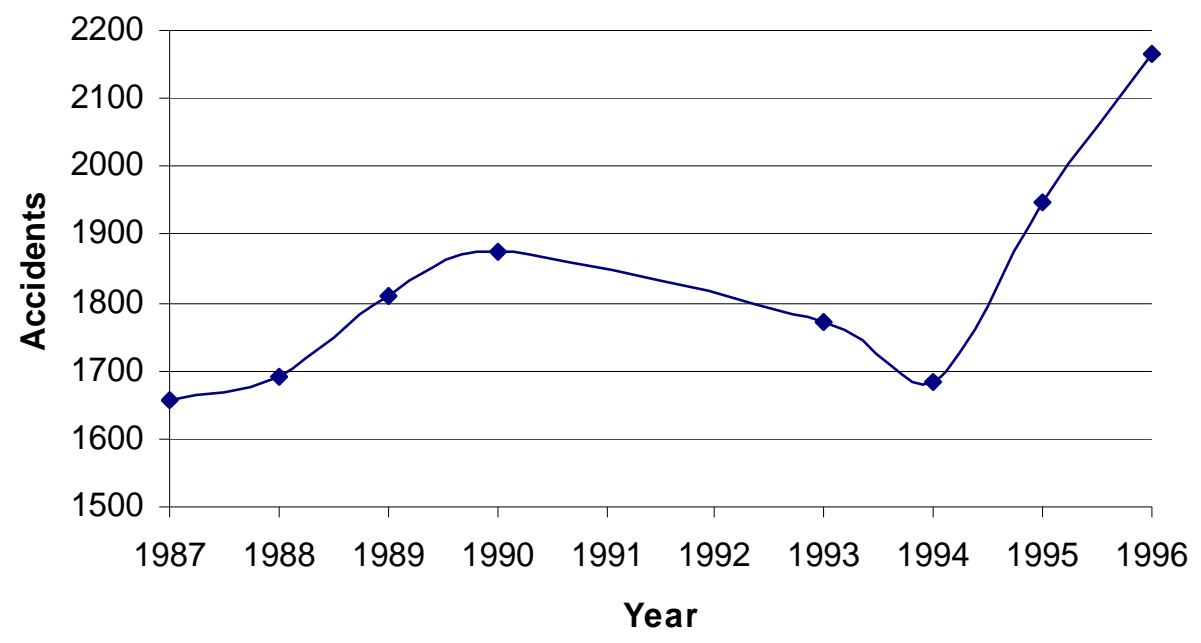

FIGURE 3.13 Total accidents on I-270.

The reductions in secondary accidents were translated into monetary values for deriving the $\mathrm{B} / \mathrm{C}$ ratio. TABLE 3.12 shows the distribution of secondary accidents by severity and was used for distributing the reduction of secondary accidents among the three severity categories. Using TABLE 3.12 and calculations for 2002 dollars, an average savings of $\$ 29,996$ per secondary incident was computed. The total safety benefit was computed by multiplying the secondary accident reduction by the average savings per accident. The resulting B/C ratio was 9.48, using 2002 as the year of comparison. 
TABLE 3.12 Distribution of Secondary Accidents by Severity

\begin{tabular}{|c|c|c|c|}
\cline { 2 - 4 } \multicolumn{1}{c|}{} & Fatal & Injury & PDO \\
\hline I-70 (87-90,93-96) & 3.00 & 271.00 & 670.00 \\
I-270 (87-90,93-93) & 3.00 & 219.00 & 555.00 \\
Total & 6.00 & 490.00 & 1225.00 \\
$\%$ & 0.35 & 28.47 & 71.18 \\
crash cost (1999) & 3390000 & 44,100 & 3220 \\
\hline
\end{tabular}

\section{LIMITATIONS OF SAFETY EVALUATION}

While evaluating the safety benefits of MA, the secondary accidents are defined as those that occur within two miles and thirty minutes of the primary accident. The values for the space-time thresholds are conservative but have drawback in the classification of some of the accidents. For example consider an accident that occurs at the same instant as the primary accident but at a distance say one mile upstream of the primary accident. This upstream accident would be misclassified as secondary accident as it is highly improbable that traffic will backup instantly, to affect a vehicle that is one mile upstream. The next chapter describes this drawback in detail and shows how to correct the space time threshold for classifying the secondary accidents. 


\section{CHAPTER 4: IMPROVED METHODOLOGY FOR CLASSFYING SECONDARY ACCIDENTS}

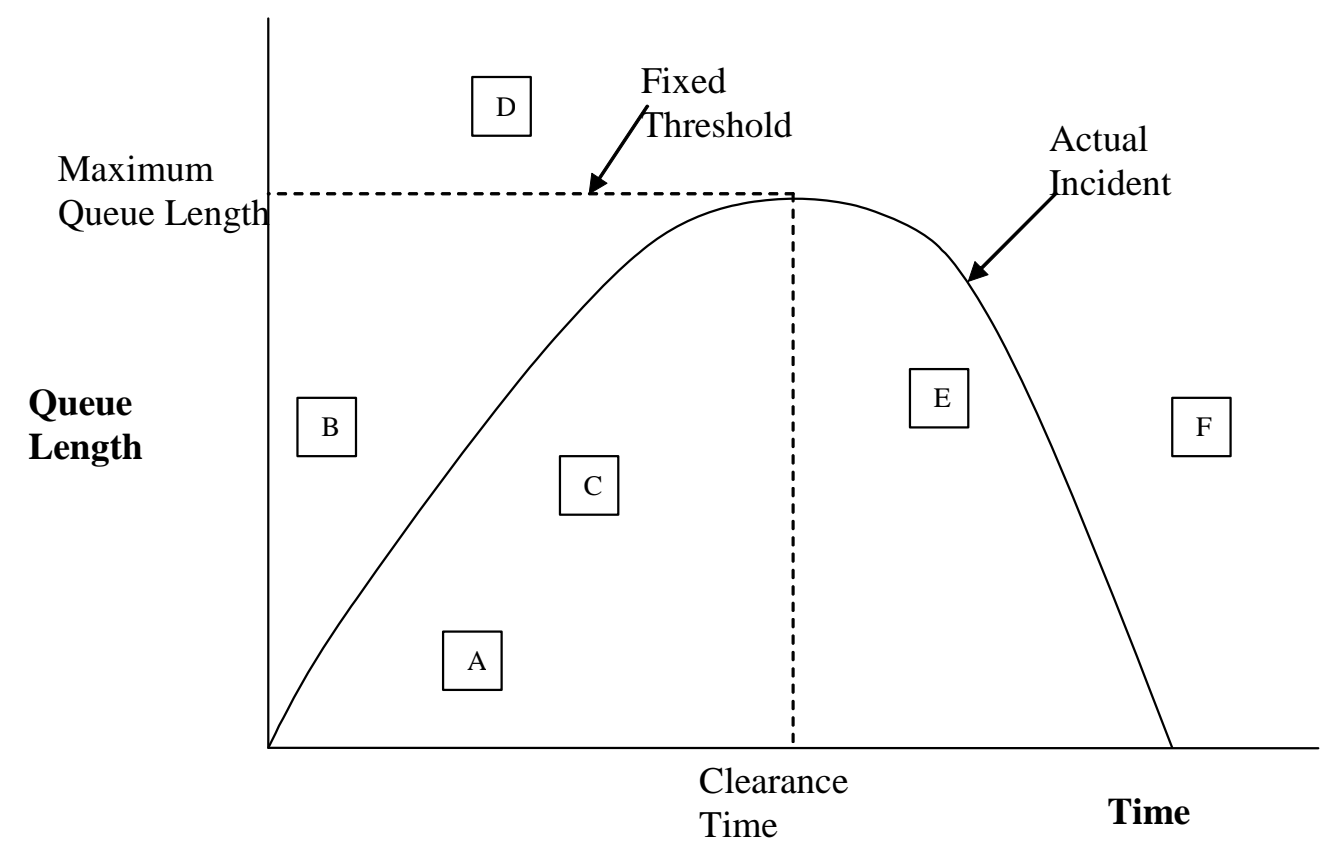

FIGURE 4.1 Rectangular thresholds versus actual incident progression.

\section{MOTIVATION}

As mentioned at the end of previous chapter, the methodology for classifying secondary accidents is discussed in this chapter. FIGURE 4.1 shows a graph of the progression of an incident, and the rectangular queue length and time thresholds superimposed on this progression. If an accident (A to F) falls within the influence of the primary accident, i.e. the accident happened within the queue of the primary then the accident is considered to be secondary. Progression refers to the growth and decline of the queue length as the 
incident progresses through the various stages. As discussed in the previous chapter, the various stages of an incident that influence the traffic queues include the 1.onset, 2. the arrival of response teams, 3.the clearance to the shoulder, the completion of clearance, and 4.the normalization of traffic. The progression is a function of both the demand (traffic) and the supply (road capacity). With the demand changing constantly, it is clear that the assumption of rectangular thresholds would not capture field conditions properly. Some would argue that on the average, the total number of secondary accidents can still be estimated accurately with rectangular thresholds if the area of the rectangular threshold is the same as the area under the progression curve. This argument also requires the assumption that accidents are independent from the location and time of the primary accident. For example, FIGURE 4.1 shows that the same number of accidents (three) is classified as secondary using a rectangular threshold or an actual incident progression curve. However, by definition, secondary accidents differ in cause from primary accidents. Therefore even if the average number of accidents is captured accurately with rectangular thresholds, the accidents themselves are still misclassified. Referring back to the example and looking at the rectangular thresholds, the total number of secondary accidents is estimated correctly even though accident B is a false positive and accident $\mathrm{E}$ is a false negative. The elimination of such type I and type II classification errors is one primary motivation for the development of polynomial thresholds. It is clear that accidents that occur near the time of the onset of the primary accident but far away from its location should be not classified as secondary. However, this can occur if a rectangular threshold is used. 


\section{LITERATURE REVIEW FOR ESTIMATING SECONDARY ACCIDENTS}

There were articles that relate to secondary accidents but did not address the extraction process directly. Karlaftis et al. (1999) examined the primary crash characteristics that influence the likelihood of secondary crash occurrence. They suggested that clearance time, season, type of vehicle involved, and lateral location of the primary crash were the most significant factors. The economic benefit of secondary crash reduction for the Hoosier Helper freeway service patrol program was also presented. There were several articles that addressed the magnitude and impact of incident delays. These include Garib et al. (1997), Giuliano (1989), Skabardonis et al. (1996), Morales (1987), Sullivan (1997), Smith et al. (2003), Lindley (1987), and Lee et al. (2003).

An important paper among the articles that discuss the extraction of secondary is (Raub, 1997) in which Raub presents a methodology for the temporal and spatial analysis of incidents on urban arterials in order to identify the secondary crashes. He found that more than $15 \%$ of the crashes reported by police may be secondary in nature. He also found that such crashes result from external distractions instead of internal distractions or driver perception error. For his analysis, he assumed an accident effect duration of 15 minutes plus the clearance time. He also assumed a distance of effect of less than 1600 meters (1 mile). In other words if an accident occurred within these temporal and spatial boundaries, then the accident is considered to be secondary.

More recently, Moore et al. (2004) examined secondary accident rates on Los Angeles freeways using accident records from the California Highway Patrol's First Incident Response Service Tracking system as well as data from loop detectors on Los Angeles freeways. They defined secondary accidents as accidents occurring upstream of 
the initial incident in either direction within or at the boundary of the queue formed by the initial incident. A rectangular threshold of $3218 \mathrm{~m}$ (2 miles) and 2 hours was used for forming this boundary. Several levels of filters served to eliminate erroneous data.

These two studies exemplify the use of rectangular (fixed) thresholds for classifying secondary accidents.

\section{METHODOLOGY}

Using the media traffic reports as described in chapter 2 a total of 480 incidents were extracted from the traffic reports for freeways I-70 and I-270 in St. Louis, Missouri. The reports were collected between January 2003 and first week of February 2004. These were the incidents that contained some sort of backup or queue information. For these incidents the extent of traffic information varied from covering the incident progression for the entire duration to reporting the incident with initial back up reports. The incidents can be classified into three types based on the completeness of the coverage. These three types can be seen visually in FIGURE 4.2. For explaining them with simplicity they can be defined as a, b, and c categories. Each of these categories is explained as follows

- a- type: These incidents have complete information about the incident progression curve (IPC) i.e. variation of queue length from the point of incident occurrence to the point where the queue dissipates completely.

- b-type: This category consists of incidents that lack complete information about the IPC but they do indicate a decreasing trend in the length of queues. The b-type curve in FIGURE 4.2 illustrates this category. 
- c-type: In this category there is some uncertainty as to whether the incident will further descend or keep on increasing before it descends. This can be seen in the c-type curve of FIGURE 4.2. After the last report it is difficult to predict whether the sample curve is going to keep on rising or is it going to decrease.

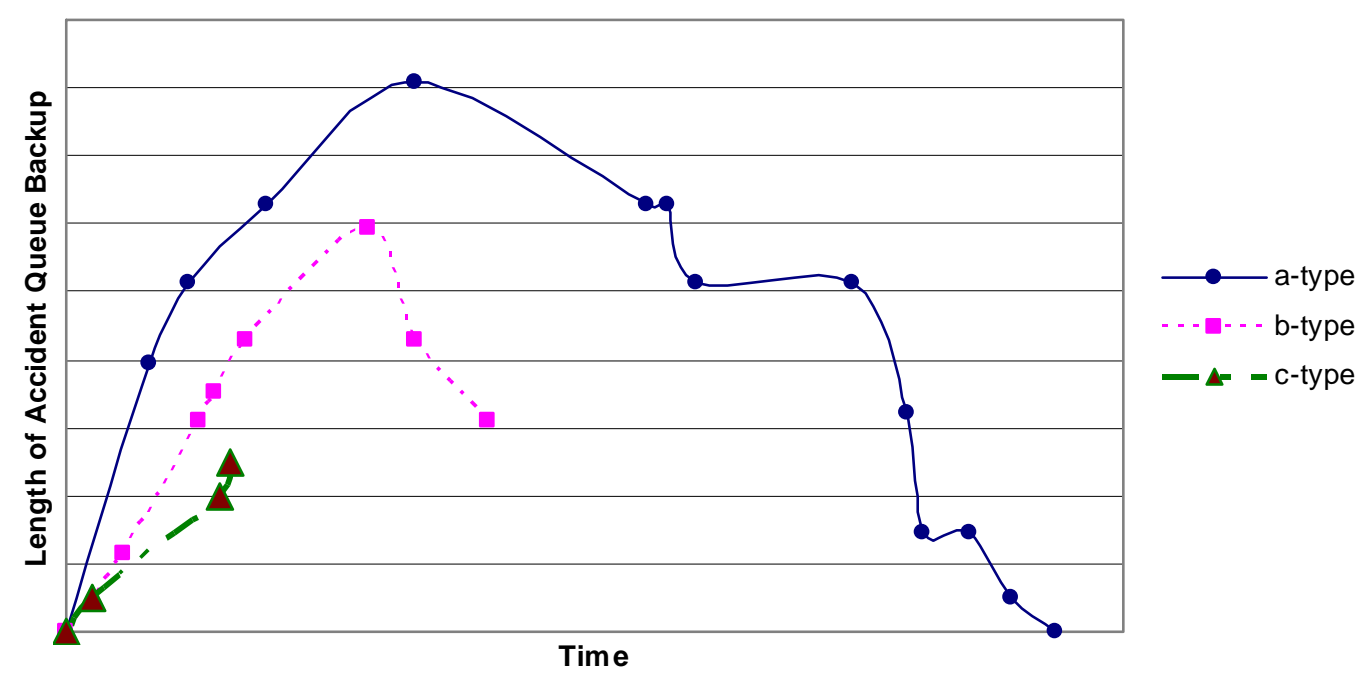

FIGURE 4.2 Categories of incident information.

\section{Filling in Incomplete Incident Data}

Since detailed incident data is difficult to obtain, it would be desirable to use the incomplete traffic reports instead of discarding them. One way of accomplishing this, is decide which set of incomplete incidents can be used and then model the incomplete information by estimating the duration of the incident and then fitting an incident progression curve. The duration of the incidents that do not have descending queue information is difficult to estimate, since neither the clearance time nor the rate of the queue reduction is known. However, if the incident is cleared and the backup queue is 
descending (like in the case of b-type) then the highway is operating under full capacity and the queue dissipation time can be estimated. Thus the first two types i.e. a-type and b-type of incidents are used for modeling the backup queue after an incident while the ctype had to be currently discarded.

Before combining the 'a' and 'b' types which have either complete information or incomplete but predictable information, an investigation is made to determine if these incidents are different from the 'c-type' which are incidents that do not have a way to know their incident progression curves The similarity of the reports in terms of the timeof-the-day is investigated by comparing temporal frequency distributions. A chi-squared test is employed to determine the goodness-of-fit of the distributions. Table 4.1 shows the temporal distributions of complete versus incomplete incident reports. Due to the paucity of data during the off-peak periods, larger bin are used at those times. The chisquared test shows that the distributions are similar at greater than a 95\% confidence level.

\section{TABLE 4.1 Distribution of Incidents Based on Time of the Day}

\begin{tabular}{|c|c|c|c|}
\hline Bin & Hours & $\begin{array}{c}\text { 'a-type' and } \\
\text { 'b-type' combined }\end{array}$ & 'c-type' \\
\hline & & 13 & 32 \\
1 & $06: 00-07: 00$ & 25 & 55 \\
2 & $07: 00-08: 00$ & 18 & 41 \\
3 & $08: 00-09: 00$ & 26 & 56 \\
4 & $09: 00-15: 00$ & 12 & 35 \\
5 & $15: 00-16: 00$ & 19 & 48 \\
6 & $16: 00-17: 00$ & 27 & 45 \\
7 & $17: 00-18: 00$ & 6 & 22 \\
8 & $18: 00-06: 00$ & 146 & 334 \\
& Total & \multicolumn{2}{|c}{} \\
\hline
\end{tabular}




\section{Data Set for Ground Truth Testing}

Out of 480 incidents, 49 incidents have complete incident information while 97 incidents have some traffic information after incident clearance. In order to test the methodology for filling in incomplete incident reports, a dataset is constructed by taking the complete incidents and then artificially eliminating traffic report information a report after the last maximum queue report. This test set tries to replicate the incomplete data and provides the ground truth. The performance of the models in estimating the missing portion of the progression curve is evaluated using this test dataset. Since the backup queue may not decrease linearly; second, third, and fourth order polynomials are tested for modeling the incomplete accidents.

\section{$\underline{\text { Criteria for Test Data Set }}$}

Accidents that have incomplete but descending queue information have at least one report after the last maximum queue report. In order to create a test data set we need to take accidents that have at least one report after the last maximum queue report and necessarily it shouldn't be the last report, in other words in order to be part of the test data set the accidents should have at least two reports after the last maximum queue report.

22 accidents out of the complete incidents had at least two reports after the last maximum queue report. The last maximum queue report indicates that the traffic queue is descending and when provided it can be verified that the clearance time occurs before the last maximum queue point. The two reasons for using last maximum queue report instead of clearance report are first not all accidents have clearance information and secondly a 
clearance report does not always confirm that the vehicles are cleared away from the site. Presence of accident vehicles or relief agency vehicles, adjacent to the highway could cause rubber necking affect and thus reduce the capacity. This reduction in capacity negatively impacts the queue length given the number of vehicles joining the end of queue are greater than or equal to previous flow condition. So for these 22 accidents different polynomial models were tested to see which could predict the incident duration and shape better.

\section{Estimated Values for Queue Dissipation}

In the case of third and fourth order polynomials predicting the shape before predicting the duration seemed problematic as for some incidents the incident progression curve did not completely descend to zero queue length instead they started to ascend. This is because the IPC started ascending before completely normalizing. So the researcher first wanted to estimate the duration reliably and hoped then to estimate the shape given the duration of the last point is fixed. TABLE 4.2 shows the estimated durations based on different polynomial models. The column "Duration at chop point" is the time duration since the accident occurred to the report where it was chopped off for modeling purpose. Where as, the column “Actual Duration” indicates the time difference between accident occurrence and normalization of the freeway. The total duration predicted using second, third and fourth degree models are presented under the columns "Predicted Duration Based on”. Among these three prediction models the second order is more reliable as it predicts for all accidents and the fourth order is least reliable as in seven out of 22 cases it prediction was a logical error(meaning the prediction was either imaginary or negative 
value). Apart from imaginary and negative values for predicted durations, the predicted value was also considered error if it was less than the duration that was chopped. For example in the case of Id 10 (i.e. Accident Id 27) the duration at chop point is 108 minutes so the actual duration should be at least 108 minutes but the predicted value based on fourth order shows that the actual duration is 100.51 minutes. Although this kind of error is relatively minor error compared to a negative or imaginary value for total duration, however it is still considered as an error. The column "Number of reports used" refers to the reports that remained after chopping the data. If we want to fit an $n^{\text {th }}$ degree polynomial uniquely to a data set then at least $n+1$ data points are needed. For example if we want to fit fourth degree polynomial for a dataset then we need at least have five data points (in our case five reports) for a unique fit. TABLE 4.2 shows that out of 22 accidents there were three cases where the number of reports were four and hence it may not suitable for obtaining unique equation for a fourth order polynomial on the data set. 
Table 4.2 Estimated Durations Based On Different Polynomial Models

\begin{tabular}{|c|c|c|c|c|c|c|}
\hline \multirow[b]{2}{*}{ Id } & \multirow[b]{2}{*}{$\begin{array}{c}\text { Number of } \\
\text { Reports } \\
\text { Used }\end{array}$} & \multirow[b]{2}{*}{$\begin{array}{l}\text { Duration } \\
\text { at Chop } \\
\text { Point } \\
\text { (Minutes) }\end{array}$} & \multirow[b]{2}{*}{$\begin{array}{c}\text { Actual } \\
\text { Duration } \\
\text { (Minutes) }\end{array}$} & \multicolumn{3}{|c|}{ Predicted Duration Based on } \\
\hline & & & & $\begin{array}{l}\text { Second Order } \\
\text { (Minutes) }\end{array}$ & $\begin{array}{c}\text { Third } \\
\text { Order } \\
\text { (Minutes) }\end{array}$ & $\begin{array}{c}\text { Fourth } \\
\text { Order } \\
\text { (Minutes) }\end{array}$ \\
\hline 1 & 5 & 61 & 70 & 69.34 & 0.04 & $\mathrm{n} / \mathrm{a}$ \\
\hline 2 & 5 & 96 & 108 & 113.15 & 98.22 & 95.20 \\
\hline 3 & 5 & 57 & 79 & 82.08 & 65.46 & 59.67 \\
\hline 4 & 5 & 69 & 77 & 82.96 & 74.88 & 77.23 \\
\hline 5 & 5 & 26 & 49 & 33.59 & 29.32 & 27.16 \\
\hline 6 & 5 & 94 & 127 & 128.26 & 104.59 & 29.12 \\
\hline 7 & 7 & 66 & 118 & 112.51 & 78.40 & 75.26 \\
\hline 8 & 6 & 110 & 187 & 146.21 & $\mathrm{n} / \mathrm{a}$ & 124.61 \\
\hline 9 & 4 & 34 & 69 & 42.96 & 42.80 & $\mathrm{n} / \mathrm{a}$ \\
\hline 10 & 6 & 108 & 135 & 126.79 & 138.86 & 100.51 \\
\hline 11 & 4 & 43 & 58 & 55.19 & 56.63 & $\mathrm{n} / \mathrm{a}$ \\
\hline 12 & 6 & 45 & 48 & 49.91 & 46.25 & 46.68 \\
\hline 13 & 9 & 121 & 139 & 160.92 & 146.78 & 127.27 \\
\hline 14 & 4 & 40 & 60 & 62.82 & 41.99 & 41.72 \\
\hline 15 & 9 & 89 & 108 & 119.45 & 112.72 & 95.39 \\
\hline 16 & 8 & 195 & 213 & 254.94 & 259.51 & 204.42 \\
\hline 17 & 8 & 72 & 76 & 81.16 & 82.81 & 78.17 \\
\hline 18 & 7 & 133 & 172 & 173.25 & 174.35 & 159.58 \\
\hline 19 & 9 & 84 & 88 & 103.66 & 93.40 & 96.03 \\
\hline 20 & 5 & 53 & 59 & 68.30 & 56.24 & 55.43 \\
\hline 21 & 5 & 55 & 126 & 86.34 & $\mathrm{n} / \mathrm{a}$ & 56.78 \\
\hline 22 & 5 & 59 & 74 & 65.06 & 68.04 & $\mathrm{n} / \mathrm{a}$ \\
\hline
\end{tabular}

\section{Shape of Accident Queue Backup}

In the above 22 cases the overall shape of the accident queue is compared with the three polynomial models. The actual duration for each accident is divided in 100 points and at each point the corresponding actual queue length is computed. Computation of actual queue length is based on the queue lengths from the traffic reports. For the points between successive reports the queue length is calculated by interpolation. For example if the first and second reports were at zero and ten minutes respectively with queue lengths 
of zero and one mile then the queue length at five minutes would be half a mile long. In reality, the queue length will hardly progress linearly but as there is no information linear case was chosen.

For each of the 100 points in duration the queue lengths estimated from second, third and fourth degree polynomials are also estimated and their difference with the actual queue length is computed for finding the error square of the models. Table 4.3 shows the sum of square errors (SSE) and R- Square values for different models. The equations for SSE and R-Square are as follows

$\mathrm{SSE}_{\mathrm{j}}=\sum_{i=0}^{i=100}\left(q_{i r}-q_{i j}\right)^{2}$

$\mathrm{SST}_{\mathrm{j}}=\sum_{i=0}^{i=100}\left(q_{\text {ir }}-q_{\text {mean }}\right)^{2}$

Adjusted R-Square $_{\mathrm{j}}=1-\left(\frac{n-1}{n-p}\right) \frac{\mathrm{SSE}_{\mathrm{j}}}{\mathrm{SST}_{\mathrm{j}}}$

Where,

qir -real queue length at duration point i.

$\mathrm{q}_{\mathrm{ij}}$-estimated queue length at duration point $\mathrm{i}$ and for a polynomial model $\mathrm{j}=2,3,4$.

$\mathrm{q}_{\text {mean- }}$ mean value of all the queue lengths

$n$-number of data points

p- number of parameters to estimate

TABLE 4.3 shows that the average adjusted R-Square of third degree is better than the second and fourth degree models. In the category of sum of square errors, the overall average value for second degree model is better compared to others but if the outliers were removed the third degree seems to be better. 
By using the test dataset, it is found that a third order polynomial provided the best fit as compared to the second and fourth order polynomials. The third order polynomial is able to reproduce the total delay estimates (or areas under the queue length/time curves) to within $\pm 10 \%$ with an average difference of $1.4 \%$ from the true value. While the average difference between second order and real data is $5.3 \%$, and the difference between fourth order model and real data is $6.5 \%$. Another criterion for evaluating the performance of the polynomial models is the $\mathrm{R}^{2}$ value, which measures the proportion of the data that can be explained by the model. FIGURE 4.3 shows the $\mathrm{R}^{2}$ values of several incidents being modeled by a second, third, and fourth order polynomial. Figure 4.3 shows that the third order polynomial results in the best $\mathrm{R}^{2}$ over the entire test dataset. Based on the aforementioned tests, it is concluded that 97 incomplete incidents can still be used and not discarded. 
TABLE 4.3 SSE and R-Square

\begin{tabular}{|c|c|c|c|c|c|c|}
\cline { 2 - 7 } \multicolumn{1}{c|}{} & \multicolumn{3}{c|}{ R Square } & \multicolumn{3}{c|}{ Sum of Square Errors } \\
\hline ID & $\begin{array}{c}\text { 2nd } \\
\text { Degree }\end{array}$ & $\begin{array}{c}\text { 3rd } \\
\text { Degree }\end{array}$ & $\begin{array}{c}\text { 4th } \\
\text { Degree }\end{array}$ & SSE2 & SSE3 & SSE4 \\
\hline 1 & 0.723 & 0.564 & 0.371 & 27 & 33 & 64 \\
2 & -0.945 & 0.768 & -0.107 & 21 & 10 & 648 \\
3 & 0.875 & 0.751 & 0.269 & 8 & 36 & 101 \\
4 & 0.899 & 0.927 & 0.903 & 4 & 6 & 8 \\
5 & 0.556 & 0.546 & 0.303 & 73 & 91 & 120 \\
6 & 0.704 & 0.915 & -0.158 & 102 & 64 & 25093 \\
7 & 0.54 & 0.679 & 0.693 & 138 & 167 & 163 \\
8 & 0.724 & 0.583 & 0.57 & 285 & 148 & 543 \\
9 & 0.179 & 0.17 & -0.056 & 147 & 148 & 72884 \\
10 & 0.699 & 0.812 & -0.129 & 67 & 31 & 5826 \\
11 & 0.962 & 0.96 & -0.311 & 7 & 7 & 2319 \\
12 & 0.762 & 0.952 & 0.949 & 7 & 2 & 3 \\
13 & 0.482 & 0.667 & 0.741 & 40 & 30 & 38 \\
14 & 0.459 & 0.674 & 0.683 & 16 & 39 & 35 \\
15 & 0.671 & 0.784 & 0.788 & 86 & 63 & 97 \\
16 & 0.649 & 0.624 & 0.699 & 8 & 9 & 20 \\
17 & 0.921 & 0.916 & 0.953 & 1 & 1 & 1 \\
18 & 0.935 & 0.929 & 0.954 & 42 & 44 & 34 \\
19 & 0.688 & 0.892 & 0.915 & 14 & 6 & 5 \\
20 & 0.455 & 0.953 & 0.975 & 30 & 7 & 3 \\
21 & 0.053 & -0.237 & -0.144 & 323 & 5165 & 860 \\
22 & 0.946 & 0.969 & 0.917 & 12 & 6 & 13 \\
\hline Mean & 0.588 & 0.718 & 0.49 & 66 & 278 & 4949 \\
$95 \%$ C.I & 0.1741 & 0.1204 & 0.1888 & 88 & 1093 & 16100 \\
\hline
\end{tabular}




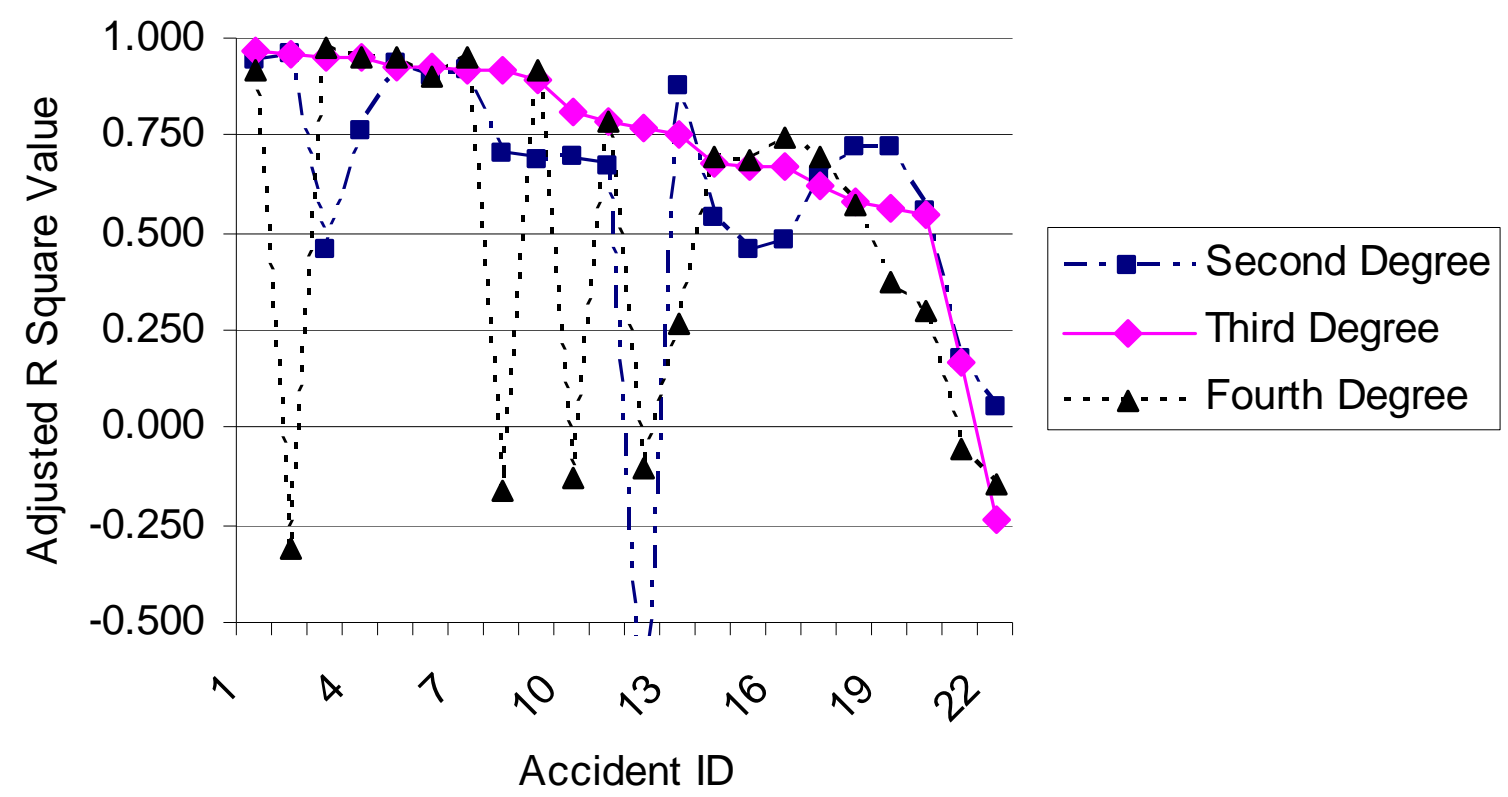

\section{FIGURE 4.3 Polynomial model fit}

\section{Master Incident Progression Curve}

Two approaches were initially considered for the development of master incident progression curves. The first approach was to perform regression on the entire database of incidents. In other words, every data point from each incident will be used for curve fitting. This approach was quickly eliminated as the resulting curve will be very complex and not look like a real incident. Another approach was to try to capture the central tendency of all the incidents. There are three common measures of central tendency: the arithmetic mean, the median, and the mode. The mean is sensitive to extreme values so that a major incident would unduly influence the result. The mode can be problematic if the data is not uni-modal. Therefore the median value is used. Each individual incident produced an incident progression curve similar to the one shown in Figure 4.1. In order 
to join multiple curves to form one curve, the curves were divided into equal increments.

For each increment, the median value of incident duration and queue length were calculated. For example, if three accidents with durations of 40, 60, and 80 minutes were considered, then the corresponding increment size would be 4,6 , and 8 minutes. The median value of the duration and queue lengths is then computed. The result of this method produced a single progression curve that looks like an actual curve from a single incident.

As was discussed previously, a threshold separates secondary accidents from primary accidents. An accident falling within the bounds of the threshold means that the accident occurred within queue of the primary accident during the duration of the primary accident. Two types of thresholds were compared in this research; namely, rectangular threshold and polynomial threshold. Each type of the threshold is a function of both a time and a distance variable. The rectangular threshold determined from the intranet incident reports was 42 minutes in duration and 3.53 miles in queue length. In contrast to this threshold, the polynomial threshold was the master incident progression curve described previously. The following equation resulted from the non-linear regression on 119 incidents.

$$
Q=-7.8264 \times 10^{-6} t^{3}-9.4363 \times 10^{-4} t^{2}+0.12652 t+0.013873
$$

where $Q$ is the queue length of the primary accident in miles and $t$ is the elapsed time in minutes after the occurrence of the primary accident. The total duration of the master incident progression curve was 80.5 minutes and the maximum queue was 3.09 miles occurring between 43 and 44 minutes. 


\section{Extraction of Secondary Accidents}

The process to extract secondary accidents from the accident database is as follows. First, the accident database needs to be formatted and processed. The database is separated by route and by year (e.g. I-70, 2003). Each of the 28 fields that describe each accident record is parsed and stored. The time and date fields are translated for computation so that they can be added and subtracted. The entire accident file is then converted into a doubly-linked list so that the file can be collapsed into one record per accident. In other words, a file with one record per vehicle involved in an accident is consolidated into one record per accident. The secondary accidents are classified by using the rectangular or polynomial thresholds as shown in Figure 4.4. The total number of secondary accidents are tallied and recorded for each route and for each year. The routine is similar to the one discussed in the previous chapter.

\section{RESULTS}

To illustrate the application of the polynomial threshold, a year's worth of accident data from I-70 and I-270 in Missouri was used. Year 2003 data was used and contained 5514 accidents. Out of these accidents 397 were classified as secondary based on the polynomial threshold curve and 390 were classified as secondary accidents based on the rectangular threshold curve. The area under the rectangular and polynomial threshold curves was 148.3 mile-minutes and 164.8 mile-minutes respectively. On the surface these numbers seem to imply that the use of rectangular or polynomial thresholds produce similar results since the area under the curves and the total number of secondary accidents classified were similar. In reality, the two thresholds yielded different results 
and can be clearly seen in FIGURE 4.4 and Table 4.4. In FIGURE 4.4, the origin is the time and location at which the primary accident occurred. So the y-axis represents the upstream displacement from the location of the primary accident and the x-axis represents the time after the onset of the primary accident. FIGURE 4.4 shows graphically a significant number of accidents that are not common to the application of both the rectangular and polynomial thresholds. Table 4.4 shows that 125 accidents were classified as secondary by the polynomial threshold but not by the rectangular threshold. Conversely, 118 accidents were classified as secondary by the rectangular threshold but not by the polynomial threshold. So the classification results actually differ by more than 30\%. This difference can be significant since accidents costs can differ significantly based on the severity of the accident. For example, the consequence of a fatal accident is much greater than property damage only (PDO) accident. TABLE 4.4 also shows that the results are similar for daytime only versus all-day. 


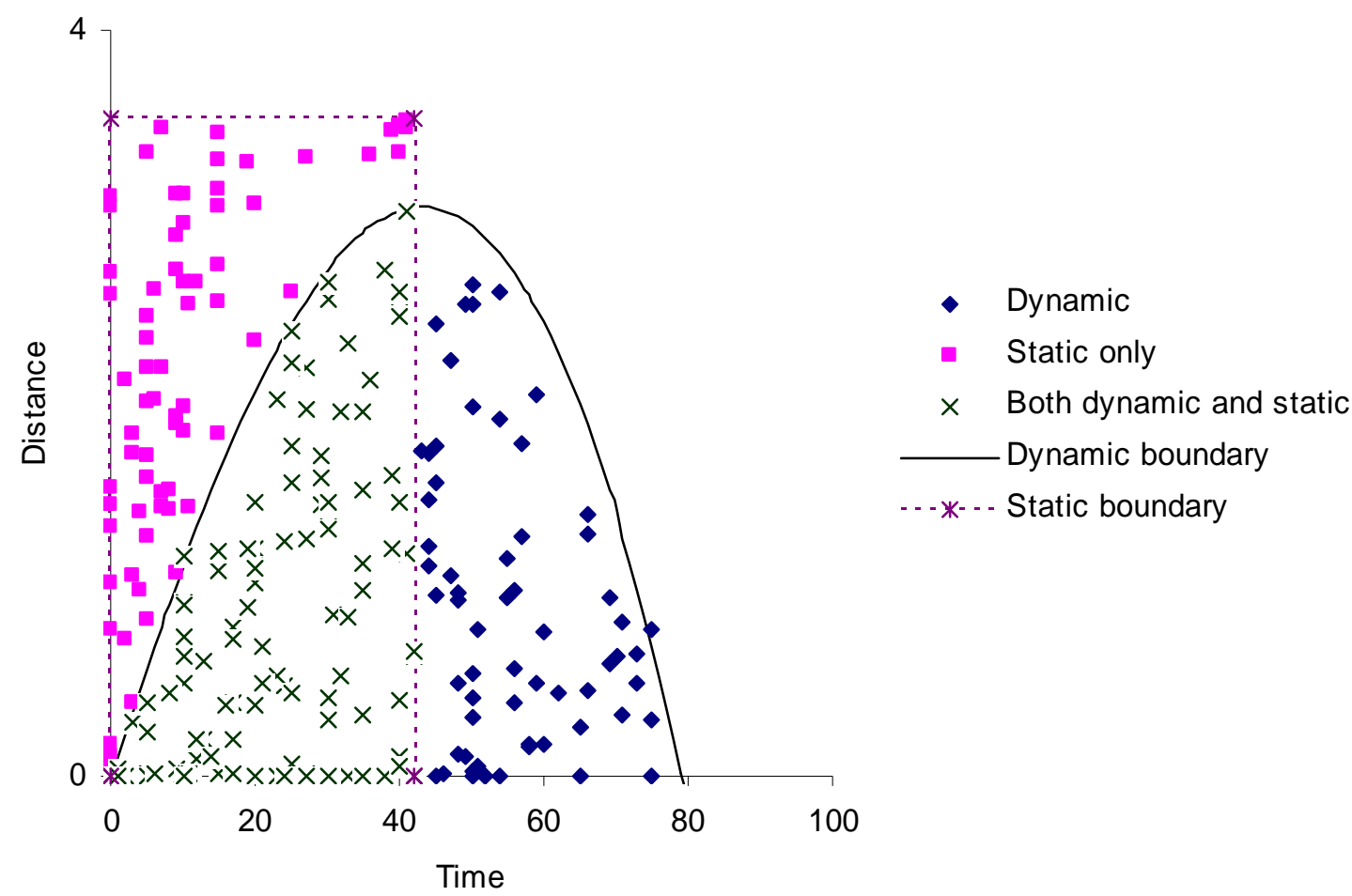

FIGURE 4.4 Secondary accidents based on rectangular and polynomial thresholds.

TABLE 4.4 Comparison of Polynomial versus Rectangular Thresholds

\begin{tabular}{|c|c|c|c|c|c|}
\cline { 2 - 6 } \multicolumn{1}{c|}{} & \multicolumn{5}{c|}{ Number of Secondary Accidents } \\
\hline Time Period & $\begin{array}{c}\text { Polynomial } \\
\text { Only }\end{array}$ & $\begin{array}{c}\text { Rectangular } \\
\text { Only }\end{array}$ & Both & $\begin{array}{c}\text { Total } \\
\text { Polynomial }\end{array}$ & $\begin{array}{c}\text { Total } \\
\text { Rectangular }\end{array}$ \\
\hline $\begin{array}{c}\text { Day Time } \\
\text { (5:30 A.M - } \\
\text { 6:30 P.M) } \\
\text { All-day }\end{array}$ & 106 & 98 & 215 & 321 & 313 \\
\hline
\end{tabular}

\section{INVESTIGATING MULTIPLE MASTER IPCs}

An investigation was conducted to determine if multiple master incident progression curves were needed. Specifically, accident data from two freeway sites were compared. 
These accidents were examined both spatially and temporally by looking at the maximum queue length and the duration of the accident. Two techniques were used to examine accidents from I-70 and I-270. First, these accidents were plotted and examined visually to see if I-70 and I-270 accidents could be separated from each other. Even though there was no clear-cut boundary that could drawn to divide accidents from these two freeways, FIGURE 4.5 shows that I-270 accidents tend to have longer queue lengths than I-70 accidents. Second, a student-t test was applied to see if there were any differences in the means between the two freeway sites. Two variables were examined; namely, maximum queue length and accident duration. The test showed that there was a statistically significant difference between the two freeway sites when the variable maximum queue length was considered ( $\mathrm{p}=0.041$ ). However, the test also showed that there was no statistically significant difference when the variable accident duration was considered $(\mathrm{p}=0.95)$. Therefore a two separate incident progression curves can be developed for each freeway. These curves were very similar to the curve described in equation (1). The total duration was 79.6 minutes for I-70 and 81.2 minutes for I-270. And the maximum queue length was 3.01 miles for I-70 and 3.14 miles for I-270 data. 


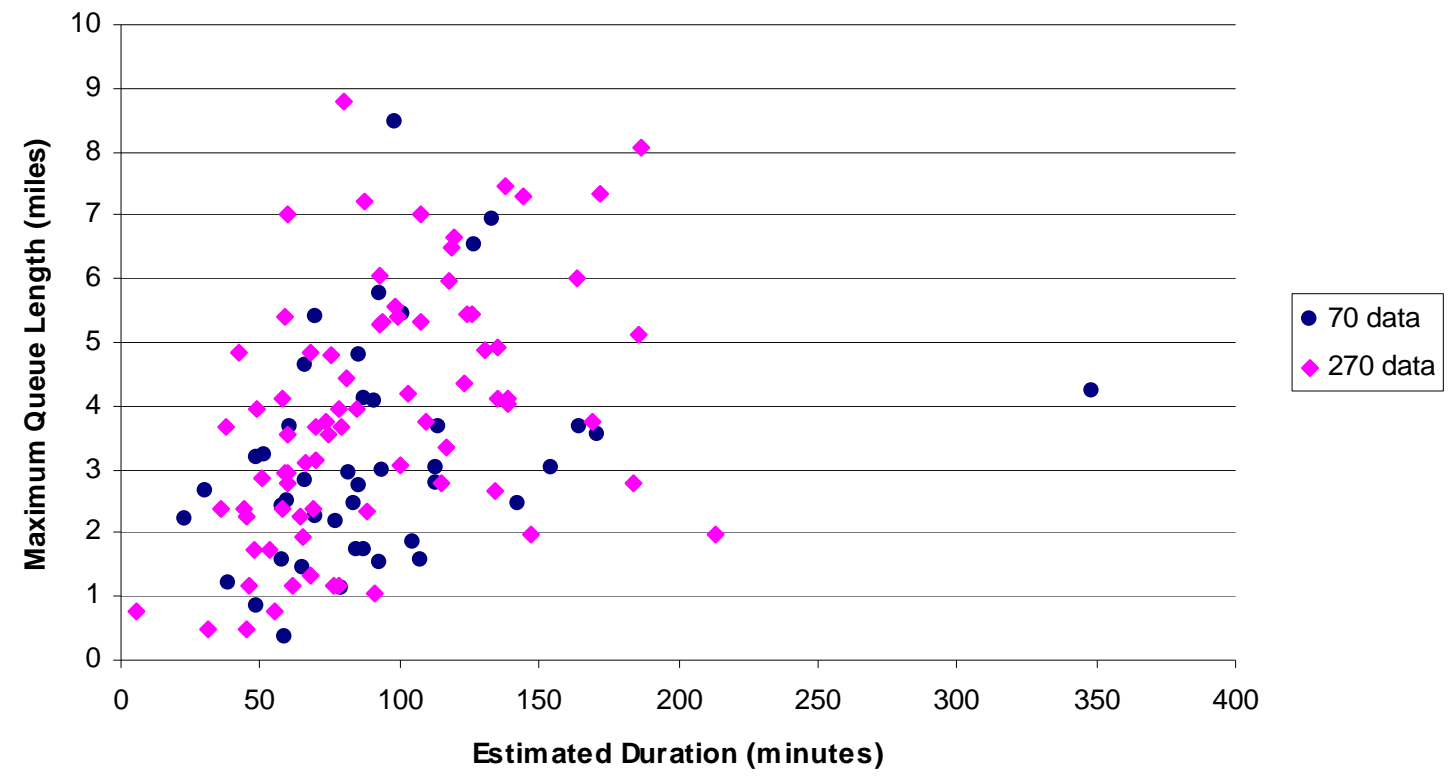

FIGURE 4.5 Visual inspection of I-70 versus I-270 accident data.

In contrast to traffic data, TMS accident database is used for estimating the secondary accidents but it does not contain any information on the maximum queue of an accident or the duration of an accident etc. which would be needed to determine the dimensional values of the queue. So the TMS attributes like severity, number of vehicles, time of accident and location of accident are used to see if any of these attributes influence maximum queue length and duration of the accident.

\section{Estimating $v / c$ ratio}

Time of accident and location of accident primarily indicate the traffic volume and capacity present at the start of accident. Since there are only 123 accidents there was not much liberty to further divide the data set into different time periods and for various freeway segments. For example accidents occurring between 6am and 9am on I-70 
eastbound could be one such data set while other data sets could include I-70 westbound, I-270 eastbound and I-270 westbound for different time periods. So the time and location are transformed to a ratio of volume to capacity which is called v/c ratio.

TMS also maintains volume information for various segments of its freeways. It maintains this information for work zone management. As this information could be used to determine a better time period for construction or maintenance activities which would result in lesser adverse impacts to the traffic. For estimating the v/c ratio, we need to estimate the capacity and also convert the traffic volume into passenger car equivalent traffic volume. The procedure for estimating the $\mathrm{v} / \mathrm{c}$ ratio is explained in the following paragraphs.

For estimating capacity, Highway Capacity Manual (HCM, 2000) suggests to determine the free flow speed (FFS) and then estimate the capacity based on the FFS. For example if the FFS is 62 miles/hour then using TABLE 4.5 (which is taken from HCM 2000), the capacity is estimated as 2320 passenger car/hour/lane. It is very time consuming to estimate the FFS for various freeway segments so the FFS is estimated by adjusting the base free flow speed (BFFS). The BFFS for urban freeways can be assumed as 70 miles/hour. The formula for estimating the FFS is as follows

$F F S=B F F S-f_{L W}-f_{L C}-f_{N}-f_{I D}$

where,

$\mathrm{f}_{\mathrm{LW}}$-adjustment for lane width in miles/hour

$\mathrm{f}_{\mathrm{LC}}$-adjustment for lateral clearance in miles/hour

$f_{N}$-adjustment for number of lanes in miles/hour

$\mathrm{f}_{\mathrm{ID}}$-adjustment for interchange density in miles/hour 
It is assumed that the all the lanes are twelve feet wide with more than six feet clearance on the right shoulder, thus the adjustments for lane width and lateral clearance ( $f_{\mathrm{LW}}$ and $\mathrm{f}_{\mathrm{LC}}$ ) are zero. Further, it is assumed that there is an interchange per mile therefore the adjustment for interchange density $\left(\mathrm{f}_{\mathrm{ID}}\right)$ was equal to $2.5 \mathrm{miles} / \mathrm{hour}$. Depending on the number of lanes in one direction, the $\mathrm{f}_{\mathrm{N}}$ varied from zero to 4.5 miles/hour.

\section{Table 4.5 Relationship between FFS and Freeway Capacity}

\begin{tabular}{|c|c|}
\hline $\begin{array}{c}\text { Free flow speed } \\
\text { miles/hour }\end{array}$ & $\begin{array}{c}\text { Capacity } \\
\text { passenger car /hour /lane }\end{array}$ \\
\hline 75 & 2400 \\
70 & 2400 \\
65 & 2350 \\
60 & 2300 \\
55 & 2250 \\
\hline
\end{tabular}

The parameters that affect the traffic flow rate are peak hour factor (PHF), number of lanes, type of driver population, proportion of trucks, buses and recreation vehicles and type of terrain. So these parameters are first estimated to compute the analysis flow rate $\mathrm{v}_{\mathrm{p}}$ which is considered as $\mathrm{v}$ in the $\mathrm{v} / \mathrm{c}$ ratio. The equations for estimating the $\mathrm{v}_{\mathrm{p}}$ are as follows.

$$
\mathrm{v}_{\mathrm{p}}=\frac{V}{P H F^{*} N^{*} f_{H V} * f_{P}}
$$

$\mathrm{f}_{\mathrm{HV}}=\frac{1}{1+P_{T}\left(E_{T}-1\right)+P_{R}\left(E_{R}-1\right)}$

where

$\mathrm{V}_{\mathrm{p}}$-analysis flow rate

V-hourly volume (vehicles/hour)

$\mathrm{N}$-number of lanes

$\mathrm{f}_{\mathrm{HV}}$ - heavy vehicle factor 
$\mathrm{f}_{\mathrm{p}}$ - driver population factor

$\mathrm{P}_{\mathrm{T}^{-}}$proportion of trucks and buses in the traffic

$\mathrm{E}_{\mathrm{T}^{-}}$passenger car equivalent for trucks or buses

$\mathrm{P}_{\mathrm{R}^{-}}$proportion of recreation vehicles in the traffic

$E_{R^{-}}$passenger car equivalent for recreation vehicles

PHF is considered 0.95 as both the freeways are in urban setting. The driver population factor $\left(f_{p}\right)$ is assumed to be one, as most of the traffic is assumed to be commuters or people who are familiar with the roadways they travel and also the proportion of recreational drivers $\left(\mathrm{P}_{\mathrm{R}}\right)$ is assumed to be zero. Based on data collected during morning and evening peak periods it was found that the proportion of trucks and buses combined was below 0.05 so $\mathrm{P}_{\mathrm{T}}$ was assumed to be 0.05 . The grade is considered to be below $2 \%$ and thus the passenger car equivalent for trucks, $\mathrm{E}_{\mathrm{T}}$ is taken as 1.5.

Table 4.6: Sample of Data Used For Developing Multiple Master Curves

\begin{tabular}{|c|c|c|c|c|c|c|c|c|}
\hline $\begin{array}{c}\text { Time } \\
\text { (mins) }\end{array}$ & $\begin{array}{c}\text { Mile } \\
\text { Marker }\end{array}$ & $\begin{array}{c}\text { Maximum } \\
\text { Queue } \\
\text { (miles) }\end{array}$ & $\begin{array}{c}\text { Duration } \\
\text { (min) }\end{array}$ & $\begin{array}{c}\text { Estimated } \\
\text { Duration } \\
\text { (min) }\end{array}$ & $\begin{array}{c}\text { Seve- } \\
\text { rity }\end{array}$ & $\begin{array}{c}\text { Num of } \\
\text { Veh. }\end{array}$ & $\begin{array}{c}\text { Seg. } \\
\text { ment } \\
\text { ID }\end{array}$ & $\begin{array}{c}\text { v/c } \\
\text { Ratio }\end{array}$ \\
\hline 495 & 20.07 & 2.38 & 57 & 58.30 & 2 & 5 & 21 & 0.355 \\
525 & 24.68 & 3.55 & 154 & 171.42 & 2 & 2 & 12 & 0.358 \\
751 & 20.07 & 3.53 & 57 & 60.17 & 2 & 4 & 21 & 0.359 \\
546 & 6.94 & 6.54 & 127 & 127.00 & 2 & 3 & 12 & 0.362 \\
810 & 19.64 & 4.90 & 120 & 135.07 & 1 & 4 & 21 & 0.363 \\
800 & 20.07 & 3.53 & 55 & 74.60 & 2 & 2 & 21 & 0.363 \\
\hline
\end{tabular}

TABLE 4.6 has the parameters chosen for accident queue modeling. This table contains only a sample of accidents of the complete set that is provided in the APPENDIX A. The first two columns show the time and mile marker of the accident. The time is represented in minutes i.e. zero stands for midnight and 360 stands for 6 AM. The mile marker is based on MoDOT continuous log point. The columns "Maximum Queue” and "Duration” contain the observed values of maximum queue length and actual 
duration of the particular accident. Whenever the accident queue information is incomplete i.e. the last traffic report still reports a queue length then in those cases the total duration is estimated presented in the column "Estimated Duration”. The severity and number of vehicles involved in the accident are presented in the next two columns. The severity codes 1, 2 and 3 represent property damage only (pdo), injury and fatality. The last column contains the value of v/c for each accident based on the time of the accident location. Out of 123 accidents chosen there were two apparent outliers for which the second degree polynomial did not estimate the duration correctly. These two outliers are in the first two rows of the dataset and their v/c ratio values are deleted to make sure they are not used in further processing. These two records were considered outliers, as the estimated duration was exceptionally high or exceptionally low. The first record which has exceptionally high estimated duration is weeded out as there would have been traffic reports beyond 138 minutes had the duration actually lasted for more than ten hours (633.61 minutes). And in the second case it can be seen the projected estimated duration has negative value, as this is not possible, the second outlier should also be weeded out of the data set for further analysis.

\section{Multiple IPCs}

\section{Based on v/c Ratio Only}

The effects of incidents differ according to the traffic conditions or the v/c ratio. Looking at the effects of incidents from the entire database, a natural separation seems to occur at a v/c value of around 0.7 . With values less than 0.7 , there does not seem to be any 
discernable differences in the effects of incidents. Therefore a two category system is developed based on v/c conditions.

Table 4.7 IPC Parameters and Static Thresholds Based on v/c Ratio

\begin{tabular}{|l|l|l|l|l|}
\hline \multicolumn{1}{|c|}{ Description } & \multicolumn{1}{|c|}{ Criterion } & \multicolumn{1}{|c|}{$\begin{array}{c}\text { Maximum } \\
\text { Queue (mi.) }\end{array}$} & $\begin{array}{l}\text { Time of Max. } \\
\text { Queue (min.) }\end{array}$ & \multicolumn{1}{c|}{$\begin{array}{c}\text { Time to } \\
\text { Normal. (min.) }\end{array}$} \\
\hline Light/Medium & v/c $<0.7$ & $3(3.16)$ & $45(45)$ & $\begin{array}{l}80(82) \text { or } \\
1 \mathrm{hr} .20 \mathrm{~min} .\end{array}$ \\
& v/c $>0.7$ & $5(4.71)$ & $70(67)$ & $\begin{array}{l}120(122) \text { or } \\
2 \mathrm{hr} .\end{array}$ \\
\hline
\end{tabular}

Table 4.8 IPC Polynomial Coefficients Based on v/c Ratio

\begin{tabular}{|c|c|c|c|c|}
\hline Criterion & a0 & a1 & a2 & a3 \\
\hline v/c $<0.7$ & 0.014200143 & 0.129503498 & -0.000965882 & $-8.01096 \mathrm{E}-06$ \\
v/c $>0.7$ & 0.021165402 & 0.193025784 & -0.001439653 & $-1.19404 \mathrm{E}-05$ \\
\hline
\end{tabular}

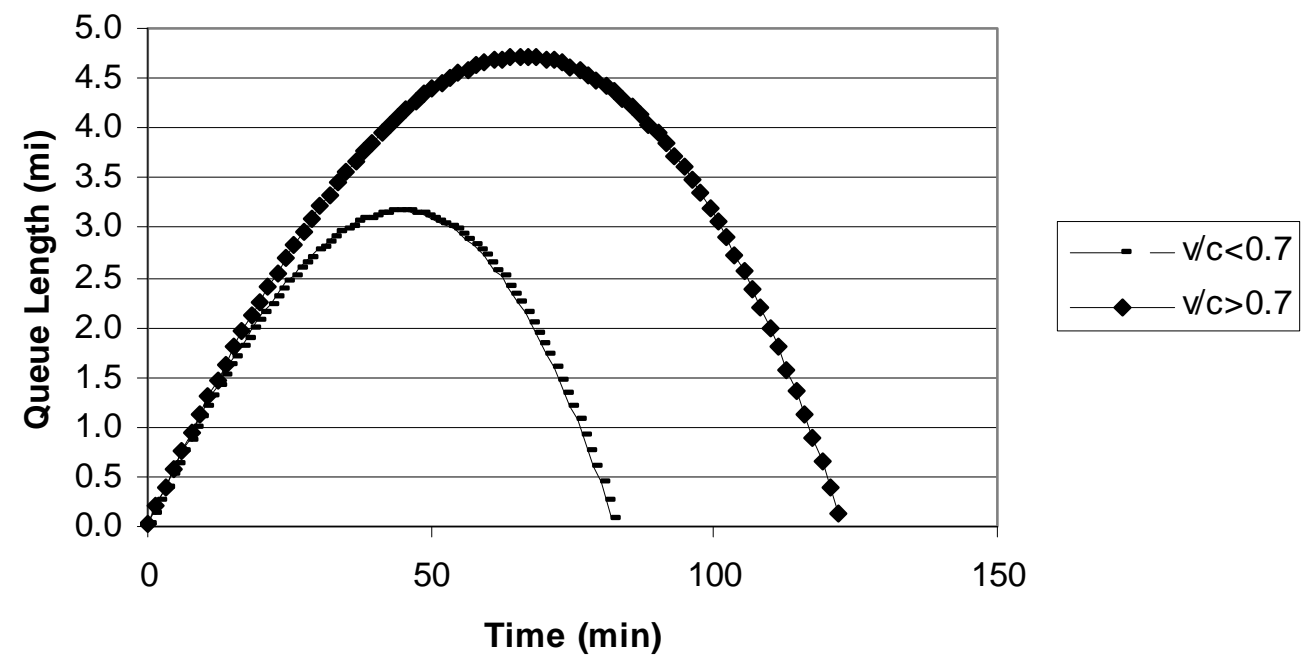

Figure 4.6 IPC Based on v/c. 
Based on Number of Vehicles Only

In general, the number of vehicles involved in an incident is correlated with the severity of the incident which is also correlated with the effects of the incident. So the number of vehicles recorded in the accident database can be a variable used for determining the appropriate IPC or threshold to be used in the determination of secondary accidents.

Table 4.9 IPC Parameters and Static Thresholds Based on Number of Vehicles

\begin{tabular}{|c|c|c|c|c|}
\hline Description & Criterion & $\begin{array}{c}\text { Maximum } \\
\text { Queue (mi.) }\end{array}$ & $\begin{array}{c}\text { Time of Max. } \\
\text { Queue (min.) }\end{array}$ & $\begin{array}{c}\text { Time to } \\
\text { Normal. (min.) }\end{array}$ \\
\hline Single & Vehicles =1 & $3(3.36)$ & $45(43)$ & $\begin{array}{c}90(89) \text { or } \\
1 \mathrm{hr} .30 \mathrm{~min} . \\
90(91) \text { or } \\
1 \mathrm{hr} .30 \mathrm{~min} . \\
95(95) \text { or } \\
1 \mathrm{hr} .35 \mathrm{~min} .\end{array}$ \\
\hline
\end{tabular}

Table 4.10 IPC Polynomial Coefficients Based on Number of Vehicles

\begin{tabular}{|c|c|c|c|c|}
\hline Criterion & a0 & a1 & a2 & a3 \\
\hline Veh $=1$ & 0.015098886 & 0.137699922 & -0.001027014 & $-8.51798 \mathrm{E}-06$ \\
Veh $=2$ & 0.015997629 & 0.145896346 & -0.001088146 & $-9.025 \mathrm{E}-06$ \\
Veh $>2$ & 0.016761561 & 0.152863307 & -0.001140108 & $-9.45597 \mathrm{E}-06$ \\
\hline
\end{tabular}




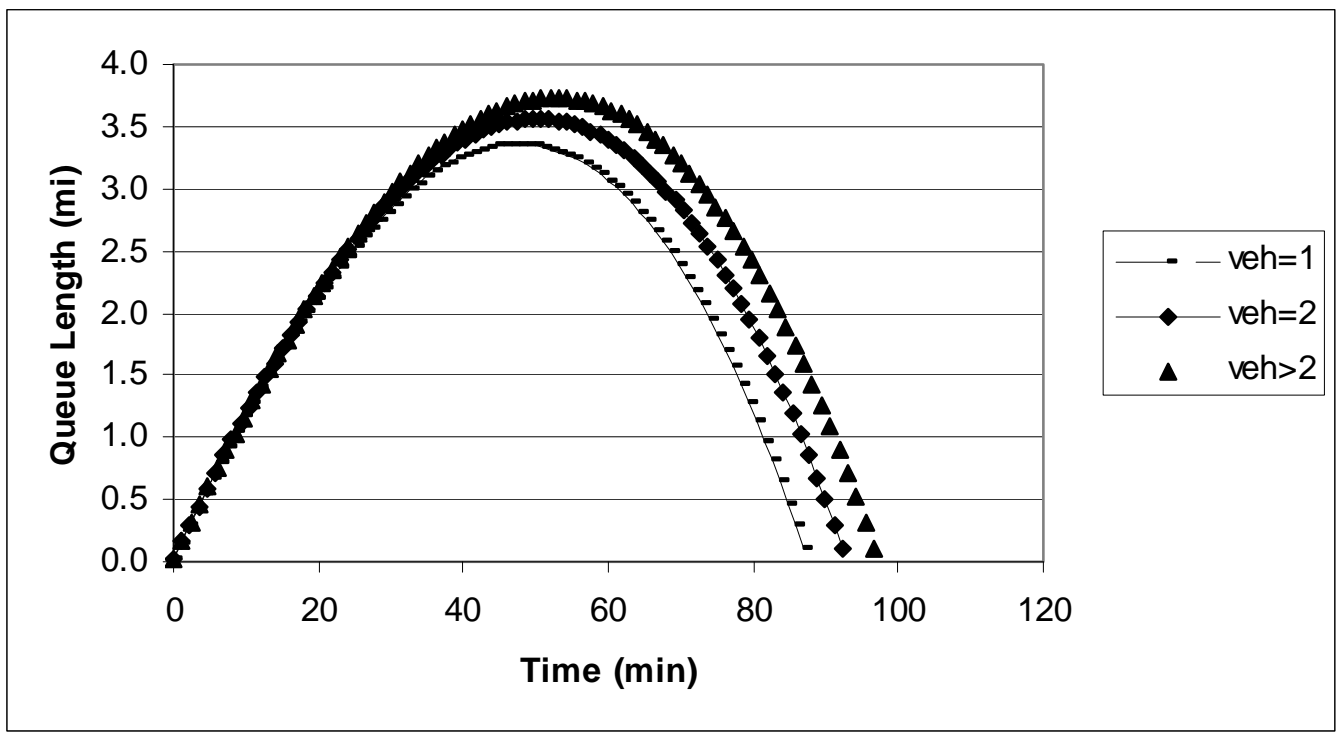

Figure 4.7 IPC Based on number of vehicles involved in the incident.

\section{Based on Severity and v/c}

The effects of incidents can be differentiated by the severity and the traffic conditions or v/c ratio. Due to the small sample size of fatal accidents, only PDO (Property Damage Only) and injury categories are used. For each severity, three different IPCs are developed based on the traffic conditions or v/c ratio. The injury accidents intuitively show larger effects than PDO accidents. 
Table 4.11 IPC Parameters and Static Thresholds Based on Severity and v/c Ratio

\begin{tabular}{|c|c|c|c|c|}
\hline Description & Criteria & $\begin{array}{l}\text { Maximum } \\
\text { Queue (mi) }\end{array}$ & $\begin{array}{l}\text { Time of Max. } \\
\text { Queue (min) }\end{array}$ & $\begin{array}{c}\text { Time to } \\
\text { Normal. (min) }\end{array}$ \\
\hline Light & $\mathrm{PDO}, \mathrm{v} / \mathrm{c}<0.4$ & $3(3.02)$ & $40(42)$ & $\begin{array}{c}80(78) \text { or } \\
1 \mathrm{hr} .20 \mathrm{~min} .\end{array}$ \\
\hline Medium & $\begin{array}{c}\text { PDO } \\
0.4<\mathrm{v} / \mathrm{c}<0.7\end{array}$ & $3.5(4.48)$ & $50(48)$ & $\begin{array}{c}90(90) \text { or } \\
1 \text { hr. } 30 \mathrm{~min} .\end{array}$ \\
\hline Heavy & $\mathrm{PDO}, \mathrm{v} / \mathrm{c}>0.7$ & $4.5(4.57)$ & $65(64)$ & $\begin{array}{c}120(118) \text { or } \\
2 \mathrm{hr} \text {. }\end{array}$ \\
\hline Light & INJ, v/c $<0.4$ & 3 (3.157) & $45(44)$ & $\begin{array}{c}80(82) \text { or } \\
1 \text { hr. } 20 \mathrm{~min} .\end{array}$ \\
\hline Medium & $\begin{array}{c}\text { INJ, } \\
0.4<\mathrm{v} / \mathrm{c}<0.7\end{array}$ & $3.75(3.68)^{*}$ & $50(51)$ & $\begin{array}{c}95(95) \text { or } \\
1 \text { hr. } 35 \text { min. }\end{array}$ \\
\hline Heavy & INJ, v/c > 0.7 & $5(4.912)$ & 70 (68) & $\begin{array}{l}125(127) \text { or } \\
2 \text { hr. } 5 \text { min. }\end{array}$ \\
\hline
\end{tabular}

Table 4.12 IPC Polynomial Coefficients Based on Severity and v/c Ratio

\begin{tabular}{|c|c|c|c|c|}
\hline Criteria & $\mathrm{a} 0$ & $\mathrm{a} 1$ & $\mathrm{a} 2$ & $\mathrm{a} 3$ \\
\hline $\mathrm{PDO}, \mathrm{v} / \mathrm{c}<0.4$ & 0.013571022 & 0.123766002 & -0.00092309 & $-7.65604 \mathrm{E}-06$ \\
$\mathrm{PDO}$, & 0.015638132 & 0.142617777 & -0.001063693 & $-8.82219 \mathrm{E}-06$ \\
$0.4<\mathrm{v} / \mathrm{c}<0.7$ & 0.020536282 & 0.187288287 & -0.001396861 & $-1.15855 \mathrm{E}-05$ \\
$\mathrm{PDO}, \mathrm{v} / \mathrm{c}>0.7$ & 0.014186661 & 0.129380552 & -0.000964965 & $-8.00335 \mathrm{E}-06$ \\
$\mathrm{INJ}, \mathrm{v} / \mathrm{c}<0.4$ & 0.150691254 & -0.001123908 & $-9.32161 \mathrm{E}-06$ \\
$\mathrm{INJ}$, \\
$0.4<\mathrm{v} / \mathrm{c}<0.7$ & 0.016523394 & 0.06 & $-1.24525 \mathrm{E}-05$ \\
$\mathrm{INJ}, \mathrm{v} / \mathrm{c}>0.7$ & 0.022073133 & 0.201304172 & -0.001501396 & \\
\hline
\end{tabular}




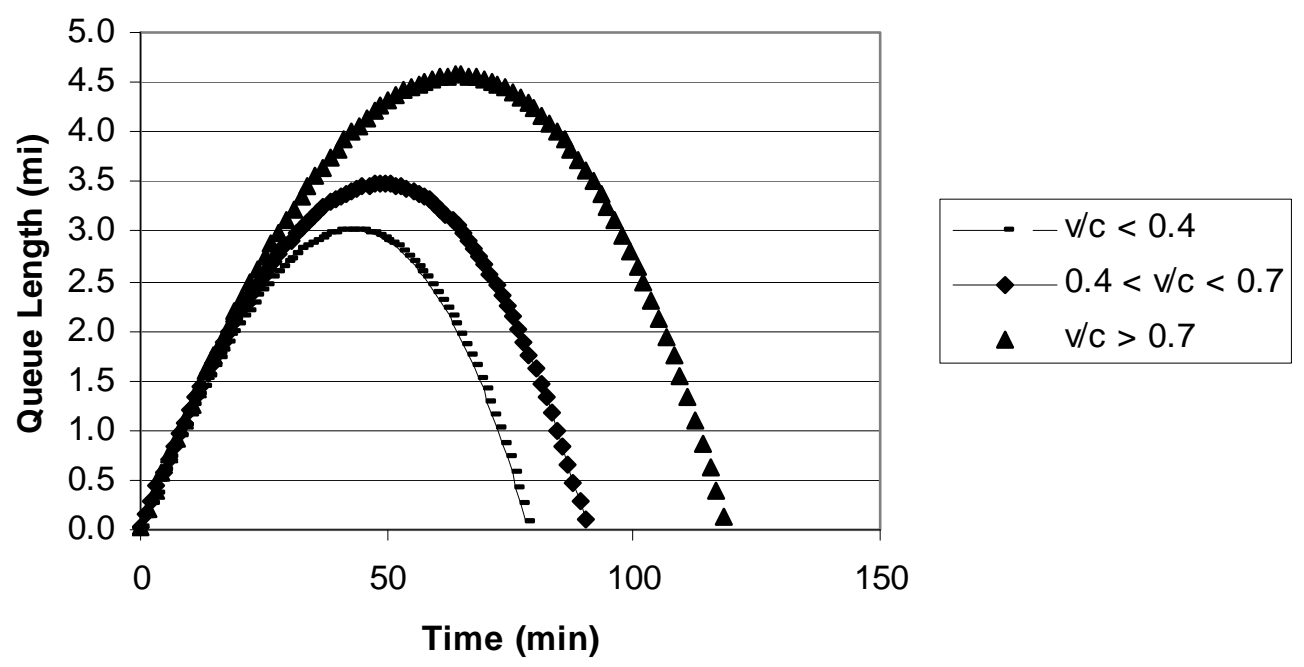

Figure 4.8 IPC Based on PDO accidents and v/c.

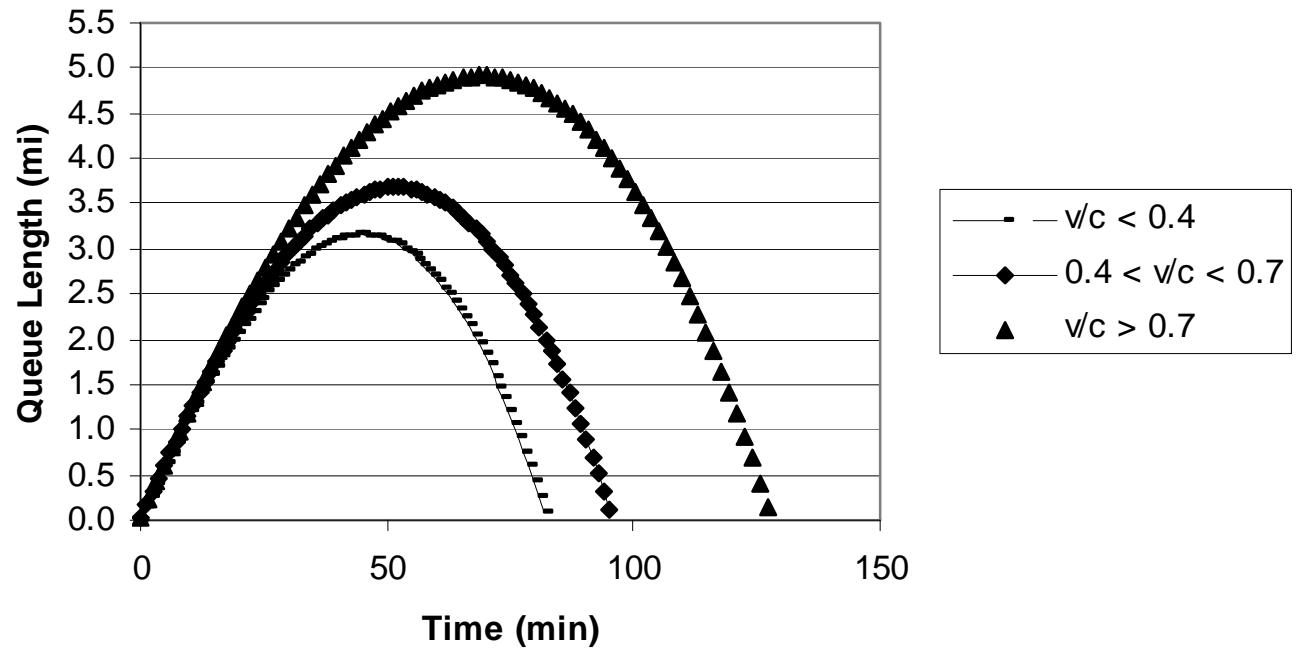

Figure 4.9 IPC Based on injury accidents and v/c. 


\section{CHAPTER 5: CONCLUSIONS}

The sponsoring agency's value on including actual data for evaluation purposes and the lack of existing studies using real data for IMS evaluations has been the real motivation to exhaustively explore and pursue all the data sets that could help in evaluating an IMS. And for this purpose some innovative data collection approaches such as ReID, incident chasing, extraction of information from media traffic reports were developed to further maximize the information about the traffic characteristics. ReID and GPS show how to obtain space mean speed, which is one of the indicators of traffic performance characteristics. Vehicle classification and vehicle volumes are also obtained as by products through the ReID procedure.

This research also shows how to extend the ReID procedure to collect incident data through the development of a novel approach called incident chasing. A total of 18 incidents were collected using this procedure. Although this type of data collection and its data reduction is time consuming, this system has the significant benefits as the data obtained is more accurate and detailed than other data collection procedures.

For evaluating an IMS one would need information about significant number of incidents. The case study presented in Chapter 3 shows the basic frame work to evaluate an IMS based on actual incident data. The main objective of the case study was to evaluate the value of MA as a part of IMS. But to accomplish this main objective the IMS was evaluated, so this case study is a good application for evaluating an IMS using real data. For the study, detailed incident logs for the interstates I-70 and I-270 were acquired. 
Data logs from a total of 42 days were sampled and manually entered into an Excel sheet. The delays caused by each of these incidents were modeled using a deterministic queuing model. The other inputs to the queuing model were the capacity reduction factors and the incident response time for each of the incidents. For evaluating the safety benefits of an IMS, an analysis of secondary accidents, was considered as the performance indicator due to their very nature of occurrence. Based on the information from traffic reports rectangular thresholds for distance and duration were developed for classifying secondary accidents.

Maximum queue length and the duration of accidents as derived from the traffic reports were used in determining the rectangular thresholds. But the methodology of using rectangular thresholds needed to be improved to a more polynomial threshold as the secondary accidents occur within or at the boundary of the traffic back up queue generated by the primary accidents and thus would not necessarily occur within a rectangular threshold.

So this research further improves upon the existing method of rectangular threshold since it does not make the assumption that the queue length is constant. The analysis of 5514 freeway accidents shows that these two methods can differ by over $30 \%$. In order to derive the polynomial threshold, 480 intranet incident reports were analyzed and 119 incident reports were used for calibrating the master incident progression curve. Some of these incident reports were incomplete; therefore they were modeled using a third order polynomial. A chi-squared test showed that the frequency distributions of the complete and incomplete incident reports were not different. An investigation into spatial difference in incidents was conducted, and the result showed that there was a statistically 
significant difference in the mean of the queue length between two freeway sites. Subsequently, two different master incident progression curves were developed for the two sites.

\section{IMPLICATIONS OF THIS RESEARCH}

The efforts of this research will useful to any transportation agency that wants to proactively evaluate its incident management system. Evaluation of the system not only helps the agency to prioritize its investments but it is also useful to communicate the value of the investment to the public and their representatives. Based on the amount of investment in IMS an agency should evaluate itself at a level of detail that is practical. This research provides several ideas to collect and evaluate IMS.

These ideas can be adapted to suit the capabilities of the agency and further they can be improved in the areas of data processing and data modeling. These two areas are interdependent. As far as the data processing is concerned, the input data into the IMS evaluation can be enriched by convincing the agencies to standardize their data sets. For example in the case of traffic media reports, if the agency is convinced that value of these reports is beyond the current incident situation then the agency would be more inclined to a standardized text for not only communicating with the public but for also saving the information in a more quantifiable way. The next area for improvement is in the modeling of incident impacts like incident progression curves. As of now this research has improved the current practice from rectangular thresholds to a more representative polynomial threshold. With more datasets other models forms can be investigated. 


\section{REFERENCES}

Bunch, J.A., Larkin, J.J., and Wunderlich, K.E. (1999). "ITS impacts assessment for Seattle MMDI Evaluation: Modeling methodology and results.”

Cambridge Systematics (1990) “Incident Management.” Alexandria, VA: Trucking Research Institute. October.

Christiansen, I. and Hauer, L. (1996) Probing for Travel Time. Traffic Technology International. August/September. Pp. 41-44.

Dailey, D. (1993) Travel Time Estimation Using Cross Correlation Techniques. Transportation Research Part B. Vol 27B, No. 2. Pp. 97-107.

Eisele,W. and Rilett, L. (2002) Estimating Corridor Travel Time Mean, Variance, and Covariance with Intelligent Transportation Systems Link Travel Time Data. Proceedings of the Annual Transportation Research Board Meeting, January 13-17, Washington, D. C.

Fenno, D. and Ogden, M. (1998). "Freeway Service Patrols: A State of the Practice.” Transportation Research Record 1634, Transportation Research Board, Washington D.C., 28-38.

Garber, N.J., and M. Zhao. (2002) Distribution and Characteristics of Crashes at Different Work Zone Locations in Virginia. Transportation Research Record 1794. Transportation Research Board, Washington, D.C., pp. 19-25.

Garib, A., A.E. Radwan, H. Al-Deek.(1997). Estimating Magnitude and Duration of Incident Delays. In Journal of Transportation Engineering, Vol. 123, No. 6, American Society of Civil Engineers, Reston, VA., 1997, pp. 459-466.

Giuliano, G. (1989). Incident Characteristics, Frequency, and Duration on a High Volume Urban Freeway. In Transportation Research A, Vol. 23A, No. 5, 1989, pp. 387-396.

Ha, T-J., and Nemeth, Z.A. (1995) Detailed Study of Accident Experience in Construction and Maintenance Zones. Transportation Research Record 1509. Transportation Research Board, Washington, D.C., pp. 38-45.

Karlaftis, M.G., S.P. Latoski, N.J. Richards, and K.C. Sinha.(1999). ITS Impacts on Safety and Traffic Management: An Investigation of Secondary Crash Causes. ITS Journal, Vol. 5, 1999, pp. 39-52. 
Kreeger, K. and McConnell, R. (1996) Structural Range Image Target Matching for Automated Link Travel Time Computation. Third Annual World Congress on Intelligent Transportation Systems, Orlando, Florida. October.

Kuhne, R. (1991) Freeway Control Using a Dynamic Traffic Flow Model and Vehicle Reidentification Techniques. Transportation Research Record 1320. Pp. 251-259.

Lee C., B. Hellinga, and F. Saccomanno. (2003). Proactive Freeway Crash Prevention Using Real Time Traffic Control. Canadian Journal of Civil Engineering Vol. 30, 2003, pp. 1034-1041.

Levinson, D., and Parthasarathi, P.K. (2001) "An Economic Evaluation of Freeway Service Patrols". IEEE/Intelligent Transportation Systems Conference. Oakland, California. August.

Lindley, J. (1987). Urban Freeway Congestion: Quantification of the Problem and Effectiveness of Potential Solutions. In ITE Journal, Vo. 57, No. 1, Institute of Transportation Engineers, Washington, D.C., 1987, pp. 27-32.

MacCarley, C. and Hemme, B. (2001) A Computer Vision Detection System for Network Model Validation. Proceedings of the 80th Annual Transportation Research Board Meeting. Washington, D.C.

Moore, J.E., G. Giuliano, and S. Cho. (2004). Secondary Accident Rates on Los Angeles Freeways. In Journal of Transportation Engineering Vol. 130, No. 3, American Society of Civil Engineers, Reston, VA., 2004 pp. 280-285.

Morales, J. Analytical Procedures for Estimating Freeway Traffic Congestion.(1987). In ITE Journal, Vol. 57, No. 1, Institute of Transportation Engineers, Washington, D.C., 1987, pp. 45-49.

Morris, M. and Lee. W.,(1994). "Survey of Efforts to Evaluate Freeway Service Patrols". Transportation Research Record, 1446, 77-85.

Raub, R.A. (1997). Secondary Crashes: An important component of Roadway Incident Management. In Transportation Quarterly. Vol. 51, No. 3, 1997, pp. 93-104.

Pal, R., and K.C. Sinha (1996) Analysis of Crash Rates at Interstate Work Zones in Indiana. Transportation Research Record 1529. Transportation Research Board, Washington, D.C., pp. 43-53.

Petty, K. (1997a) Accurate Estimation of Travel Times from Single Loop Detectors. Preprint from the $76^{\text {th }}$ Annual Transportation Research Board Meeting. Washington, D.C. 
Petty, K., et. al. (1997b). "The Los Angeles Freeway Service Patrol (FSP) Evaluation: Study Methodology and Preliminary Findings".

http://paleale.eecs.berkeley.edu/PATH/Publications/PATH/PWP-97-17.pdf [accessed 9/22/03]

Pierce, R., Sun. C., and Lemp, J. (2005) Incident Delay Modeling with the Use of Video Reidentification. Proceedings of the Annual Transportation Research Board Meeting. Washington, D.C. January 9-13.

Shah, V.P. and Wunderlich, K. (2001) "Detroit Freeway Corridor ITS Evaluation.“ FHWA Contract No.: DTFH61-00-C-0001, Project No.: 0998610D-01.

Skabardonis, A., K. Petty, H. Noeimi, D. Rydzewski, and P. Varaiya.(1996). I-880 Field Experiment: Database Development and Incident Delay Estimation Procedures. In Transportation Research Record: Journal of Transportation Research Board No. 1554,TRB, National Research Council, Washington, D.C., 1996.

Smith, B., L. Qin, and R. Venkatanarayana. (2003). Characterization of Freeway Capacity Reduction Resulting from Traffic Accidents. In Journal of Transportation Engineering, Vol. 129, No. 4, American Society of Civil Engineers, Reston, VA., 2003, pp. 362-368.

Stamatiadis,C., et. al. (1998). "Evaluation of the Massachusetts Motorist Assistance Program" Transportation Research Record, 1634, 2-9.

Sullivan, E. New Model for Predicting Freeway Incidents and Incident Delays.(1997). In Journal of Transportation Engineering, Vol. 123, No. 4, American Society of Civil Engineers, Reston, VA.,1997, pp. 267-275.

Traffic Incident Management Handbook.(2000). Prepared for Federal Highway Administration, Office of Travel Management. P.B. Farradyne. November 2000. http://www.itsdocs.fhwa.dot.gov/jpodocs/rept_mis/@9201!.pdf

Texas Transportation Institute (TTI). (2003). “2003 Urban Mobility Report.”, http://mobility.tamu.edu/ums/appendix_a/ (accessed January 30, 2004).

Turner, S., Eisele, W., Benz, R. and Holdener, D. (1998) Travel Time Data Collection Handbook. FHWA-PL-98-035. Federal Highway Administration and Texas Transportation Institute.

Yokota, T, Inoue, T., Kobayashi, Y., and Takagi, K. (1996) Travel Time Measuring System Based on Platoon Matching: A Field Study. Proceedings of the ITS America Annual Meeting. Houston, Texas, April. 
Zeng, N. and Crisman, J. (1998) Vehicle Matching Using Color. Proceedings of the IEEE Conference on Intelligent Transportation Systems. Boston, Massachusetts, November 912. Pp. 206-211. 


\section{APPENDIX A}

TABLE A1 Data Used For Developing Multiple Master Curves

\begin{tabular}{|c|c|c|c|c|c|c|c|c|}
\hline $\begin{array}{c}\text { Time } \\
\text { (Minutes) }\end{array}$ & $\begin{array}{c}\text { Mile } \\
\text { Marker } \\
\text { (Miles) }\end{array}$ & $\begin{array}{c}\text { Maximum } \\
\text { Queue } \\
\text { (Miles) }\end{array}$ & $\begin{array}{l}\text { Duration } \\
\text { (Minutes) }\end{array}$ & $\begin{array}{c}\text { Estimated } \\
\text { Duration } \\
\text { (minutes) }\end{array}$ & Severity & $\begin{array}{l}\text { Num } \\
\text { of Veh. }\end{array}$ & Seg. ID & $\begin{array}{c}\text { v/c } \\
\text { Ratio }\end{array}$ \\
\hline 840 & 39.66 & 10.94 & 138 & 633.61 & 1 & 2 & 12 & -- \\
\hline 608 & 17.99 & 8.57 & 103 & -9.87 & 2 & 2 & 22 & -- \\
\hline 400 & 2.88 & 2.68 & 113 & 134.58 & 2 & 3 & 22 & 0.068 \\
\hline 400 & 3.87 & 1.98 & 57 & 146.76 & 1 & 2 & 22 & 0.092 \\
\hline 1392 & 31.14 & 2.42 & 46 & 58.22 & 2 & 2 & 12 & 0.141 \\
\hline 322 & 14.17 & 1.75 & 48 & 48.00 & 2 & 1 & 21 & 0.273 \\
\hline 444 & 29.49 & 1.53 & 93 & 93.00 & 2 & 3 & 12 & 0.273 \\
\hline 435 & 23.31 & 2.18 & 77 & 77.00 & 1 & 3 & 12 & 0.319 \\
\hline 619 & 23.62 & 1.96 & 213 & 213.00 & 3 & 3 & 21 & 0.322 \\
\hline 495 & 20.07 & 2.38 & 57 & 58.30 & 2 & 5 & 21 & 0.355 \\
\hline 525 & 24.68 & 3.55 & 154 & 171.42 & 2 & 2 & 12 & 0.358 \\
\hline 751 & 20.07 & 3.53 & 57 & 60.17 & 2 & 4 & 21 & 0.359 \\
\hline 546 & 6.94 & 6.54 & 127 & 127.00 & 2 & 3 & 12 & 0.362 \\
\hline 810 & 19.64 & 4.9 & 120 & 135.07 & 1 & 4 & 21 & 0.363 \\
\hline 800 & 20.07 & 3.53 & 55 & 74.60 & 2 & 2 & 21 & 0.363 \\
\hline 330 & 235.16 & 3.66 & 74 & 113.64 & 2 & 1 & 11 & 0.367 \\
\hline 780 & 234.45 & 1.75 & 68 & 87.58 & 2 & 2 & 11 & 0.408 \\
\hline 480 & 14.86 & 4.44 & 59 & 81.29 & 2 & 1 & 22 & 0.410 \\
\hline 984 & 20.82 & 0.75 & 55 & 55.00 & 2 & 1 & 21 & 0.432 \\
\hline 790 & 223.69 & 1.59 & 49 & 58.13 & 1 & 4 & 11 & 0.436 \\
\hline 680 & 13.59 & 3.67 & 38 & 38.00 & 2 & 1 & 21 & 0.453 \\
\hline 585 & 11.17 & 4.23 & 292 & 348.63 & 2 & 2 & 12 & 0.453 \\
\hline 815 & 11.67 & 1.75 & 53 & 53.00 & 2 & 2 & 21 & 0.459 \\
\hline 900 & 24.01 & 6.02 & 143 & 163.49 & 2 & 1 & 22 & 0.462 \\
\hline 855 & 32.07 & 2.24 & 43 & 44.89 & 2 & 1 & 22 & 0.466 \\
\hline 759 & 17.69 & 1.15 & 41 & 46.11 & 2 & 5 & 21 & 0.468 \\
\hline 768 & 17.69 & 1.15 & 54 & 61.38 & 2 & 2 & 21 & 0.468 \\
\hline 725 & 17.69 & 1.15 & 69 & 78.14 & 2 & 3 & 21 & 0.468 \\
\hline 564 & 17.69 & 0.5 & 31 & 31.00 & 2 & 2 & 21 & 0.468 \\
\hline 437 & 26.26 & 3.77 & 107 & 169.53 & 2 & 3 & 21 & 0.476 \\
\hline 915 & 241.83 & 3.03 & 122 & 154.83 & 2 & 4 & 11 & 0.479 \\
\hline 830 & 16.54 & 0.5 & 45 & 45.00 & 2 & 4 & 21 & 0.481 \\
\hline 785 & 17.69 & 4.1 & 139 & 139.00 & 2 & 6 & 21 & 0.483 \\
\hline 932 & 25.26 & 2.77 & 145 & 183.77 & 2 & 3 & 21 & 0.483 \\
\hline 1075 & 232.72 & 1.22 & 39 & 39.00 & 2 & 2 & 11 & 0.486 \\
\hline 829 & 225.15 & 2.25 & 70 & 70.00 & 1 & 1 & 11 & 0.497 \\
\hline
\end{tabular}


TABLE A1 (Continued)

\begin{tabular}{|c|c|c|c|c|c|c|c|c|}
\hline $\begin{array}{c}\text { Time } \\
\text { (Minutes) }\end{array}$ & $\begin{array}{c}\text { Mile } \\
\text { Marker } \\
\text { (Miles) }\end{array}$ & $\begin{array}{l}\text { Maximum } \\
\text { Queue } \\
\text { (Miles) }\end{array}$ & $\begin{array}{l}\text { Duration } \\
\text { (Minutes) }\end{array}$ & $\begin{array}{l}\text { Estimated } \\
\text { Duration } \\
\text { (minutes) }\end{array}$ & Severity & $\begin{array}{l}\text { Num } \\
\text { of Veh. }\end{array}$ & Seg. ID & $\begin{array}{c}\text { v/c } \\
\text { Ratio }\end{array}$ \\
\hline 412 & 19.14 & 5.95 & 118 & 118.00 & 2 & 3 & 22 & 0.507 \\
\hline 380 & 5.04 & 3.06 & 83 & 100.38 & 2 & 2 & 22 & 0.511 \\
\hline 380 & 245.7 & 2.8 & 62 & 113.42 & 2 & 4 & 11 & 0.514 \\
\hline 1039 & 13.59 & 1.92 & 59 & 65.17 & 1 & 2 & 21 & 0.517 \\
\hline 863 & 8.41 & 4.11 & 84 & 87.33 & 2 & 2 & 12 & 0.518 \\
\hline 1032 & 9.42 & 1.34 & 68 & 68.00 & 2 & 3 & 22 & 0.521 \\
\hline 505 & 17.69 & 1.15 & 76 & 76.00 & 2 & 3 & 21 & 0.528 \\
\hline 1011 & 241.06 & 5.46 & 100 & 101.38 & 1 & 2 & 11 & 0.534 \\
\hline 978 & 12.42 & 5.39 & 72 & 99.17 & 2 & 4 & 21 & 0.534 \\
\hline 956 & 31.14 & 3.18 & 49 & 49.00 & 1 & 2 & 12 & 0.544 \\
\hline 990 & 234.45 & 2.95 & 79 & 82.29 & 1 & 2 & 11 & 0.548 \\
\hline 413 & 4.3 & 0.85 & 49 & 49.00 & 2 & 2 & 12 & 0.548 \\
\hline 998 & 29.49 & 4.81 & 73 & 85.56 & 2 & 2 & 12 & 0.554 \\
\hline 985 & 29.49 & 2.99 & 72 & 93.56 & 2 & 3 & 12 & 0.554 \\
\hline 446 & 17.69 & 5.27 & 67 & 93.19 & 2 & 3 & 21 & 0.554 \\
\hline 465 & 20.06 & 1.13 & 79 & 79.00 & 2 & 3 & 12 & 0.554 \\
\hline 939 & 23.26 & 4.12 & 135 & 135.00 & 1 & 2 & 22 & 0.566 \\
\hline 775 & 16.49 & 3.68 & 135 & 164.81 & 2 & 4 & 12 & 0.566 \\
\hline 1005 & 233.06 & 0.36 & 46 & 58.60 & 1 & 1 & 11 & 0.567 \\
\hline 1010 & 14.74 & 2.32 & 88 & 88.00 & 2 & 2 & 21 & 0.569 \\
\hline 525 & 20.94 & 5.33 & 78 & 107.45 & 2 & 2 & 22 & 0.570 \\
\hline 492 & 20.94 & 5.33 & 75 & 93.41 & 2 & 3 & 22 & 0.570 \\
\hline 447 & 16.04 & 2.85 & 41 & 51.02 & 2 & 2 & 22 & 0.570 \\
\hline 530 & 11.17 & 2.44 & 72 & 83.22 & 2 & 2 & 12 & 0.574 \\
\hline 388 & 5.85 & 3.95 & 65 & 78.00 & 1 & 3 & 21 & 0.576 \\
\hline 435 & 18.93 & 2.44 & 102 & 142.98 & 2 & 2 & 12 & 0.579 \\
\hline 520 & 10.59 & 1.86 & 62 & 105.01 & 2 & 4 & 12 & 0.580 \\
\hline 1015 & 6.07 & 1.03 & 71 & 91.22 & 1 & 2 & 22 & 0.580 \\
\hline 504 & 243.24 & 2.84 & 58 & 66.46 & 1 & 3 & 11 & 0.583 \\
\hline 490 & 230.52 & 2.22 & 20 & 22.77 & 1 & 4 & 11 & 0.586 \\
\hline 1050 & 25.76 & 3.67 & 52 & 70.17 & 2 & 2 & 22 & 0.591 \\
\hline 1047 & 25.76 & 4.82 & 37 & 42.73 & 1 & 3 & 22 & 0.591 \\
\hline 1025 & 25.76 & 4.82 & 55 & 68.10 & 1 & 2 & 22 & 0.591 \\
\hline 435 & 241.83 & 3.03 & 82 & 113.33 & 2 & 2 & 11 & 0.603 \\
\hline 896 & 26.26 & 5.44 & 105 & 123.87 & 2 & 2 & 21 & 0.605 \\
\hline 954 & 23.62 & 2.8 & 60 & 60.00 & 2 & 2 & 21 & 0.606 \\
\hline 930 & 23.62 & 2.8 & 92 & 114.73 & 2 & 2 & 21 & 0.606 \\
\hline 465 & 22.09 & 7.23 & 74 & 87.62 & 1 & 2 & 22 & 0.608 \\
\hline 1000 & 33.78 & 3.95 & 82 & 85.04 & 1 & 2 & 22 & 0.608 \\
\hline 1000 & 33.78 & 3.95 & 40 & 48.69 & 1 & 4 & 22 & 0.608 \\
\hline 1040 & 18.59 & 5.78 & 93 & 93.08 & 1 & 3 & 12 & 0.631 \\
\hline 506 & 12.42 & 0.75 & 5 & 5.84 & 1 & 4 & 21 & 0.637 \\
\hline 958 & 25.76 & 3.67 & 63 & 79.17 & 1 & 4 & 22 & 0.640 \\
\hline 1060 & 20.07 & 2.38 & 34 & 35.68 & 1 & 2 & 21 & 0.645 \\
\hline 962 & 32.07 & 2.24 & 64 & 64.00 & 2 & 2 & 22 & 0.657 \\
\hline 482 & 19.14 & 3.1 & 66 & 66.00 & 1 & 2 & 22 & 0.658 \\
\hline 1032 & 32.07 & 8.81 & 53 & 80.25 & 1 & 4 & 22 & 0.666 \\
\hline 507 & 17.99 & 2.38 & 44 & 44.00 & 1 & 3 & 22 & 0.667 \\
\hline 414 & 12.06 & 6.67 & 106 & 119.57 & 2 & 1 & 22 & 0.681 \\
\hline 430 & 234.45 & 1.75 & 61 & 84.60 & 2 & 2 & 11 & 0.692 \\
\hline
\end{tabular}


TABLE A1 (Continued)

\begin{tabular}{|c|c|c|c|c|c|c|c|c|}
\hline $\begin{array}{c}\text { Time } \\
\text { (Minutes) }\end{array}$ & $\begin{array}{c}\text { Mile } \\
\text { Marker } \\
\text { (Miles) }\end{array}$ & $\begin{array}{l}\text { Maximum } \\
\text { Queue } \\
\text { (Miles) }\end{array}$ & $\begin{array}{l}\text { Duration } \\
\text { (Minutes) }\end{array}$ & $\begin{array}{c}\text { Estimated } \\
\text { Duration } \\
\text { (minutes) }\end{array}$ & $\begin{array}{l}\text { Sev } \\
\text { erity }\end{array}$ & $\begin{array}{c}\text { Num } \\
\text { of Veh. }\end{array}$ & $\begin{array}{c}\text { Seg. } \\
\text { ID }\end{array}$ & $\begin{array}{c}\text { v/c } \\
\text { Ratio }\end{array}$ \\
\hline 1060 & 17.69 & 2.95 & 59 & 59.00 & 2 & 3 & 21 & 0.701 \\
\hline 1048 & 22.09 & 4.1 & 58 & 58.00 & 1 & 2 & 22 & 0.706 \\
\hline 1079 & 22.09 & 2.95 & 52 & 59.84 & 1 & 2 & 22 & 0.706 \\
\hline 1042 & 22.09 & 6.48 & 96 & 118.63 & 2 & 5 & 22 & 0.706 \\
\hline 936 & 23.31 & 8.46 & 52 & 97.97 & 2 & 2 & 12 & 0.708 \\
\hline 480 & 12.42 & 5.39 & 54 & 58.58 & 2 & 4 & 21 & 0.715 \\
\hline 1007 & 22.09 & 6.05 & 74 & 92.84 & 1 & 3 & 22 & 0.725 \\
\hline 960 & 24.68 & 2.48 & 60 & 60.00 & 2 & 2 & 12 & 0.735 \\
\hline 971 & 16.54 & 4.87 & 78 & 130.94 & 2 & 2 & 21 & 0.738 \\
\hline 1020 & 11.17 & 2.76 & 75 & 85.52 & 1 & 3 & 12 & 0.751 \\
\hline 412 & 233.06 & 1.56 & 108 & 108.00 & 2 & 3 & 11 & 0.762 \\
\hline 908 & 27.21 & 8.07 & 187 & 187.00 & 1 & 2 & 22 & 0.774 \\
\hline 446 & 17.99 & 2.38 & 69 & 69.00 & 1 & 2 & 22 & 0.775 \\
\hline 456 & 17.99 & 4.8 & 65 & 75.66 & 1 & 2 & 22 & 0.775 \\
\hline 466 & 17.99 & 3.13 & 58 & 70.24 & 1 & 3 & 22 & 0.775 \\
\hline 450 & 230.52 & 6.92 & 101 & 133.19 & 1 & 3 & 11 & 0.791 \\
\hline 455 & 230.52 & 5.42 & 57 & 69.71 & 1 & 2 & 11 & 0.791 \\
\hline 446 & 7.03 & 7.03 & 108 & 108.00 & 2 & 3 & 21 & 0.793 \\
\hline 479 & 7.35 & 3.74 & 74 & 74.00 & 1 & 2 & 21 & 0.793 \\
\hline 430 & 228.34 & 3.24 & 42 & 51.91 & 1 & 2 & 11 & 0.812 \\
\hline 398 & 7.35 & 7.35 & 172 & 172.00 & 1 & 4 & 21 & 0.822 \\
\hline 390 & 7.03 & 7.03 & 48 & 59.33 & 1 & 2 & 21 & 0.822 \\
\hline 995 & 27.21 & 5.12 & 133 & 185.43 & 2 & 1 & 22 & 0.824 \\
\hline 412 & 226.97 & 4.07 & 60 & 90.66 & 1 & 3 & 11 & 0.828 \\
\hline 1000 & 26.26 & 5.44 & 126 & 126.00 & 2 & 3 & 21 & 0.830 \\
\hline 982 & 26.26 & 3.77 & 101 & 109.73 & 2 & 3 & 21 & 0.830 \\
\hline 395 & 9.32 & 3.35 & 117 & 117.00 & 1 & 2 & 22 & 0.831 \\
\hline 420 & 9.42 & 5.55 & 81 & 98.43 & 1 & 2 & 22 & 0.831 \\
\hline 387 & 9.42 & 7.44 & 109 & 138.28 & 2 & 2 & 22 & 0.831 \\
\hline 390 & 9.42 & 4.03 & 109 & 138.46 & 1 & 2 & 22 & 0.831 \\
\hline 437 & 9.42 & 4.36 & 106 & 123.09 & 2 & 5 & 22 & 0.844 \\
\hline 964 & 28.1 & 7.28 & 115 & 144.33 & 1 & 5 & 21 & 0.854 \\
\hline 428 & 8.08 & 4.21 & 61 & 102.72 & 1 & 2 & 22 & 0.858 \\
\hline 1025 & 16.49 & 3.68 & 61 & 61.00 & 2 & 2 & 12 & 0.890 \\
\hline 1070 & 27.96 & 4.65 & 46 & 66.41 & 2 & 3 & 12 & 0.932 \\
\hline 1020 & 20.06 & 2.66 & 27 & 30.41 & 1 & 3 & 12 & 0.933 \\
\hline 910 & 27.96 & 1.46 & 65 & 65.00 & 1 & 2 & 12 & 0.936 \\
\hline
\end{tabular}




\section{VITA}

Venkata Chilukuri was born in India to Sreelakshmi and Bhaskar Chilukuri. He is the first person in the family to attend college. He obtained his Undergraduate degree from Andhra Univeristy, India and his Graduate degrees from University of MissouriColumbia. 